University of Louisville

ThinkIR: The University of Louisville's Institutional Repository

Electronic Theses and Dissertations

$12-2014$

\title{
A mechanism for trif adaptor-biased signaling by toll-like receptor
}

4.

Joseph Peterson Kolb

University of Louisville

Follow this and additional works at: https://ir.library.louisville.edu/etd

Part of the Microbiology Commons

\section{Recommended Citation}

Kolb, Joseph Peterson, "A mechanism for trif adaptor-biased signaling by toll-like receptor 4." (2014). Electronic Theses and Dissertations. Paper 1755.

https://doi.org/10.18297/etd/1755

This Doctoral Dissertation is brought to you for free and open access by ThinkIR: The University of Louisville's Institutional Repository. It has been accepted for inclusion in Electronic Theses and Dissertations by an authorized administrator of ThinkIR: The University of Louisville's Institutional Repository. This title appears here courtesy of the author, who has retained all other copyrights. For more information, please contact thinkir@louisville.edu. 
A MECHANISM FOR TRIF ADAPTOR-BIASED SIGNALING BY TOLL-LIKE RECEPTOR 4

\author{
By \\ Joseph Peterson Kolb, Jr. \\ B.A., Transylvania University, 2008 \\ M.S., University of Louisville, 2011

\begin{abstract}
A Dissertation
Submitted to the Faculty of the School of Medicine of the University of Louisville

in Partial Fulfillment of the Requirements

for the Degree of
\end{abstract}

Doctor of Philosophy

Department of Microbiology and Immunology

University of Louisville

Louisville, Kentucky

December 2014 
Copyright 2014 by Joseph Peterson Kolb, Jr.

All rights reserved 

A MECHANISM FOR TRIF ADAPTOR-BIASED SIGNALING BY TOLL-LIKE RECEPTOR 4

\author{
By \\ Joseph Peterson Kolb, Jr. \\ B.A., Transylvania University, 2008 \\ M.S., University of Louisville, 2011 \\ A Dissertation Approved on
}

November 20, 2014

by the following Dissertation Committee:

$\overline{\text { Dr. Thomas C. Mitchell (Dissertation Director) }}$

Dr. Pascale Alard

Dr. Haribabu Bodduluri

Dr. Paula M. Chilton

Dr. David Scott

Dr. Huang-Ge Zhang 


\section{DEDICATION}

This dissertation is dedicated to my parents

Joe and Maria Kolb

who sacrificed so much to give me the finest educational opportunities. 


\section{ACKNOWLEDGEMENTS}

I was fortunate to have the support of a fantastic group of individuals during the completion of this dissertation. I thank my mentor, Tom Mitchell, for pushing me to become a better scientist and for devoting countless hours to my education and career development. I would not have been able to publish this work if not for his unceasing devotion and enthusiasm for my project. Foremost, I thank him for his friendship and for his caring for my wellbeing as a person. I also thank my labmates, Carolyn Casella, Paula Chilton, Bill Bowen, Shuvasree SenGupta, Siva Gandhapudi, Dereje Desta, Diana Hadel, Caglar Cekic, Chelsea Mabry, and Yiqi Wang. Each of you has served as an outstanding role model and as a dear friend to me. Thank you for enriching my life. I will miss you all.

I also thank my family, the most important people in my life, for their unwavering love and support during the completion of this work. I am so happy that I could share my life with them during these years. Especially, I thank my mother, Maria, for devoting her entire being to ensuring that I reached my full potential as a student and as a person. Without her care I would not have achieved this degree. 


\section{ABSTRACT \\ A MECHANISM FOR TRIF ADAPTOR-BIASED SIGNALING BY TOLL-LIKE RECEPTOR 4 \\ Joseph Peterson Kolb, Jr.}

November 20, 2014

Host cells respond to bacterial lipid A through Toll-like receptor 4 (TLR4). Activation of TLR4 by lipid A triggers a response that involves two main adaptor proteins, MyD88 and TRIF. MyD88-dependent gene expression is associated with proinflammatory protein production, while TRIF-dependent gene expression is essential for optimal activation of adaptive immunity by antigen-presenting cells. Detoxified, monophosphoryl lipid A agonists (MPLA or synthetic MLA) were previously suggested to elicit TRIF-biased TLR4 signaling; that is, induction of weaker MyD88-associated gene expression but relatively intact TRIF-dependent gene expression when compared to fully active diphosphoryl lipid A (lipid A). In this work, we explored potential mechanisms by which monophosphoryl lipid A could induce TRIF-biased signaling in mouse cells. TRIF-dependent and MyD88-associated gene expression induced by both MPLA and lipid A was reduced to a similar extent by CD14 ablation, indicating that these two agonists do not differentially utilize CD14, despite this coreceptor's primary role in directing the TRIF signaling pathway. In a second study, we demonstrated that the observation of TRIF-biased gene expression by sMLA was not because the agonist induced a TRIF-biased gene expression profile, but rather that TLR4 itself was TRIF- 
biased. The potencies of three different agonists were significantly higher for the induction of expression of TRIF-dependent genes than they were for induction of expression of MyD88-associated genes. Autocrine and paracrine signaling by type I interferons contributed to higher potency of TLR4 agonists for induction of TRIFdependent gene expression because blocking the type I interferon receptor before agonist treatment diminished the effect. We propose that TLR4 is a prime target for vaccine adjuvants. The therapeutic window of TLR4 agonists may be inherently large due to the ease with which TRIF-dependent genes required for adaptive priming are activated relative to MyD88-dependent genes associated with toxicity 
TABLE OF CONTENTS

PAGE

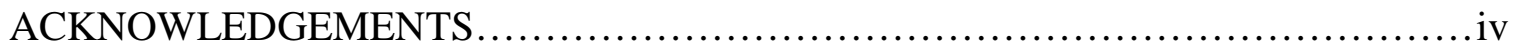

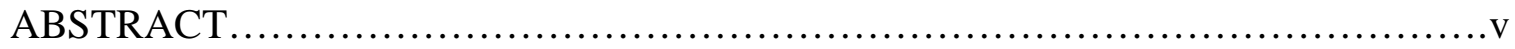

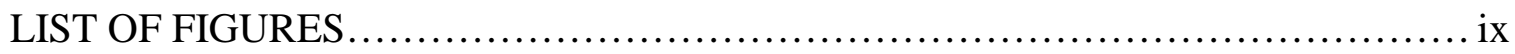

CHAPTER I: INTRODUCTION..................................................

Discovery of the lipopolysaccharide receptor.................................

The TLR4 signaling pathway.................................................

The TLR4 agonist monophosphoryl lipid A as a vaccine adjuvant................7

Monophosphoryl lipid A as a TRIF-biased agonist of TLR4 .................. 10

Dissertation goals.......................................................13

CHAPTER II: METHODS..................................................... 17

Mice and reagents....................................................... 17

Generation and culture of bone marrow-derived dendritic cells (BMDCs) ........18

Collection of mouse serum ..............................................19

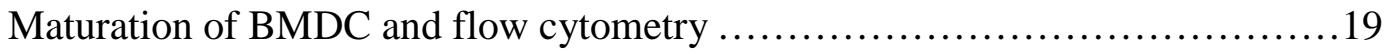

Intracellular phospho-protein staining.................................... 20

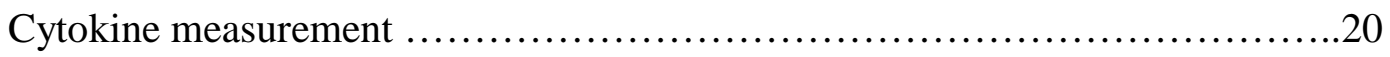

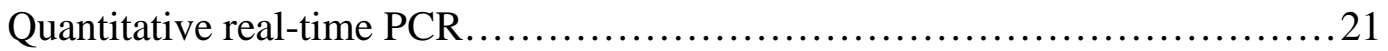

Western blotting analysis................................................. 21

Statistical analysis and $\log (\mathrm{EC} 50)$ measurement.............................22 
CHAPTER III: THE CONTRIBUTION OF CD14 TO MYD88- AND TRIF-

ASSOCIATED RESPONSES ELICITED BY BIOLOGICAL MPLA AND LIPID A... 24

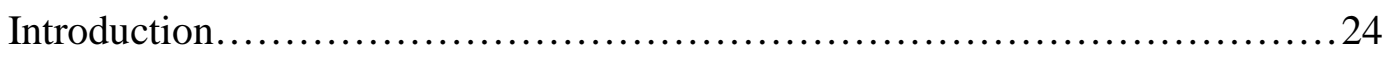

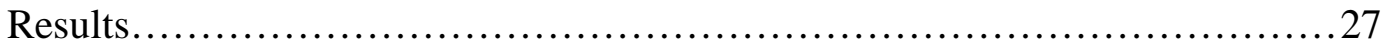

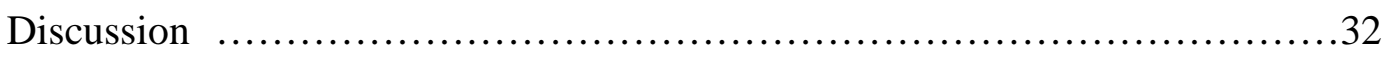

CHAPTER IV: AUTOCRINE AND PARACRINE SIGNALING BY TYPE I

INTERFERONS CONTRIBUTES TO TOLL-LIKE RECEPTOR 4 TRIF-BIAS .........45

Introduction............................................................ 45

Results................................................................. 47

Discussion............................................................ 58

CHAPTER V: CONCLUSION .................................................. 81

CD14 does not play a special role in TLR4 signaling in response to

monophosphoryl lipid A................................................. 81

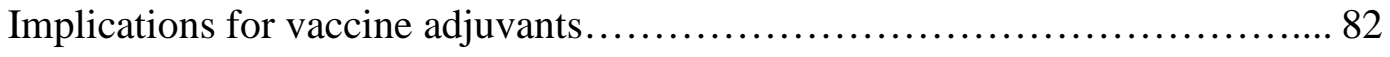

Implications for the coevolution of commensal bacteria and innate immunity... 89

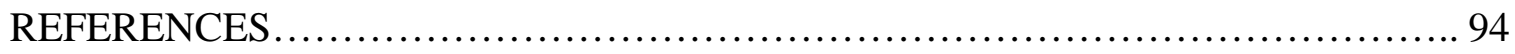

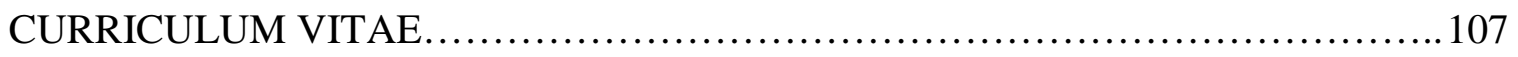




\section{LIST OF FIGURES}

FIGURE PAGE

1. The TLR4 signaling pathway........................................... 14

2. Salmonella minnesota lipid A and MPLA structures.......................... 15

3. Synthetic lipid A (sLipid A) and MPLA (sMLA) structures........................16

4. MPLA is not a TRIF-biased agonist in mouse BMDCs......................... 37

5. WT and CD14 $4^{-/-}$BMDC are phenotypically similar............................ 38

6. MPLA and lipid A utilize CD14 similarly to induce expression of MyD88- and TRIFco-dependent genes.................................................. 39

7. MPLA and lipid A both require CD14 for optimal TRIF-dependent gene expression.............................................................. 40

8. Serum collected from WT mice does not rescue IL-6 production in response to MPLA or lipid A........................................................ 41

9. Upregulation of mCD14 expression on BMDCs by TNF $\alpha$-induced maturation......42

10. Increased surface expression of mCD14 does not preferentially enhance TRIF-

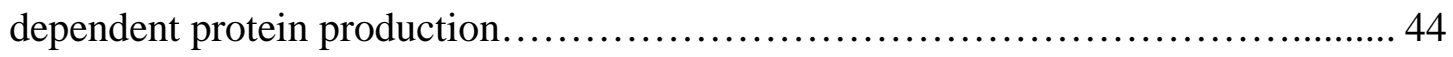

11. sMLA is not a TRIF-biased TLR4 agonist................................. 64

12. The expression of TRIF-dependent genes is activated with lower concentrations of TLR4 agonists than are required for the expression of MyD88- and TRIF-codependent genes...... 
13. The TRIF-dependent expression of Cd86 is activated with lower TLR4 agonist concentrations than are required for the MyD88- and TRIF-co-dependent expression

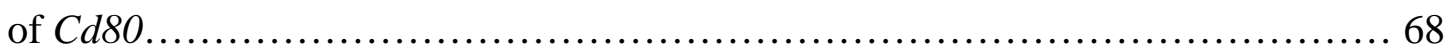

14. Low $\log ($ EC50) values for TRIF-dependent genes are not explained by biased adaptor

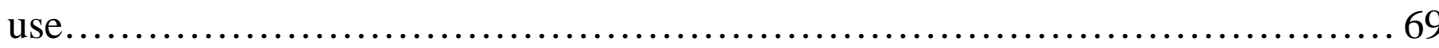

15. The logEC50s of sLipid A for MAPKs and NF-אB are distinct...................71

16. MyD88- and TRIF-co-dependent genes with high $\log (\mathrm{EC} 50)$ values have a greater dependence on JNK for their expression than do TRIF-dependent genes..............72

17. SB202190 and SP600125 inhibit p38 MAPK and JNK signaling, respectively...... 74

18. The high $\log (\mathrm{EC} 50)$ values for the expression of Ifnb correlate with a dependence on JNK signaling. 75

19. IFN- $\beta$ is sufficient to induce the maximal expression of genes with low $\log (\mathrm{EC} 50)$ values

20. MAR-5A3 effectively blocks IFNAR signaling. 78

21. Autocrine and paracrine signaling by IFN- $\beta$ contributes to the low $\log (\mathrm{EC} 50)$ values of TRIF-dependent genes. 79

22. The proposed mechanism for TRIF-biased TLR4 signaling...................... 92

23. TLR4 TRIF-bias opens a therapeutic window for vaccine adjuvants 93 


\section{CHAPTER I}

\section{INTRODUCTION}

\section{DISCOVERY OF THE LIPOPOLYSACCHARIDE RECEPTOR}

For many years, immunologists knew that $\mathrm{T}$ and $\mathrm{B}$ cell activation in response to a protein antigen required the addition of certain mixtures called adjuvants, but the way adjuvants worked was largely unknown. In 1989, the preeminent scientist Charles Janeway proposed the existence of evolutionarily ancient pattern recognition receptors (PRRs) expressed on innate immune cells that had evolved to respond to conserved microbial products called pathogen-associated molecular patterns (PAMPs) (1). Janeway postulated that the cellular response elicited by these PAMPs must somehow provide a second signal to lymphocytes, instructing their activation, and allowing them to discriminate between self and non-self antigens. In the following years, intensive searches for PRRs and their corresponding PAMPs were carried out.

One of the most well studied PAMPs is lipopolysaccharide (LPS). LPS is a major component of the outer membrane of Gram-negative bacteria that promotes structural integrity and provides the bacteria a protective barrier to toxic compounds in the extracellular environment (2). The inflammatory and immunostimulatory effects of LPS, initially known as endotoxin, had long been recognized since its discovery by Richard Pfeiffer in 1892 (3). For example, endotoxin tolerance, or the hypo-responsiveness of a host to LPS treatment following an initial LPS exposure, was first described in 1946 by 
Beeson (4). In addition, LPS was known to induce B cell proliferation since the early 1970s $(5,6)$.

In 1969, Sultzer published work describing a strain of mouse which was highly resistant to the toxic effects of LPS (7). This mouse, called C3H/HeJ, provided evidence that responsiveness to LPS was genetically encoded. It was not until the 1980s that strides began to be made in determining the nuts and bolts of the LPS response. Tobias et al. (8) were the first to isolate the acute phase LPS-binding protein (LBP) from rabbit serum and to provide evidence of its interaction with LPS. A few years later, another protein, CD14, was shown to bind LBP-LPS complexes (9). CD14 is expressed on the surface of cells of the myelomonocytic lineage (10). Initially, many considered CD14 to be a polyspecific PRR responsible for inducing the inflammatory response to LPS as well as Gram-positive bacterial components (11), but several lines of evidence indicated that CD14 was not alone in propagating the LPS response. First, CD14 is expressed on the cell membrane via a short glycosylphosphatidylinositol (GPI) anchor which is incapable of transducing a signal by itself (12). Second, deacylated LPS, which is antagonistic to LPS in human cells, inhibited the inflammatory response to LPS without preventing LPS binding to CD14, indicating that LPS might induce its signal at a different location (13). Third, the activity of LPS antagonists was dependent upon the species from which a cell was derived but independent of the species from which CD14 was derived (14). In addition, experiments in CD14-deficient macrophages demonstrated the existence of CD14-independent LPS activation (15).

Several breakthroughs in our understanding of LPS recognition occurred in the late 1990s. In 1996, Lemaitre et al. (16) published work demonstrating that the 
Drosophila Toll signaling pathway, which was known to control embryonic dorsoventral patterning, was also responsible for the induction of an antifungal response by way of activation of an NF-kB-related transcription factor. Most importantly, this work implicated the existence of conserved Toll-NF-kB-like signaling pathways responsible for non-adaptive activation of antimicrobial genes in mammalian cells (17). In the following year, Janeway and Medzhitov (18) cloned the human homologue of Drosophila Toll (hToll) and expressed a constitutively active form of it in the human monocytic cell line THP-1. Cells which expressed this hToll mutant also expressed higher levels of proinflammatory cytokines and the T cell costimulatory molecule CD80. This data provided the first evidence that Toll signaling pathway activation in the context of infection was potentially involved in the activation of innate immune cells, which were, in turn, required to educate adaptive immune cells.

In 1998, Janeway’s PAMP and PRR hypothesis was clearly born out with the discovery by Beutler and colleagues (19) that LPS hyporesponsive C3H/HeJ and C57BL/10ScCr mice bore mutations in the Toll-like receptor 4 (TLR4) gene. In particular, $\mathrm{C} 3 \mathrm{H} / \mathrm{HeJ}$ mice have a point mutation in the intracellular signaling domain of TLR4, and C57BL/10ScCr mice carry a TLR4 null mutation. This work clearly demonstrated that TLR4 was responsible for inducing the inflammatory response to LPS. Interestingly, Janeway had unwittingly stumbled upon the LPS receptor before Beutler because hToll was actually the human TLR4 gene (20). Shortly after Beutler's publication, it was discovered that a coreceptor called MD-2, along with TLR4, made up the complete LPS receptor complex. MD-2, in complex with TLR4, directly bound LPS, while TLR4 was responsible for transducing the intracellular signal $(21,22)$. The 
discovery of TLR4 ignited a flurry of research activities in the field of innate immune recognition of pathogen components that continues today. It did not take long for much of the TLR4 signaling mechanism to be elucidated.

\section{THE TLR4 SIGNALING PATHWAY}

TLR4 is expressed on a wide variety of immune and non-immune cells including monocytes, macrophages, dendritic cells, neutrophils, B cells, and endothelial cells, but the majority of TLR4 signaling work has been performed in macrophages and dendritic cells. In order for TLR4 signaling to take place, monomeric LPS must be delivered to the receptor. This process is accomplished by two coreceptors, LBP and CD14 (discussed in detail in Chapter III). LBP in the serum extracts LPS monomers from bacteria or aggregates, and catalytically transfers them to $\operatorname{CD} 14(23,24)$. CD14 is expressed on the cell surface and is found in soluble form in the serum $(12,25)$. CD14 transfers LPS from its binding pockets to MD-2 complexed with TLR4 on the cell surface (26).

In general, the LPS molecule contains three structural components: the Opolysaccharide or O-antigen, the core oligosaccharide, and lipid A (reviewed in (27)). The O-polysaccharide is the most variable moiety, consisting of 0 to 50 repeating sugar subgroups. This high variability is responsible for the diversity of host antibody serotypes to Gram-negative bacteria. The core oligosaccharide is much less variable than the O-polysaccharide. It consists of an outer core composed of common hexose sugars and an inner core consisting of rare sugars such as 3-deoxy-D-manno-octulosonic acid (Kdo) and L-glycero-D-manno heptose. Lipid A is the highly hydrophobic core of LPS which anchors into the outer Gram-negative bacteria membrane. It is generally 
composed of a di-glucosamine headgroup with two phosphate groups at the 1 and 4' positions. Up to 4 amide or ester linked primary acyl chains are attached to the diglucosamine, and up to 3 additional secondary acyl chains may be linked to the primary chains (up to 7 acyl chains in total). Lipid A is called the "endotoxic principle" because it alone is sufficient to induce a response like that of the complete LPS molecule (28). This is because lipid A is the component of LPS that binds directly to MD-2 and interacts with TLR4 (29).

TLR4 is a type I transmembrane protein. Its extracellular N-terminal domain is made up of leucine-rich repeats (LRRs) which form a horseshoe-like shape. TLR4's Cterminal cytoplasmic region is homologous to the intracellular domain of the IL-1 receptor and is, therefore, called the Toll/IL-1 receptor (TIR) domain. MD-2 is composed of two sandwiched anti-parallel $\beta$-sheets that form the lipid A-binding pocket (30). The inside of the pocket is lined with hydrophobic residues that accommodate lipid A's fatty acyl chains, and the pocket's rim contains hydrophilic residues which are also important for ligand interaction (29, 30). MD-2 stably binds with TLR4 on the concave surface of its extracellular domain through charge-charge interactions (31).

Lipid A interaction with MD-2 at the cell surface induces the dimerization of two TLR4:MD-2 complexes (also called heterotetramerization) that brings TIR domains in the cytoplasmic tails into close proximity with one another $(29,31-33)$. It is thought that the close interaction of TIR domains promotes the recruitment of signaling adaptor proteins. There are four main adaptor proteins associated with TLR signaling: myeloid differentiation primary response gene 88 (MyD88), MyD88 adaptor-like (Mal), TIR domain-containing adaptor inducing interferon- $\beta$ (IFN- $\beta$ ) (TRIF), and TRIF-related 
adaptor molecule (TRAM). TLR4 is unique in that is the only TLR which utilizes all four adaptor proteins (34). The MyD88-dependent and the TRIF-dependent signaling pathways have unique characteristics and are required for the activation of different sets of genes.

Upon TLR4 activation (Fig. 1), Mal and MyD88 are rapidly recruited to the cytoplasmic TIR domain of TLR4 and bind to it through their own TIR domains. Mal is localized to the cell membrane via a phosphatidylinositol 4,5-bisphosphate (PIP2) binding domain, and facilitates the recruitment of MyD88 (35). These events initiate the formation of the myddosome, a helical oligomer of IL-1 receptor-associated kinases (IRAKs)-4, -1, or -2 which interact through their death domains (36). Close association causes IRAKs to become phosphorylated and to be released from the myddosome to then interact with TNF receptor-associated factor 6 (TRAF6), an E3 ubiquitin ligase (37). Both IRAK1 and TRAF6 are K63-polyubiquitinated in the process (38-40). TGF- $\beta$ associated kinase-1 (TAK1)-binding proteins (TABs), the regulatory components of TAK1, bind to the long ubiquitin chains attached to TRAF6 through their zinc-finger ubiquitin-binding domains $(41,42)$. This then leads to activation of TAK-1, which activates downstream MAPKs. Inhibitor of NF-אB kinase- $\gamma($ IKK $\gamma)$ also binds to polyubiquitinated TRAF6, which brings the catalytic subunits IKK $\alpha$ and IKK $\beta$ into close proximity to TAK1 $(37,41,43)$. TAK1 phosphorylates IKK $\beta$, which allows the IKK complex to phosphorylate I $\mathrm{KB}$ and mark it for ubiquitin-dependent degradation. This

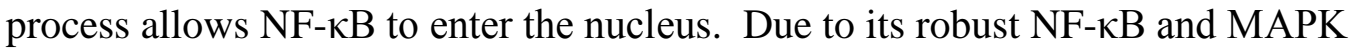
activation the MyD88-dependent pathway is associated with proinflammatory gene induction (44-46). 
Several minutes after MyD88-dependent signaling is initiated, TLR4:MD-2 complexes are endocytosed via a CD14-dependent pathway (47). This process induces the recruitment TRAM and TRIF to the TLR4 cytoplasmic TIR domains (48-50), which activates the E3 ubiquitin ligase TRAF3 (51). TRAF3 become polyubiquitinated and activates TANK-binding kinase-1 (TBK1), which then activates IKKe. This signaling cascade results in the activating phosphorylation of the transcription factor interferon regulatory factor 3 (IRF3), which is required for type I interferon production (52-55). TRIF signaling also overlaps with the MyD88 pathway by recruiting the E3 ubiquitin ligases TRAF6 and Pelino1 which polyubiquitinate receptor interacting protein-1 (RIP1) (56, 57). Ubiquitinated RIP1 recruits and activates TAK1 and the IKK complex, which then activate MAPKs and NF- $\mathrm{BB}$ (58). As a result of this overlap in signaling pathways, TRIF-deficiency frequently decreases production of proinflammatory mediators associated with the MyD88 pathway (59-62).

\section{THE TLR4 AGONIST MONOPHOSPHORYL LIPID A AS A VACCINE ADJUVANT}

Unquestionably, one of the most important medical achievements in current human history is vaccination against disease causing pathogens. Vaccination has saved countless lives and countless dollars in medical treatment expenses by eradicating or dramatically decreasing the incidence of many diseases worldwide. Despite the success of whole-pathogen vaccines, which make use of inactivated or attenuated microbes, there is a still a need for the development of new and safer vaccine strategies. Current vaccination strategies have been unsuccessful in preventing intractable diseases such as cancer and HIV, as well as emerging threats such as Ebola (which at the time of writing 
this dissertation is causing a severe epidemic in West Africa and global concern). In addition, the rare occurrence of serious adverse events associated with whole-pathogen vaccination, whether real or perceived, has caused many to opt out of vaccination due to safety concerns (63).

The answers to some of these problems may lie in subunit vaccination. This strategy uses only the essential microbial antigens, and not the whole organism, to stimulate immunity. Although subunit vaccines are considered very safe, protein antigens alone are usually inherently weak stimulators of the innate arm of the immune system, which is essential to long-term adaptive immunity. Therefore, adjuvants (PAMPs or other immunostimulatory compounds) must be formulated with subunit vaccines.

The first successful clinical vaccine adjuvant was alum (non-crystalline gels of aluminum salts), which has been used in vaccines since 1926 (64). To date, alum is the most commonly used adjuvant. Alum promotes delivery of antigen to APCs and stimulates APC maturation by inducing an intracellular signaling pathway caused by its interaction with cell membrane lipids (65). Alum promotes a Th2 humoral immune response typified by non-complement fixing antibody isotypes. While these responses are effective against microbes where neutralizing are required for protection, they are not well suited for stimulating protective immunity to intracellular pathogens or to endogenous antigens present in pre-cancerous, transformed cells (66). Therefore, there is still a need for the development of new vaccine adjuvants which stimulate different facets of the immune response. 
LPS has long been known as an effective vaccine adjuvant, but its strong pyrogenicity and association with septic shock has precluded its use in the clinical setting. Beginning in the late 1970s, Edgar Ribi systematically studied the biological properties of chemically modified LPS. Acid hydrolysis of Salmonella minnesota Re595 (deep rough mutant) LPS, which contains a mixture of congeners with different numbers of acyl chains, removed the core-oligosaccharide (Kdo), as well as the diglucosamine 1phosphate group (67). The resulting molecule (Fig. 2), called monophosphoryl lipid A (MPLA), was shown to be at least 1,000 times less toxic than parental LPS in a battery of tests, including chick embryo lethality and rabbit pyrogenicity (68). Surprisingly, MPLA retained $100 \%$ of the ability of LPS to induce tumor regression and systemic immunity in the transplantable line-10 tumor model in guinea pigs (68). This seminal work demonstrated that the beneficial immunomodulatory functions of LPS could be separated from its toxicity.

Ribi's discovery would make a dramatic impact in the field of vaccine adjuvant development with the purchase and mass production of clinical grade MPLA called MPL adjuvant by Corixa Corporation and later GlaxoSmithKline (GSK). MPL adjuvant is approved for use in the hepatitis B virus vaccine Fendrix in Europe and in the human papillomavirus (HPV) vaccine Cervarix in the USA. In both of these vaccines, MPL adjuvant is used in combination with alum in the GSK adjuvant system called AS04. The benefits of MPL were clearly shown in follow-up studies in women vaccinated with either Cervarix or Merck’s Gardasil, which is adjuvanted with alum alone. Up to 24 months after vaccination, Cervarix was shown to induce significantly higher titers of HPV-18 and HPV-16 neutralizing antibodies, and better antigen specific CD4 T cell and 
memory B cell responses $(69,70)$. To date, MPL adjuvant is the only TLR agonist-based adjuvant to be approved by the FDA. Its success demonstrated the feasibility of using TLR4 agonists in the clinical setting and caused a dramatic increase in studies aimed at elucidating the structural features of LPS or lipid A required for beneficial adjuvanticity but low toxicity, with the hope that these features could be fine tuned.

\section{MONOPHOSPHORYL LIPID A AS A TRIF-BIASED AGONIST OF TLR4}

The basis of MPLA's unique adjuvant properties has been debated. Early studies comparing the ability of MPLA and LPS to elicit gene products downstream of TLR4 seemed to indicate that MPLA was a less potent version of LPS (71-73). Over a dose range of 0.1 to $1000 \mathrm{ng} / \mathrm{ml}$, MPLA was weaker than LPS in the induction of Ifng, Il12p40, and Il12p35 mRNA in mouse peritoneal macrophages (71). MPLA was also weaker than LPS in stimulating IL-12 protein production by both mouse macrophages and human monocyte-derived DC $(71,72)$. In contrast, additional studies indicated that MPLA may retain the ability to induce certain responses just as well as LPS, while remaining weak in others $(71,74,75)$. More MPLA than LPS was required to induce endotoxin tolerance in mice, but at doses where equivalent tolerance was induced, MPLA was still less capable than LPS at eliciting proinflammatory cytokines (74). Also, MPLA was reported to induce a similar abundance of Il1 b mRNA compared to LPS, but lower amounts of IL-1 $\beta$ protein (75). Still, others concluded that MPLA may be better able to induce certain responses than LPS. For example, MPLA treatment induced more Il10 mRNA expression in mouse macrophages than LPS (71). Lower production of 
proinflammatory cytokines like IL-1 $\beta$, and higher production of anti-inflammatory cytokines like IL-10 were proposed to contribute to the low toxicity of MPLA.

During the time in which MPL adjuvant was showing promise in the clinic, our lab became interested in determining how a low inflammatory environment elicited by MPLA would specifically affect the quality of T cell priming. Our initial studies (76) demonstrated that MPLA was better able than LPS to induce early clonal expansion of ovalbumin-specific CD4 T cells, despite being about 5 times less toxic. In contrast, MPLA was less capable than LPS at stimulating long-term retention of antigen-specific CD4 T cells.

A breakthrough in our understanding of MPLA's adjuvanticity occurred with the work of Mata-Haro et al. (77). In this study, 30 ug of MPLA and 10 ug of LPS induced indistinguishable expansion kinetics and numbers of antigen-specific CD4 and CD8 T cells in an adoptive transfer model with OT-I and OT-II T cells in mice. Strikingly, MPLA was not equivalent to LPS in inducing production of certain serum cytokines and chemokines during this T cell activation. Serum levels of MyD88-associated proteins, such as IL-6, IL-1 $\beta$, and IFN- $\gamma$ were significantly lower when MPLA was used as an adjuvant as opposed to LPS. In contrast, production of TRIF-associated proteins such as G-CSF and IP-10 was induced similarly by MPLA and LPS. This phenomenon, which we termed "TRIF-bias," was confirmed by gene chip mRNA expression analysis on spleen cells harvested 6 hours after immunization with MPLA or LPS. TRIF-bias was also shown in vitro with mouse macrophages. MPLA was significantly weaker than LPS in inducing MyD88-associated IL-6 production and NF- $\mathrm{kB}$ activation, but was equivalent to LPS in TRIF-dependent IP-10 production and IRF3 activation. 
In this same study, we demonstrated that the TRIF pathway, and not the MyD88 pathway, was required for the early expansion of antigen-specific CD4 and CD8 T cells with MPLA or LPS as adjuvant. This observation and the association of MyD88 signaling with proinflammatory outcomes gave rise to the hypothesis that TRIF-biased signaling by MPLA allowed it to be an effective adjuvant without overwhelming toxicity.

Our lab went on to demonstrate that the absence of the 1-phosphate on lipid A was a potential determinate of TRIF-biased TLR4 signaling in mice $(78,79)$. The synthetic monophosphoryl lipid A based on the E. coli chemotype, which we call sMLA, was equivalent to diphosphoryl lipid A (called sLipid A in this dissertation) (Fig. 3) in the induction of TRIF-dependent gene products but weaker in MyD88-associated gene products at the concentrations tested (78). In addition, we showed that sMLA, like MPLA, was equivalent to sLipid A in its induction of $I l 1 b$ mRNA, but weaker in induction of IL-1 $\beta$ protein due to its weak activation of the MyD88-dependent NLRP3 inflammasome (79). Still, we were aware of the fact that TLR4 signaling caused by MPLA and sMLA was not completely devoid of MyD88 activity. For example, sMLA induced more sustained MyD88-dependent SHIP1 phosphatase than sLipid A (80). In addition, sMLA was capable of inducing the same amount of many MyD88-associated events as sLipid A if sMLA was given at a higher dose $(78,81)$. Therefore, TRIF-biased signaling by MPLA and sMLA was always appreciated as being more nuanced than simply TLR4 signaling in the absence of MyD88 engagement. 


\section{DISSERTATION GOALS}

Although we have begun to characterize many of the qualitative aspects of TLR4 signaling by MPLA and sMLA, we have yet to determine a definitive mechanism for TRIF-bias. Observations of TLR4 adaptor signaling biases have been published by other labs, but adaptor bias remains a controversial topic within the scientific community. The goal of this dissertation was to expand our understanding of TRIF-biased signaling by monophosphorylated lipid A agonists and to define a potential mechanism for its occurrence. In Chapter III, the role of the coreceptor CD14 in signaling by MPLA is analyzed to determine whether this receptor, which plays a prominent role in TRIF signaling, is utilized differently by a TRIF-biased agonist. In Chapter IV, we refine our definition of TRIF-biased signaling and propose a mechanism which depends upon the interaction of TLR4 and the type I interferon receptor signaling pathways. These findings have direct implications for the design and utilization of TLR4 agonists as vaccine adjuvants. They may also provide insight into the coevolution of the microbiome and the host innate immune system. 


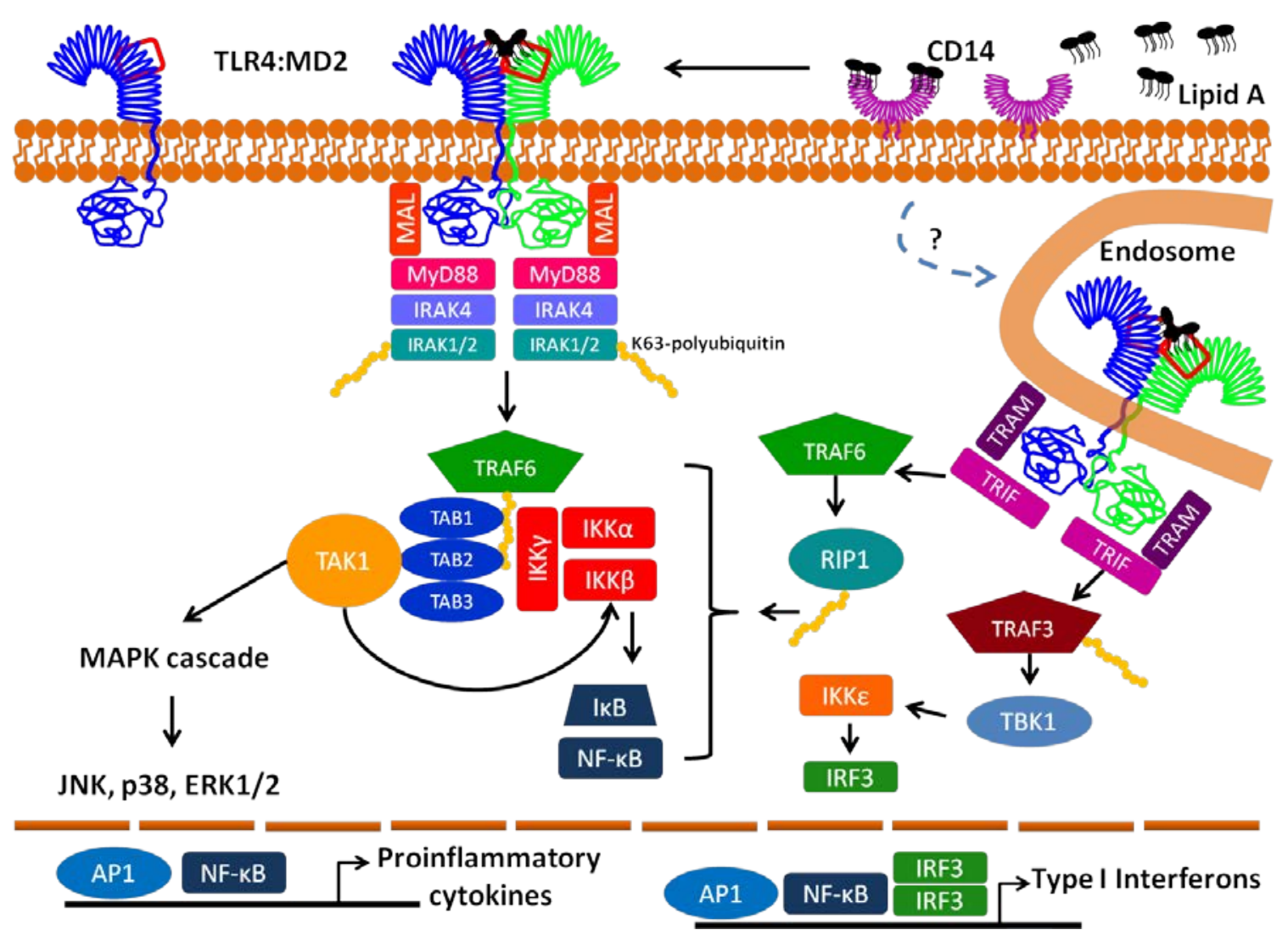

Fig. 1. The TLR4 signaling pathway. LPS or lipid A induced heterotetramerization of

TLR4:MD-2 causes signaling through the MyD88- and TRIF-dependent pathways.

MyD88 signaling occurs first from the cell membrane and leads to rapid activation of

MAPKs and NF- $\kappa$ B. MAPKs activate transcription factors, such as the AP1 family.

These transcription factors, along with NF- $\kappa \mathrm{B}$ drive the expression of proinflammatory

genes such as Il6, Cox2, and Il1b. TRIF signaling occurs after endocytosis of TLR4:MD-

2 and is, therefore, delayed. TRIF activates NF- $\kappa$ B and MAPKs through RIP1 and

TAK1. It also uniquely induces IRF3 activating phosphorylation and dimerization which is required for type I interferon expression. 
Lipid A (hepta-acyl form)

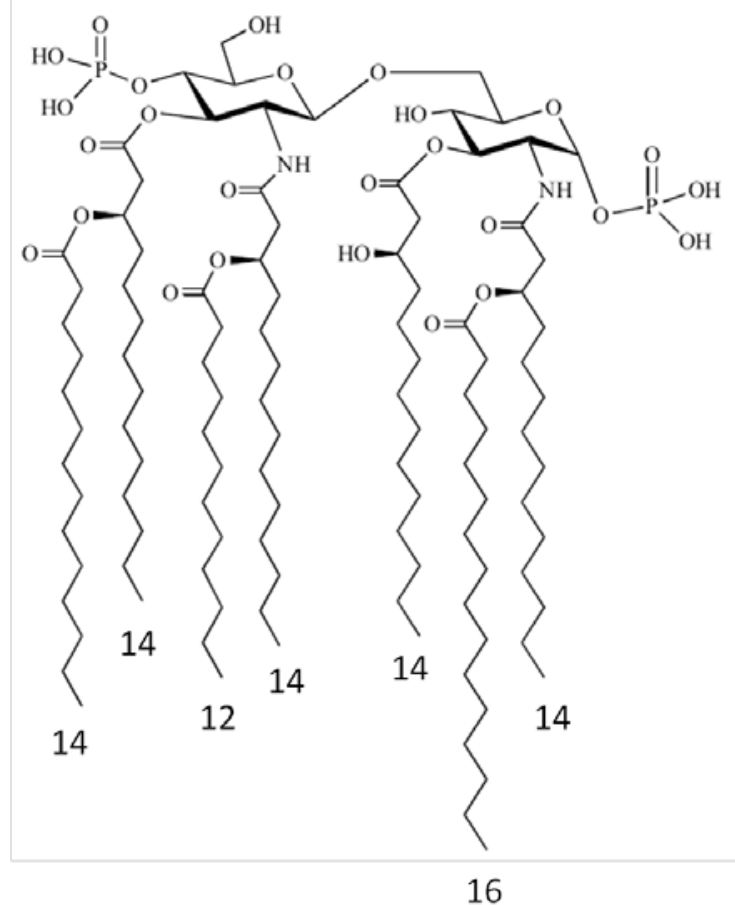

MPLA (hexa-acyl form)

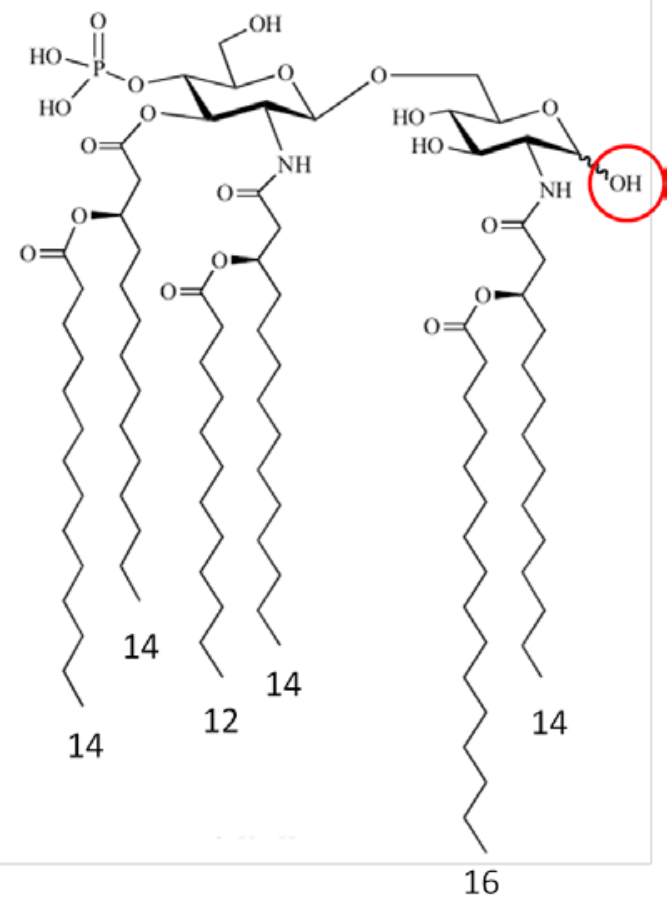

Fig. 2. Salmonella minnesota lipid A and MPLA structures. Acid hydrolysis of $S$. minnesota LPS removes the Kdo group to yield lipid A. Because lipid A is prepared from biological LPS isolates, it is composed of a mixture of congeners with different numbers of acyl chains (from 3 to 7). This variability is due to inherent heterogeneity in the biosynthesis of LPS by the bacterium. The hepta-acyl form is shown above. Further acid hydrolysis removes the 1-phosphate of lipid A to yield MPLA. Shown above is the hexa-acyl form which is presumably the most active congener. Although the hepta-acyl form is removed from clinical preparations of MPL adjuvant by alkaline hydrolysis, this was not the case for the agonists used in these studies. 

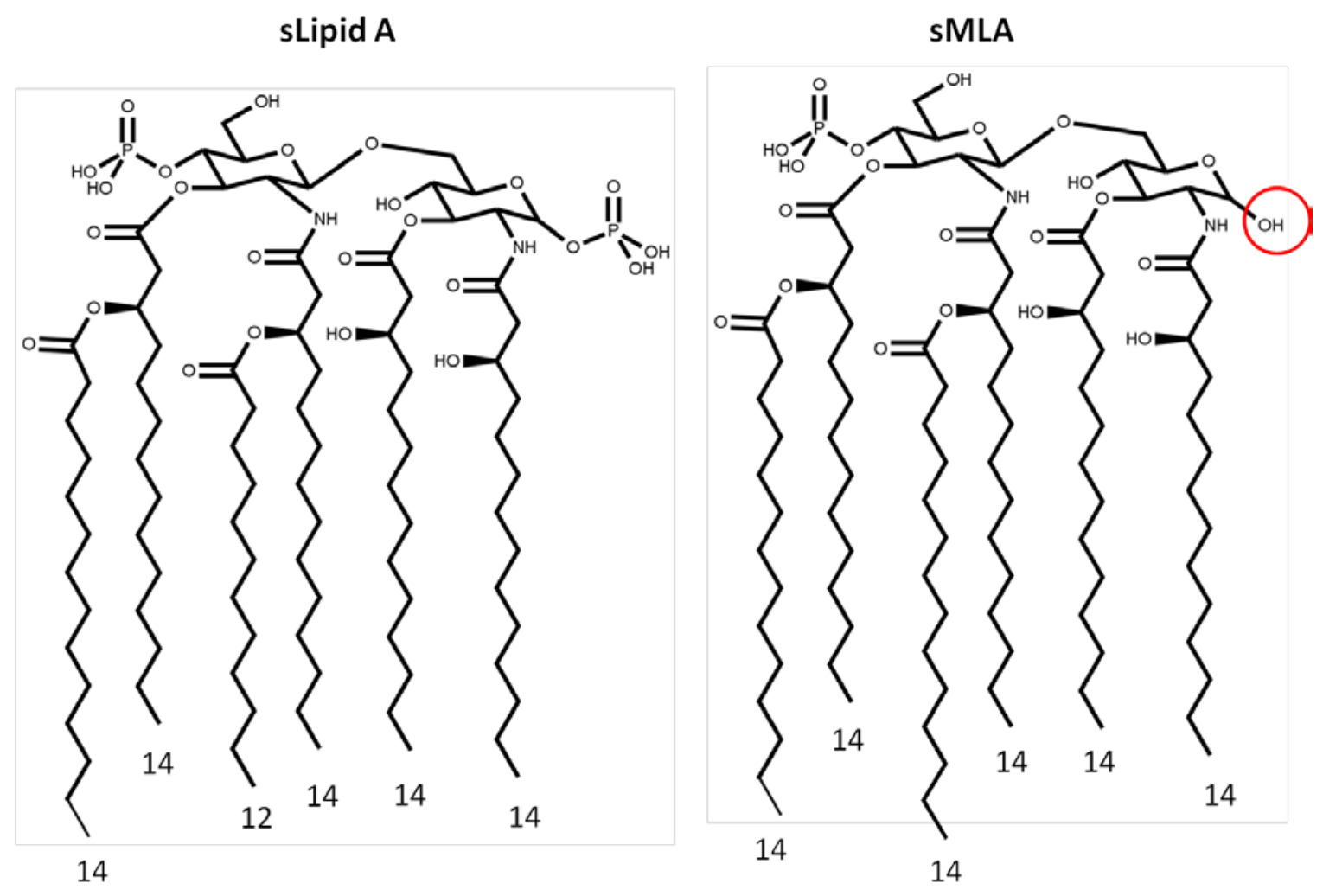

Fig. 3. Synthetic lipid A (sLipid A) and MPLA (sMLA) structures. The synthetically prepared lipid A and MPLA based on the E. coli chemotype are homogeneous, both bearing 6 acyl chains. sMLA differs from sLipid A at the 1-position and at the third acyl chain from the left. 


\section{CHAPTER II}

\section{METHODS}

\section{Mice and reagents}

C57BL/6, TRIF $F^{l p s 2 / p s 2}$ and $C D 14^{-/-}$mice were purchased from the Jackson Laboratory. $M y D 88^{-/-}$mice were a gift of S. Akira (through R. Kedl, University of Colorado School of Medicine). Mice were housed in a specific pathogen-free barrier facility at the University of Louisville and cared for according to regulations set forth by its Institutional Animal Care and Use Committee. Salmonella minnesota MPLA and lipid A (sold dissolved in water) were purchased from Alexis/Enzo Life Sciences. The compounds sMLA (MW 1763.5, sold as PHAD, Cat. no. 699800, Avanti Polar Lipids), sLipid A [MW 1798.4, sold as Lipid A (E. coli), Cat. no. CLP-24005-s, Peptides International], and synthetic lipid IVa (MW 1405.7, Cat. no. CLP-24006-s, Peptides International) were dissolved by vortexing in 100\% DMSO (Sigma-Aldrich) at $1 \mathrm{mg} / \mathrm{ml}$ and then promptly frozen in single use aliquots at $-80^{\circ} \mathrm{C}$. Agonists were serially diluted in culture medium before being added to cell cultures. The DMSO concentration in cell culture was $\leq 0.32 \%$. A vehicle control corresponding to the highest DMSO concentration in each experiment ( 0.1 or $0.32 \%$ ) was always used. Primary antibodies for the Western blotting analysis of the following targets were purchased from Cell Signaling Technology: pIRF3 (Ser ${ }^{396}$, Cat. no. 4947), pJNK (Thr ${ }^{183} / \mathrm{Tyr}^{185}$, Cat. no. 4668), pp38 (Thr ${ }^{180} / \mathrm{Tyr}^{182}$, Cat. no. 9215), pERK1/2 (Thr ${ }^{202} / \mathrm{Tyr}^{204}$, Cat. no. 4370), pcJun (Ser ${ }^{63}$, Cat. no. 9261), pMAPKAPK2 
(Thr ${ }^{222}$, Cat. no. 3316), total p38 (Cat. no. 9212), total ERK1/2 (Cat. no. 4695), total cJun (Cat. no. 9165), total MAPKAPK2 (Cat. no. 3042), and IкB $\alpha$ (Cat. no. 4814). Primary antibodies for the Western blotting analysis of the following targets were purchased from Santa Cruz Biotechnology: IRAK1 (Cat. no. sc-5288), total IRF3 (Cat. no. sc-9082), $\beta$ actin (Cat. no. sc-1616), and total JNK (Cat. no. sc-137018). All horseradish peroxidase (HRP)-conjugated secondary antibodies were purchased from Jackson ImmunoResearch. The JNK inhibitor SP600125 (Sigma-Aldrich) and the p38 MAPK inhibitor SB202190 (Calbiochem) were dissolved in 100\% DMSO at concentrations of 25 and 3 mM, respectively, and were frozen at $-20^{\circ} \mathrm{C}$ until needed for use. The anti-mouse IFNAR1 antibody MAR1-5A3 and the functional grade mouse IgG $_{1}$ isotype control were purchased from Leinco Technologies. Recombinant mouse IFN- $\beta$ protein was purchased from the PBL Interferon Source. Recombinant mouse TNF $\alpha$ was purchased from eBioscience.

Generation and culture of bone marrow-derived dendritic cells (BMDCs) BMDCs were prepared with a procedure modified from that of Lutz et al. (82). Briefly, bone marrow plugs were flushed from the femurs and tibiae of mice with sterile Hank's balanced salt solution (HBSS) and resuspended in BMDC medium containing R10F [RPMI 1640 supplemented with 10\% heat-inactivated fetal bovine serum (FBS), 2 mM L-glutamine, $1 \mathrm{mM}$ sodium pyruvate, penicillin (50 U/ml), streptomycin (50 $\mu \mathrm{g} / \mathrm{ml}), 50$ $\mu \mathrm{M} \beta$-mercaptoethanol, and GM-CSF (5 ng/ml, Miltenyi Biotec or R\&D Systems]. Bone marrow cells $\left(2 \times 10^{6}\right.$, excluding red blood cells) were seeded in 100 -mm bacteriological petri dishes in $10 \mathrm{ml}$ of $\mathrm{BMDC}$ medium and incubated at $37^{\circ} \mathrm{C}$. On days 3 and $8,10 \mathrm{ml}$ of 
BMDC medium was added to the cultures. On day 6, $10 \mathrm{ml}$ of BMDC medium was removed and replaced with fresh medium. On day 10, non-adherent BMDCs were collected. BMDCs were typically $>85 \% \mathrm{CD} 11 \mathrm{c}^{+} \mathrm{CD} 11 \mathrm{~b}^{+} \mathrm{MHCII}^{+} \mathrm{CD} 86^{\text {low }} \mathrm{CD} 14^{+} \mathrm{CD} 4^{-}$ $\mathrm{CD}^{\top} \mathrm{B} 22{ }^{\circ} \mathrm{CD} 19^{-} \mathrm{GR} 1^{-}$as determined by flow cytometric analysis.

\section{Collection of mouse serum}

Mice were euthanized by $\mathrm{CO}_{2}$ asphyxiation. Blood was collected in Microtainer tubes with a serum separator (BD) after cardiac puncture, and serum was collected after centrifugation. Fully concentrated serum and serum diluted to 30\% in RPMI was frozen at $-80^{\circ} \mathrm{C}$ until needed.

\section{Maturation of BMDC and flow cytometry}

BMDC were seeded at $1 \times 10^{6}$ cells/well in 6 well plates and incubated for 2 hours at $37^{\circ} \mathrm{C}$. TNF $\alpha$ or sLipid A diluted in R10F was used to activate the cells for approximately 18 hours. Matured BMDC were then collected using cell scrapers. Calcium and magnesium free HBSS washes and versene treatment was used to facilitate cell removal. Cells were incubated in 20\% FC receptor block (2.4.G2 supernatants) for about 10 minutes and then stained with the following antibodies: CD11c-FITC, CD40-APC, CD14-APC (all from eBioscience). CD40-APC and CD14-APC were replaced with the corresponding isotype control antibodies in separate tubes. Cells were stained for approximately $45 \mathrm{~min}$ in the dark at $4^{\circ} \mathrm{C}$. Five minutes before acquiring data on the FACScalibur, 7AAD viability staining solution (eBioscience) was added to the cells with vortexing. In ELISA experiments, BMDC were seeded in 96 well plates at $1 \times 10^{5}$ 
cells/well and incubated at $37^{\circ} \mathrm{C}$ for 2 hours. BMDC were then activated with TNF $\alpha$ or left unactivated for about 18 hours. The cells were then washed twice with HBSS and new media added to the wells. Cells were rested for an additional 2 hours at $37^{\circ} \mathrm{C}$, followed by activation with agonist for about 18 hours. Supernatants were then collected and protein concentrations analyzed by ELISA.

Intracellular phospho-protein staining

BMDC $\left(1 \times 10^{6}\right)$ were incubated with MAR1-5A3 or media alone for 1 hour in polystyrene snap cap tubes. The cells were then activated for 1 hour with $100 \mathrm{ng} / \mathrm{ml}$ sLipid A or DMSO as control. Cells were then washed in ice cold HBSS and resuspended in cold Fc block for 10 min. After another wash with cold HBSS, 1.5\% formaldehyde was added to the cells slowly with vortexing. The cells were then incubated for 10 at room temperature. After washing out the formaldehyde, ice cold methanol was added to the cells with vortexing and the cells were incubated at $4^{\circ} \mathrm{C}$ for 10 min. The methanol was then washed out and the cells were stained with anti-pSTAT1 (pY701)-PE (BD) or isotype control antibody. Data was acquired on a FACScalibur.

\section{Cytokine measurement}

BMDCs $\left(1 \times 10^{5} /\right.$ well $)$ suspended in R10F medium were incubated in flat-bottom, 96well plates for 2 hours at $37^{\circ} \mathrm{C}$ before TLR4 agonists or DMSO (vehicle control) diluted in R10F were added. In the MAPK inhibition experiments, $10 \mu \mathrm{M}$ SP600125, $10 \mu \mathrm{M}$ SB202190, or DMSO (vehicle control) was added 30 min before addition of the TLR4 agonists. In the IFNAR1-blocking experiments, MAR1-5A3 $(10 \mu \mathrm{g} / \mathrm{ml})$ or isotype control 
antibody was added immediately before plating the BMDCs for a 2-hour pre-incubation. After 18 hours of stimulation with TLR4 agonists at $37^{\circ} \mathrm{C}$, supernatants were collected, and IL-6 (BD Biosciences) and IP-10 (R\&D Systems) concentrations were measured by ELISA, according to each manufacturer’s specifications.

\section{Quantitative real-time PCR}

BMDCs $\left(5 \times 10^{5}\right)$ suspended in R10F medium were incubated in 5-ml polystyrene roundbottom tubes at $37^{\circ} \mathrm{C}$ for 2 hours before TLR4 agonists or IFN- $\beta$ was added. MAPK inhibitors and the IFNAR1 blocking antibody were used in the manner described earlier. After they were stimulated, the cells were washed with ice-cold HBSS. Cell lysis and total RNA isolation were performed with RNeasy plus mini kits (Qiagen) according to the manufacturer's protocol, and complementary DNA (cDNA) was synthesized with Qscript cDNA Supermix (Quanta BioSciences). qPCR analysis was performed with a Bio-Rad CFX96 real-time system with Power SYBR Green PCR Mastermix (Applied Biosystems) and pre-optimized Quantitect primer pairs (Qiagen). Fold-increases in mRNA abundances in treated cells relative to those in vehicle control cells were calculated with the $2^{-\Delta \Delta \mathrm{Ct}}$ method, and GAPDH mRNA abundance was used for normalization.

\section{Western blotting analysis}

BMDCs $\left(2.5\right.$ to $\left.3 \times 10^{6}\right)$ in R10F medium were pre-incubated for 2 hours in 5 -ml polystyrene round-bottom tubes at $37^{\circ} \mathrm{C}$, which was followed by activation with different concentrations of sLipid A or DMSO. After stimulation for 15 min or 1 hour, BMDCs 
were washed with ice-cold HBSS containing $50 \mu \mathrm{M}$ NaF. Cells were lysed with radioimmunoprecipitation buffer [50 mM Tris- $\mathrm{HCl}$ (pH 7.4), $150 \mathrm{mM} \mathrm{NaCl,} 1 \mathrm{mM}$ EDTA, 1\% Triton $\mathrm{x}-100,1 \%$ sodium deoxycholate, and $0.1 \%$ SDS] containing Complete Mini protease inhibitor cocktail tablets (Roche) and phosphatase inhibitor cocktail (Sigma), and the BCA assay (Pierce) was used to determine the protein concentrations of the lysates. Samples normalized for protein content were resolved by 10\% SDS-PAGE. Proteins were transferred onto nitrocellulose membranes (GE Healthcare). The membranes were blocked with 5\% non-fat dry milk or 5\% bovine serum albumin (BSA, for the analysis of pIRF3 only) for 1 hour and then were incubated overnight at $4^{\circ} \mathrm{C}$ with primary antibodies in 5\% BSA or 5\% non-fat dry milk (for the detection of $\beta$-actin, IRAK1, and total IRF3 only). HRP-conjugated secondary antibodies were resuspended in 5\% non-fat dry milk and incubated with the Western blots for 1 hour. The blots were developed with ECL Prime (GE Healthcare) or SuperSignal ELISA Femto substrate (Pierce) on a Fujifilm LAS-4000 Mini, and data were quantified with Multi Gauge V3.0 software (Fujifilm).

\section{Statistical analysis and $\log ($ EC50) measurement}

$\log \left(\mathrm{EC}_{50}\right)$ values for each agonist-induced response were calculated by generating fourparameter nonlinear fits to dose-response data with GraphPad Prism software using the following equation:

$y=$ Bottom $+\frac{(\text { Top }- \text { Bottom })}{1+10^{(\text {LogEC } 50-x) * H i l l s l o p e}}$ 
Differences between logEC50 values were analyzed by unpaired two-tailed t test (for comparisons between two sets of genes) or by ordinary one-way ANOVA with Tukey's multiple comparisons post-test (for comparisons between three or more sets of genes). Differences between protein production in the presence of WT or CD14KO mouse serum were determined with ordinary two-way ANOVA with Sidak's multiple comparisons test. TNF $\alpha$-induced upregulation of CD14 surface expression was analyzed by a paired two-tailed $\mathrm{T}$ test. Statistically significant inhibition of increases in mRNA abundance by MAPK inhibitors was determined with repeated measures two-way ANOVA with Dunnett's multiple comparison post-test. Ordinary two-way ANOVA analysis with Sidak's multiple comparisons post-test was used to analyze the effects of MAPK inhibitors on gene $\operatorname{logEC} 50$ s, and to compare IFN $\beta$ vs sLipid A-induced time courses. Differences in the logEC50 values in the IFNAR1-blocking experiments were analyzed with repeated measures two-way ANOVA with Sidak's post-test. 


\section{CHAPTER III \\ THE CONTRIBUTION OF CD14 TO MYD88- AND TRIF-ASSOCIATED RESPONSES ELICITED BY BIOLOGICAL MPLA AND LIPID A}

\section{INTRODUCTION}

The quality of the cellular response to a TLR4 agonist depends not only upon the structural characteristics of the agonist itself, but also upon the presence of the TLR4 coreceptor CD14. Like the TLRs, CD14 is a member of the LLR family of proteins (83). It is expressed in varying abundance as a GPI-anchored surface protein (called membranebound or mCD14) (12) on certain non-myeloid and myeloid cells including endothelial and epithelial cells, monocytes, macrophages, dendritic cells, and granulocytes (84). In addition, CD14 is found in a soluble form (sCD14) in the serum and is thought to be released by enzymatic cleavage of mCD14 or cellular secretion (25). Its structure is that of a curved solenoid which forms an N-terminal hydrophobic ligand-binding pocket with peripheral cationic amino acid residues (85). The ligand-binding pocket is deep and flexible (85), presumably allowing CD14 to bind a variety of different molecules including LPS (9), peptidoglycan (86), and lipoteichoic acid (87). Interaction between hydrophobic patches at the C-termini cause CD14 to form a horseshoe-like homodimer (85).

A major role of CD14 is to enhance TLR4 activity in response to low concentrations of LPS. Initially, LBP in the serum extracts LPS monomers from either 
bacterial membranes or smaller aggregates and catalytically transfers them to CD14 (23, 24). CD14 then loads monomeric LPS into the binding pocket of MD-2 associated with TLR4 which promotes TLR4/MD2 heterotetramerization and intracellular signaling (88, 89). Both mCD14 and sCD14 are capable of this process, and sCD14 may be especially important for TLR4 responsiveness in cell types that express little if any mCD14 such as human umbilical vein endothelial cells $(90,91)$. If extracellular concentrations of LPS are very high, TLR4 is activated independently of CD14 (15).

In addition to its function as an LPS transport protein, CD14 was shown to be actively involved in the TRIF-dependent signaling pathway of TLR4. Early work by Perera et al. supported the existence of unique CD14-dependent and CD14-independent pathways in the response of macrophages to LPS even before the discovery of TLR4 (15). In this study, CD14-deficient macrophages expressed minimal TRIF-dependent Ip10 mRNA compared to WT macrophages at high LPS concentrations. At these same agonist doses, MyD88-associated Il1b and Tnfa expression was unaffected by CD14deficiency. Jiang et al. (92) were the first to make a direct connection between CD14 and TRIF signaling, demonstrating that CD14-deficient mouse macrophages were defective in TRIF-dependent type I IFN production in response to smooth (containing O-antigen) and rough (lacking O-antigen) LPS chemotypes, but were largely unaffected in MyD88associated TNF $\alpha$ production in response to rough LPS. Later, Zanoni et al. (47) elaborated on this work, confirming the dependence of TRIF signaling on CD14, but also showing that CD14 itself directs the endocytosis of TLR4, independent of TLR4-induced signaling events. Therefore, TRIF signaling, which is initiated from an endocytic compartment (50), is weak in the absence of CD14 because TLR4 endocytosis is minimal 
under these conditions. Presumably, CD14 controls endocytosis of TLR4 through an immunoreceptor tyrosine-based activation motif (ITAM)-mediated event that then activates PLC $\gamma 2$ and Syk (47).

Several groups have reported that certain TLR4 agonists may have a reduced requirement for CD14-dependent TLR4 stimulation (72, 93, 94). MPLA has been placed in this category $(72,93)$. Blocking CD14 on the surface of human monocyte-derived DC had no effect on MPLA-induced IL-12p40 secretion, although the use of very high doses of MPLA may have biased these experiments (72). In addition, Tanimura et al. (93) showed that TNF $\alpha$ production by CD14-deficient mouse BMDC in response to MPLA was not reduced when compared to WT BMDC. On the other hand, this same study concluded that CD14 was required for MPLA-induced heterotetramerization and endocytosis of TLR4/MD2, suggesting that MPLA may engage CD14 and require its presence for full activity. Therefore, there is still some confusion concerning the extent to which MPLA requires CD14 to stimulate TLR4 and to the specific responses that MPLA can elicit independently of CD14.

We previously published that MPLA was a TRIF-biased agonist in mouse, both in vitro and in vivo (77), but the mechanism by which this occurs has not been fully revealed. One hypothesis is that MPLA interacts with TLR4:MD-2 or CD14 in a fundamentally different manner than LPS or lipid A, which allows the TRIF pathway to be more completely engaged while MyD88 signaling remains weak. Given that mCD14 expression is linked to TLR4 endocytosis and TRIF signaling, we sought to determine the extent to which CD14 ablation affects TRIF-dependent and MyD88/TRIF co-dependent responses to MPLA and lipid A in mouse DC. High and low concentrations of these 
agonists were tested to fully assess the degree to which both pathways are affected. In this study, MPLA did not induce a TRIF-biased response profile in WT BMDC. Instead, MPLA was less potent than lipid A in stimulating both TRIF- and MyD88 and TRIF-codependent outcomes. Tests in WT and CD14-deficient BMDC did not reveal obvious differences between MPLA and lipid A requirements for CD14 for either TRIF- or codependent signaling events. Therefore, variations in the interaction of MPLA or lipid A with CD14 in the TLR4 receptor complex are unlikely to explain any TRIF-bias by MPLA in mouse.

\section{RESULTS}

MPLA is not a TRIF-biased agonist in mouse dendritic cells.

In previous experiments, we characterized MPLA as a TRIF-biased agonist by comparing the inflammatory response of mouse macrophages (thioglycolate-elicited or bone marrow-derived) to MPLA or LPS, or by measuring inflammatory outcomes in vivo (77). The roles of macrophages and DC differ during the response to an infection.

Macrophages are critical in the initial control of pathogens while DC specialize in antigen presentation in lymph nodes. Therefore, it is plausible that these cells' responses to MPLA may differ. In order to determine whether MPLA is a TRIF-biased agonist in DC, BMDCs were exposed to different concentrations of MPLA and lipid A, followed by measurement of MyD88- and TRIF-co-dependent or TRIF-dependent gene products. MPLA induced co-dependent IL-6 protein production and Cox2 mRNA more weakly than did lipid A, confirming our previous results (77) (Fig. 4A). Surprisingly, MPLA was also less potent than lipid A in inducing TRIF-dependent Ifit1 mRNA, a response the 
two agonists induced equivalently in previous experiments (77) (Fig. 4B). To quantitatively determine the extent of MPLA's potency deficit for each analyte, we used non-linear regression to fit curves to the data points, allowing the estimation of each agonist's $\log (\mathrm{EC} 50)$ values. Lipid A was approximately 30 times more potent than MPLA for both TRIF- and co-dependent gene products, indicating no obvious biases in adaptor signaling by MPLA [log(EC50) values for lipid A: IL-6 = 0.86; Cox2 = 1.17; Ifit1 = 1.19; $\log (\mathrm{EC} 50)$ values for MPLA: IL-6 = 2.33; Cox2 = 2.67; Ifit1 = 2.97]. These results indicate that MPLA is not a TRIF-biased agonist in mouse BMDC.

MyD88- and TRIF-co-dependent responses are reduced at low concentrations of MPLA and lipid A in CD14-deficient BMDCs.

Regardless of the fact that MPLA did not behave as a TRIF-biased agonist in BMDC, we compared the responses of MPLA and lipid A in WT and CD14KO BMDCs to determine whether one of these agonists exhibited a greater dependence on CD14 to induce signaling outcomes downstream of MyD88 or TRIF. Several studies have shown that induction of MyD88- and TRIF-co-dependent genes like Tnf $\alpha$ in CD14-deficient cells is reduced in response to low concentrations (less than $1000 \mathrm{ng} / \mathrm{ml}$ ) of LPS (15, 47, 95). We activated WT and CD14KO BMDCs with different concentrations of MPLA or lipid A in medium containing mouse serum collected from CD14KO mice. This allowed us to focus solely on mCD14's contribution to TLR4 signaling because sCD14 was absent from the system.

Phenotyping by flow cytometry demonstrated that WT and CD14KO BMDCs expressed an equivalent surface abundance of CD11c, CD86, and MHCII. The 
expression of both CD86 and MHCII was low indicating an immature phenotype (Fig. 5). MyD88- and TRIF-co-dependent IL-6 protein abundance in culture supernatants, measured after 6 hours activation, was reduced in CD14KO versus WT BMDC activated with lipid A concentrations below $1000 \mathrm{ng} / \mathrm{ml}$ (Fig. 6A). Similarly, IL-6 production was reduced in CD14KO BMDC activated with MPLA concentrations below 10,000 ng/ml (Fig. 6B). Co-dependent Cox2 mRNA measured 2 hours after activation followed the same pattern as IL-6 when induced with either agonist (Fig. 6 A and B).

In order to estimate the decrease in potency of lipid A and MPLA in the absence of mCD14, we compared the agonist concentrations required to induce equivalent expression of IL-6 protein or Cox2 mRNA in WT or CD14KO BMDC. Calculation of agonist $\log (\mathrm{EC} 50)$ values by non-linear regression was not possible in this case because the concentrations of agonist need to produce a plateau in the dose response curves were not feasible. Equivalent production of IL-6 protein and expression of Cox2 mRNA was induced by $100 \mathrm{ng} / \mathrm{ml}$ lipid A in WT BMDC and $1000 \mathrm{ng} / \mathrm{ml}$ lipid A in CD14KO BMDC (Fig. 6A), a 10 fold difference. Similarly, approximately 10 times more MPLA was needed to induce maximal IL-6 and Cox2 in CD14KO BMDC. Similar expression levels of IL-6 and Cox2 were induced by $1000 \mathrm{ng} / \mathrm{ml}$ and $100 \mathrm{ng} / \mathrm{ml}$ in CD14KO and WT BMDC, respectively (Fig. 6B). Therefore, it is likely that mCD14 contributes similarly to MyD88-associated signaling events induced by lipid A or MPLA. 
TRIF-dependent responses are reduced at both high and low concentrations of lipid A and MPLA in CD14-deficient BMDCs.

TRIF-dependent responses like type I IFN production and the induction of type I interferon-inducible genes has been shown to be severely decreased by the absence of mCD14 (15, 47, 92, 93). In order to determine whether MPLA differed from lipid A in its requirement for mCD14 for TRIF-dependent signaling events, we compared MPLAand lipid A-induced Ifit1 mRNA expression in WT and CD14KO BMDC. Ifit1 mRNA expression was reduced in CD14KO BMDC compared to WT over all doses of lipid A and MPLA tested. Although a very high dose of lipid A $(10,000 \mathrm{ng} / \mathrm{ml})$ was unable to completely compensate for the lack of mCD14, approximately 50\% of maximum Ifit1 mRNA expression was retained (Fig. 7). In contrast, MPLA-induced Ifit1 mRNA expression remained very low over all doses (Fig. 7). These results confirm that optimal TRIF-dependent TLR4 signaling is dependent upon mCD14 expression. The lack of complete dose response curves in these experiments made it difficult to conclude that MPLA and lipid A differ in their dependence on mCD14 for TRIF-dependent signaling. Similar Ifit1 mRNA expression was induced by $1000 \mathrm{ng} / \mathrm{ml}$ and $10 \mathrm{ng} / \mathrm{ml}$ lipid A in CD14KO and WT BMDC, respectively. Similar expression was induced by 10,000 $\mathrm{ng} / \mathrm{ml}$ and $100 \mathrm{ng} / \mathrm{ml}$ MPLA in CD14KO and WT BMDC, respectively. Therefore, the decrease in potency of both agonists in the absence of CD14 may be about 100 fold. The apparent weakness in MPLA's ability to induce Ifit1 compared to lipid A in CD14KO BMDC may be due to the fact that it is an inherently less potent agonist. 
BMDC culture in serum from wild-type mice has no effect on IL-6 production.

Previous studies have shown that sCD14 can partially rescue MyD88-associated responses in CD14KO macrophages $(92,96)$. In contrast, only mCD14 seems to be able to rescue TRIF-dependent responses such as IFN $\beta$ production (97). In certain cases, sCD14 may also inhibit the response to LPS, presumably by sequestering it from TLR4:MD2 $(98,99)$. It is unknown whether lipid A or MPLA have differential abilities to utilize sCD14 in order to enhance TLR4 signaling. Therefore, we asked whether sCD14 in WT mouse serum could rescue the IL-6 response to lipid A or MPLA. WT and CD14KO BMDC were cultured in media containing the serum collected from WT and CD14KO mice, and activated with different concentrations of MPLA or lipid A. Activation in WT, sCD14 replete, serum had no significant effect on the IL-6 response to either agonist in WT or CD14KO BMDC (Fig. 8). Because we were unable to demonstrate a restoration of the IL-6 response with the addition of WT serum in CD14deficient BMDC, we could not make a conclusion about MPLA or lipid A's ability to utilize sCD14.

Maturation of BMDC does not enhance MyD88- and TRIF-co-dependent or TRIFdependent responses.

During the completion of the experiments presented above, we also discovered that a sMLA (Fig. 3) which we had also proposed was a TRIF-biased agonist $(78,79)$, was not behaving as a true TRIF-biased agonist over a complete concentration range (discussed in Chapter IV). We wondered if some unintentional phenotypic drift had occurred in our BMDC cultures over time that had caused TRIF-bias to disappear. One 
such difference could be the maturation state of the cells. BMDCs matured with TNF $\alpha$ were shown to upregulate mCD14 expression, in addition to costimulatory molecules (47). Higher mCD14 surface expression correlated with faster and more robust internalization of TLR4, and with secretion of larger amounts of TRIF-dependent type I IFN in response to stimulation with LPS. MyD88- and TRIF-co-dependent TNF $\alpha$, on the other hand, was unaffected (47). Therefore, we hypothesized that monophosphorylated agonists would exhibit greater TRIF-bias if used to activate matured BMDC.

BMDC were matured with TNF $\alpha$ for 18 hours and then activated with different doses of sMLA or sLipid A for an additional 18 hours. A clear increase in BMDC CD40 expression occurred upon TNF $\alpha$ treatment indicating maturation (Fig. 9). As predicted, mCD14 expression also increased, although this increase did not score as significant $(\mathrm{p}=$ 0.0834). Unexpectedly, TNF $\alpha$ maturation decreased production of TRIF-dependent IP10 in response to low doses of sMLA or sLipid A (Fig. 10B). Co-dependent IL-6 was largely unaffected by TNF $\alpha$ maturation (Fig. 10A). Therefore, maturation and increased surface expression of mCD14 did not promote sMLA TRIF-bias by selectively enhancing the TRIF-dependent gene product IP-10.

\section{DISCUSSION}

A major goal has been the elucidation of a mechanism for TRIF-biased TLR4 signaling since we proposed that MPLA's TRIF-bias allowed it to retain beneficial effects on adaptive priming without major toxicity (77). We now know that MPLA and sMLA only weakly induce heterotetramerization of TLR4:MD-2, which explains why they are defective in MyD88-associated signaling events such as IRAK-1 activation (81). 
Even so, these compounds can induce some MyD88 signaling, which may be beneficial in certain cases $(77,80)$. The aim of this work was to narrow the gap in our understanding of how MPLA is able to retain robust TRIF-dependent signaling alongside weak MyD88-dependent signaling. We reasoned that a mechanism could be in place that boosts MPLA-induced TRIF-dependent signaling despite its weakness in induction of TLR4:MD-2 heterotetramerization. A stronger dependence on, or perhaps interaction with, CD14 that promotes TRIF signaling was hypothesized to drive MPLA's TRIF-bias. Therefore, removal of CD14 from the cell system was expected to have a much greater impact on MPLA's versus lipid A's ability to induce both co-dependent and TRIFdependent gene products.

Interpretation of the results of this study was made difficult by the fact that MPLA did not behave as a TRIF-biased agonist in BMDC over the doses tested (Fig. 4). Comparison of the lipid A and MPLA log(EC50) values for co-dependent IL-6 protein and Cox2 mRNA, and TRIF-dependent Ifit1 mRNA, clearly demonstrated that lipid A was about 30 times more potent than MPLA in both pathways (Fig. 4). Despite its potency deficit, MPLA was able to induce the same maximum response in all analytes tested, indicating that the two agonist share the same efficacy. Therefore, MPLA is not a partial agonist in the mouse BMDC system.

There are at least two ways to explain this observation. First, the TLR4:MD-2 heterotetramerization that MPLA is capable of inducing may be as efficient as that of lipid A in the recruitment of downstream signaling adaptors. In this case, MPLA's low potency would be explained by a lower affinity for the receptor. Second, MPLA may induce TLR4:MD-2 heterotetramerization in a conformation that less efficiently recruits 
signaling adapters, but that is capable of inducing a maximal response given the presence of enough receptors on the cell surface. In this case, the affinities of MPLA and lipid A for TLR4:MD-2 could be comparable.

We were unable to pinpoint the exact reason why MPLA did not exhibit TRIFbias in these experiments. TRIF-dependent IP-10 production was not selectively enhanced by pre-stimulation with TNF $\alpha$ that caused increased mCD14 expression on BMDC (Figs. 9 and 10), indicating that mature DC are not more likely to engage in TRIF-biased signaling versus immature DC.

A second reason for the lack of TRIF-bias by MPLA could be due to the use of BMDC instead of macrophages. As noted above, MPLA was initially characterized as a TRIF-biased agonist in macrophages. Activated macrophages at an infection site play a role in potentiating the inflammatory response and then contribute to anti-inflammatory resolution, such as wound healing. On the other hand, activated dendritic cells become potent antigen presenting cells and acquire the ability to home to secondary lymphoid organs. Therefore, the nature of the inflammatory response to MPLA by these two cell types could very well be different and reflect their unique physiological function (100). Recent work by Ling et al. (101) demonstrated that CD11b expression in DC, but not in macrophages, regulates LPS-induced TLR4 endocytosis, and MyD88- and TRIFdependent TLR4 signaling. Interestingly, TRIF signaling outcomes in BMDC required CD11b expression even when LPS-induced TLR4 internalization was rescued by mCD14 upregulation by CpG treatment. Therefore, differences between DC and macrophage responses to LPS, especially in the TRIF-dependent pathway, may be important. 
Despite a lack of TRIF-bias, we were still able to assess the level of dependence of MPLA and lipid A on mCD14. Approximately 10 times more lipid A or MPLA was needed to induce equivalent MyD88/TRIF co-dependent IL-6 protein and Cox2 mRNA induction in CD14KO BMDC (Fig. 6), suggesting that MPLA and lipid A utilize mCD14 in a similar fashion. Soluble CD14 seemed to play a negligible role in this system because the use of WT serum had no effect on IL-6 production (Fig. 8). These results do not support the conclusion of Tanimura et al. (93), who showed that MPLA can induce co-dependent TNF $\alpha$ protein independently of mCD14 at low doses. The influence of mCD14 on the MyD88-dependent pathway is linked to its transport of agonist to and loading of TLR4:MD-2; therefore, we speculate that mCD14 has a similar affinity for MPLA and lipid A.

Neither lipid A nor MPLA were capable of inducing maximal TRIF-dependent Ifit1 mRNA expression, even at very high doses (Fig. 7). These data confirm the strong dependence of TRIF-dependent signaling on mCD14 (47, 92, 93). MPLA induced minimal Ifit1 mRNA in the absence of mCD14 when compared to lipid A, which could lead to the conclusion that MPLA does indeed have a stronger dependence upon the coreceptor. But this might also be due to MPLA's low potency, in which case a higher MPLA dose might induce Ifit1 mRNA levels comparable to lipid A. Given the similar dependence of MPLA and lipid A on mCD14 for MyD88 activity, the latter explanation is more plausible.

The fact that in CD14KO BMDC, lipid A was capable of inducing up to 50\% of the maximal TRIF-dependent Ifit1 mRNA expressed in WT BMDC (Fig. 7) demonstrates that CD14 is not absolutely required for TRIF signaling and that a CD14-independent 
mechanism is also involved. Such a CD14-independent process has already been described in DC, whereby a TLR4 agonist in the form of large, particulate phagocytic cargo (i.e. whole E. coli) can induce TLR4 endocytosis and type I IFN production in CD14KO DC (47). Alternatively, scavenger receptor-mediated uptake may provide a means of delivering TLR4 agonists to the endocytic compartment where TRIF signaling can proceed (102).

In conclusion, this chapter provides evidence to support the claim that a unique interaction or utilization of CD14 by MPLA is not responsible for the difference between its signaling profile and that of native lipid A. Rather, MPLA is likely a weak agonist of TLR4 in mouse BMDC. As explored in Chapter IV, observation of a TRIF-biased response by MPLA is likely related to cross-talk between TLR4 and the type I IFN receptor. In addition, this work supports a qualification of the notion that mCD14 directs endocytosis of TLR4/MD2 and TRIF-dependent signaling. We suggest the existence of a CD14-independent pathway that drives appreciable TRIF-dependent signaling in response to soluble TLR4 agonists like lipid A. Future work is needed to explore this phenomenon. 

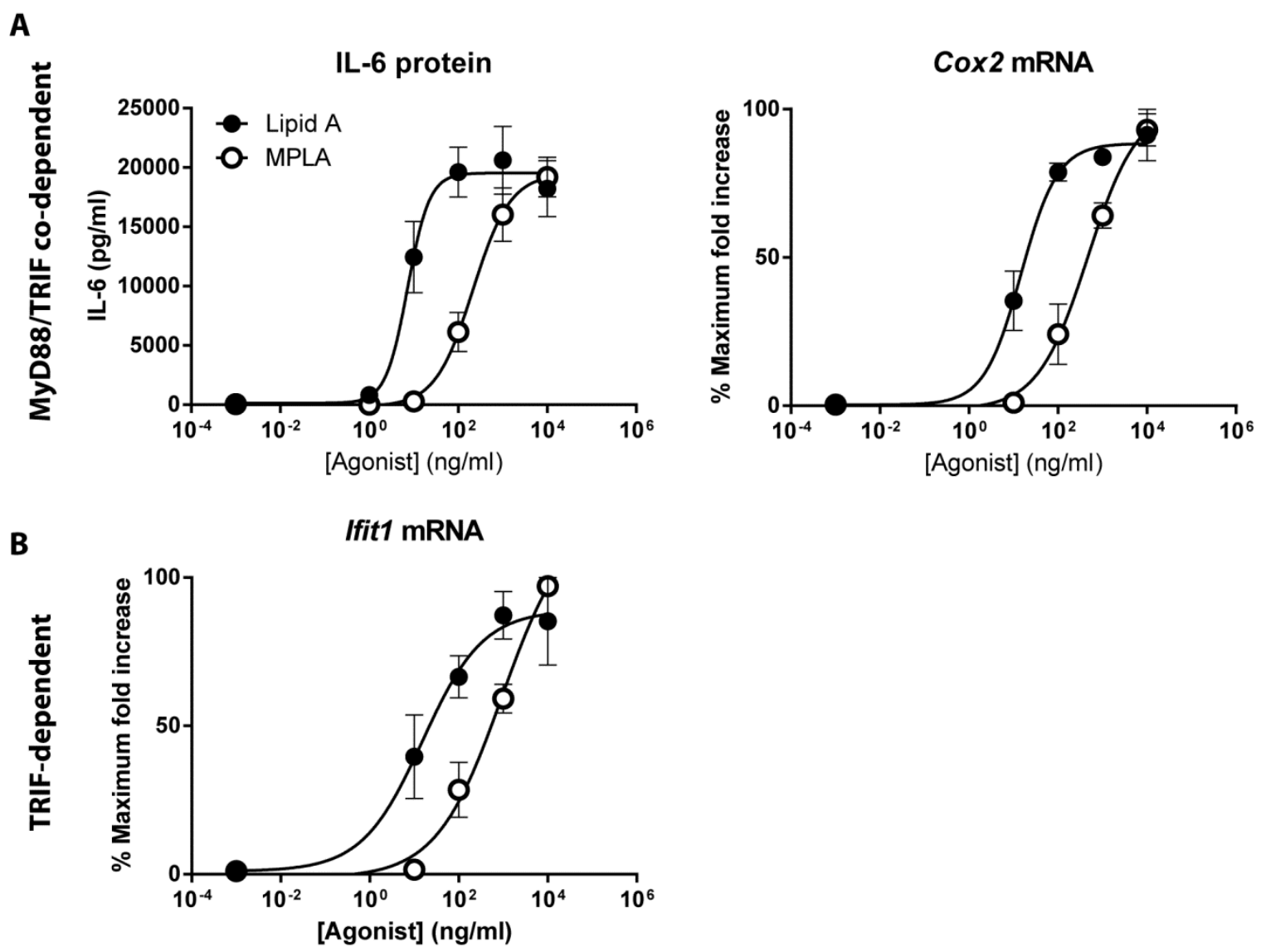

Fig. 4. MPLA is not a TRIF-biased agonist in mouse BMDCs. WT BMDCs were activated with the indicated concentrations of MPLA or lipid A in media containing 1 to 3\% serum collected from CD14-deficient mice. (A, left) After 6 hours activation, culture supernatants were measured for IL-6 protein abundance by ELISA. Steady-state abundance of Cox2 mRNA (A, right) and Ifit1 mRNA (B) relative to control (water) treated samples was measured after 2 hours activation by qPCR. The fold increase over control was measured in triplicate and converted to a percentage of maximum fold increase within each independent experiment. $\log (\mathrm{EC} 50)$ values were calculated by 4parameter nonlinear regression. Data are the mean \pm SEM for at least 3 independent experiments. 
Wild-type
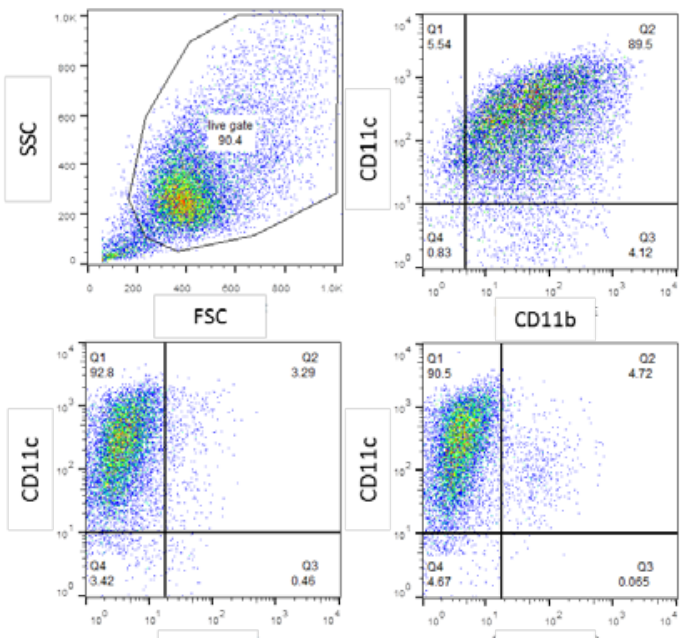

GR1

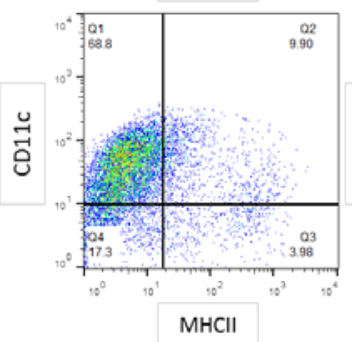

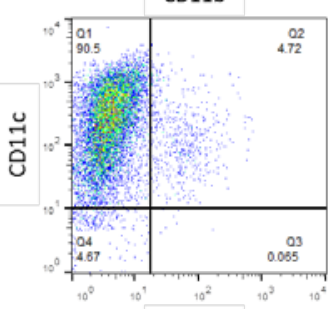

CD86

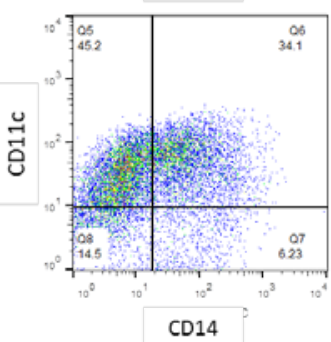

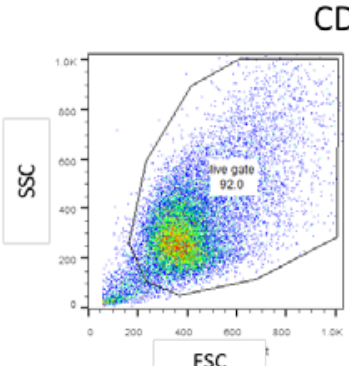

CD14KO
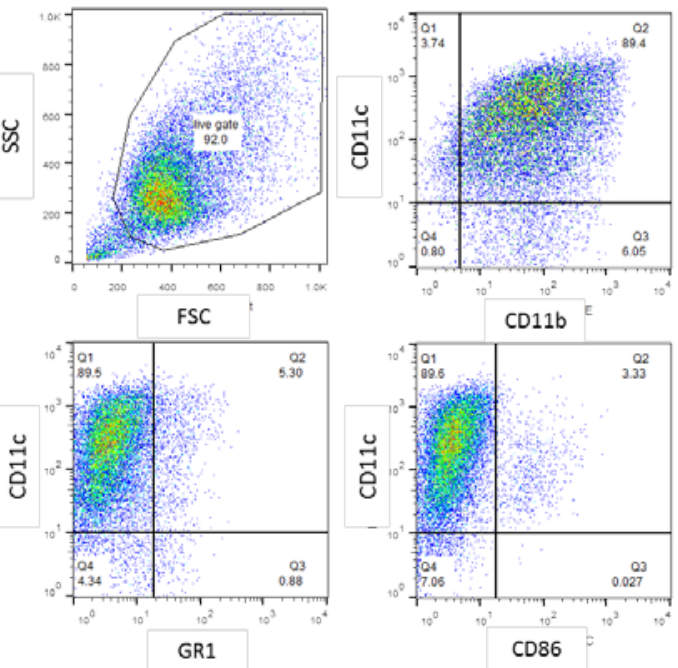

$\operatorname{CD} 86$
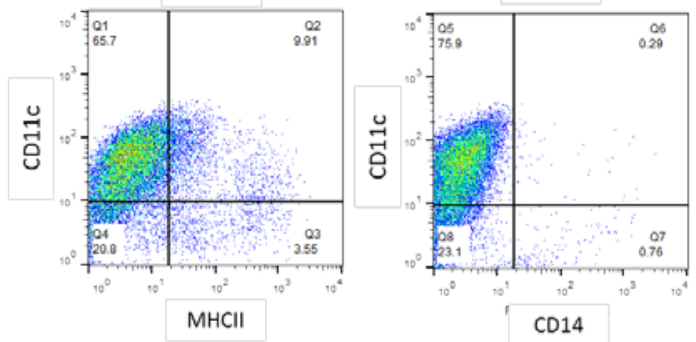

Fig. 5. WT and CD14 ${ }^{-/-}$BMDC are phenotypically similar. WT and CD14KO

BMDCs were stained with fluorochrome-conjugated antibodies against CD11b, CD11c, MHCII (I-A/I-E), GR1, CD86, and CD14. Data were acquired using a FACScalibur and analyzed with Flowjo software. Data shown are one representative experiment of 3 performed. 
A Lipid A-induced IL-6 protein

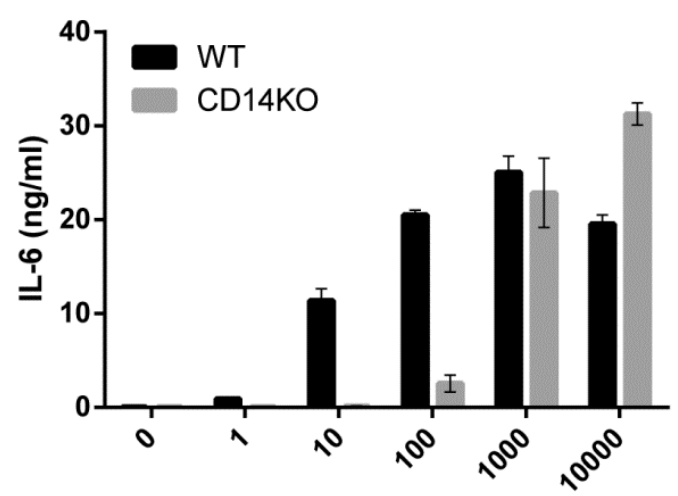

[Agonist] (ng/ml)

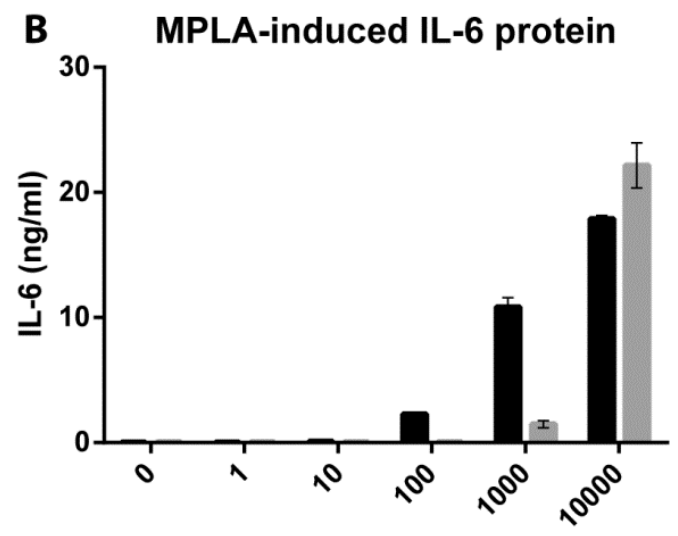

[Agonist] (ng/ml)
Lipid A-induced Cox2 mRNA

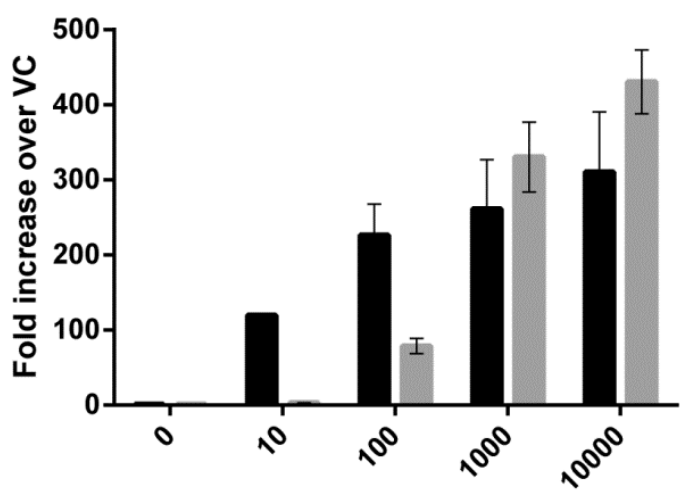

[Agonist] (ng/ml)

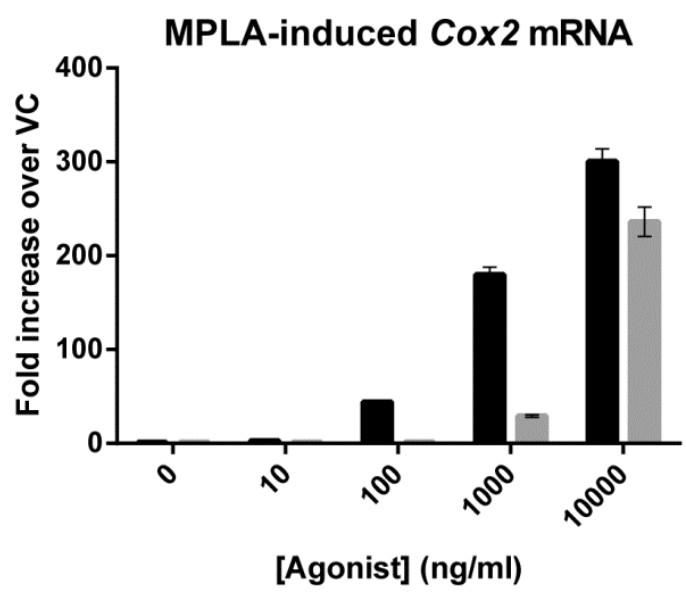

Fig. 6. MPLA and lipid A utilize CD14 similarly to induce expression of MyD88and TRIF-co-dependent genes. WT and CD14KO BMDC were activated with the indicated concentrations of (A) lipid A or (B) MPLA in media containing 1 to 3\% serum from CD14KO mice. IL-6 protein in culture supernatants was measured after 6 hours activation by ELISA. The fold increase in abundance of steady-state Cox2 mRNA relative to vehicle treated cells was measured by qPCR after 2 hours activation. Data are the mean \pm SD of triplicate samples. An experiment representative of at least 3 independent experiments is shown. 
Lipid A-induced Ifit1 mRNA

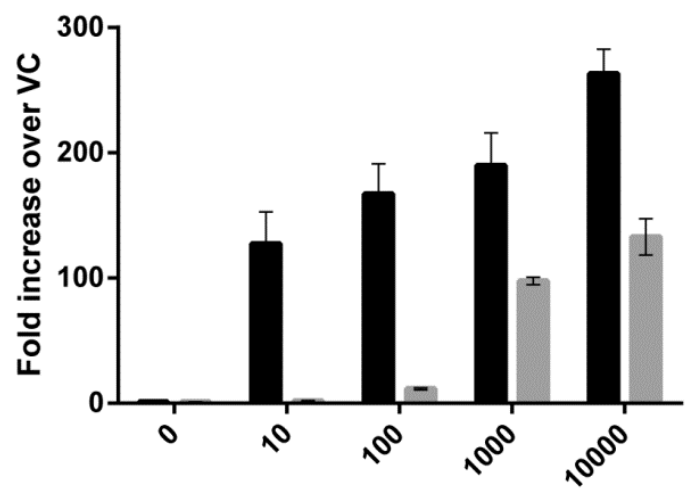

[Agonist] (ng/ml)
MPLA-induced Ifit1 mRNA

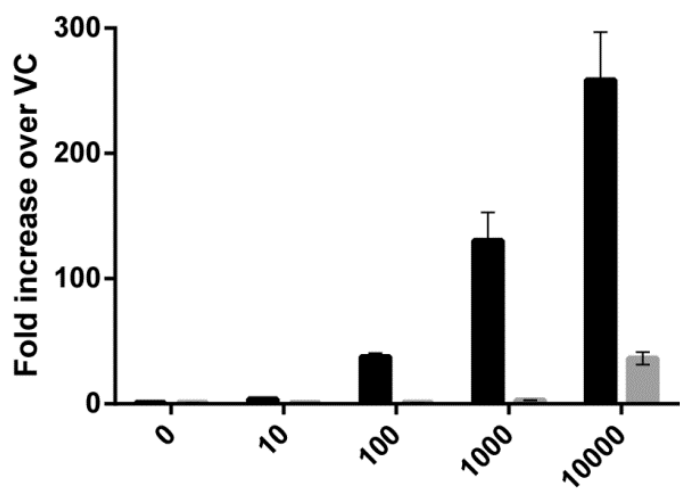

[Agonist] (ng/ml)

Fig. 7. MPLA and lipid A both require CD14 for optimal TRIF-dependent gene expression. WT and CD14KO BMDC were activated with the indicated concentrations of lipid A or MPLA in media containing 1 to 3\% serum from CD14KO mice. The fold increase in abundance of steady-state Ifit1 mRNA relative to vehicle treated cells was measured by qPCR after 2 hours activation. Data are the mean \pm SD of triplicate samples. An experiment representative of 3 independent experiments is shown. 
Lipid A-induced IL-6 protein

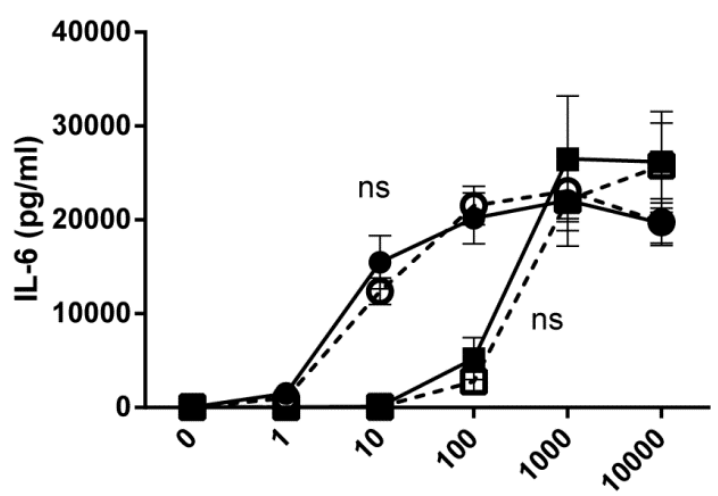

[Agonist] (ng/ml)

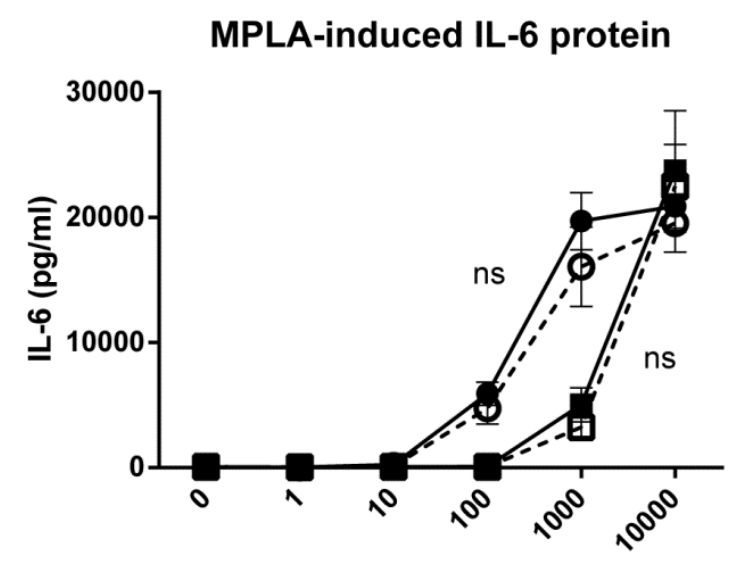

[Agonist] $(\mathrm{ng} / \mathrm{ml})$

$$
\begin{aligned}
& \text { ․ KO BMDC + KO serum } \\
& \text { - KO BMDC + WT serum } \\
& \text { O. WT BMDC + KO serum } \\
& \text { - WT BMDC + WT serum }
\end{aligned}
$$

Fig. 8. Serum collected from WT mice does not rescue IL-6 production in response to MPLA or lipid A. BMDC derived from WT and CD14KO mice were activated for 6 hours with the indicated concentrations of lipid A (left) or MPLA (right) in media containing 1 to 3\% serum collected from WT or CD14KO mice. IL-6 protein abundance in culture supernatants was measured by ELISA. Data are the mean \pm SEM of 3 independent experiments. Data were not significant by two-way ANOVA with Sidak’s multiple comparisons test; ns ( $\mathrm{P}>0.05)$. 

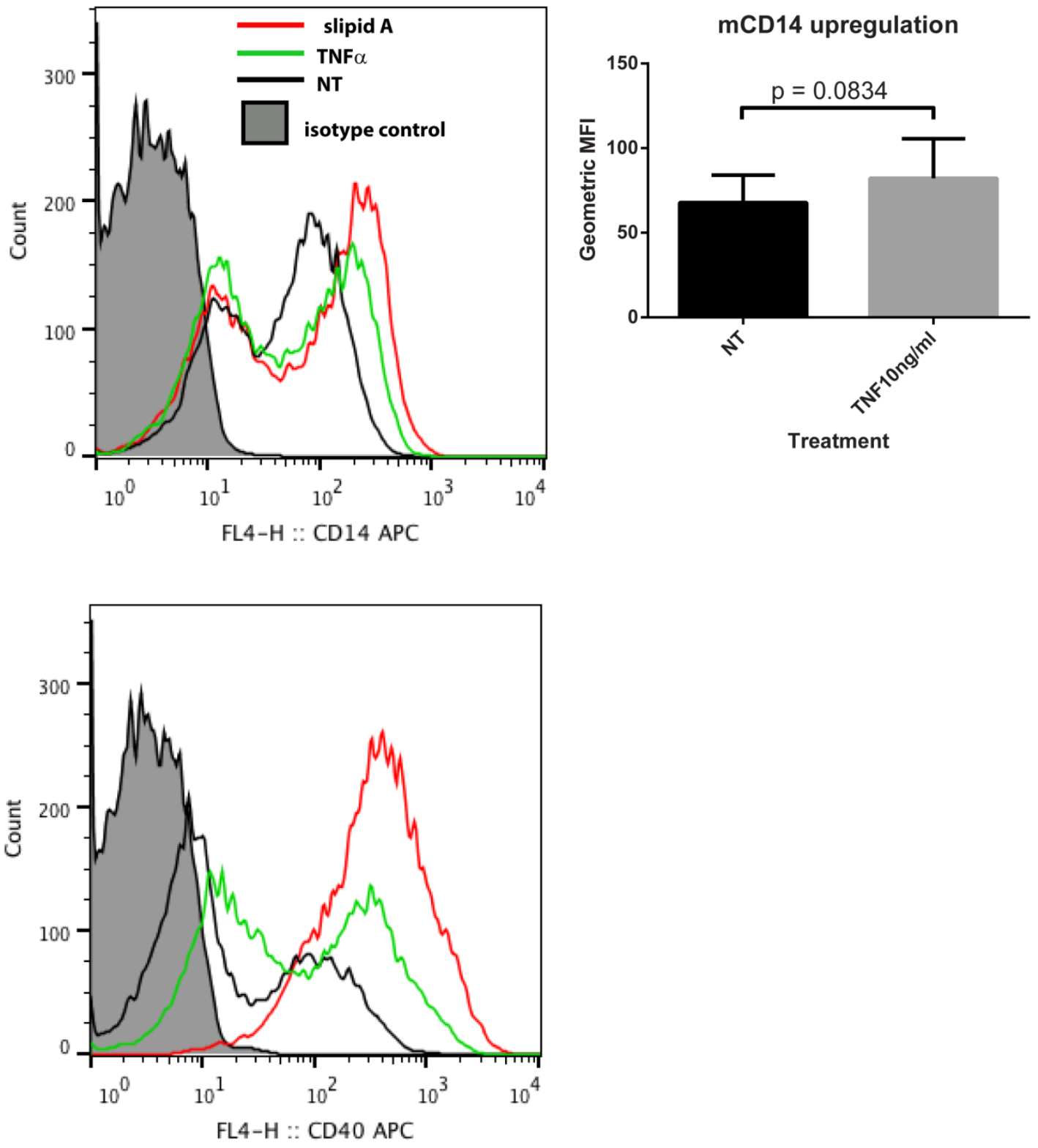

Fig. 9. Upregulation of mCD14 expression on BMDCs by TNF $\alpha$-induced

maturation. WT BMDC were treated with $10 \mathrm{ng} / \mathrm{ml} \mathrm{TNF} \alpha, 100 \mathrm{ng} / \mathrm{ml}$ slipid A, or vehicle control (NT) for 18 to 19 hours. BMDC were then stained with APC-conjugated anti-CD14, APC-conjugated anti-CD40, or the corresponding isotype controls. Data were collected on a FACScalibur and analyzed with Flowjo software. (Right) The geometric mean of surface $\mathrm{CD} 14$ was compared between untreated and TNF $\alpha$ treated 
cells. Data are the mean \pm SEM of 5 independent experiments. Statistics were determined using the paired two-tailed $\mathrm{T}$ test. 

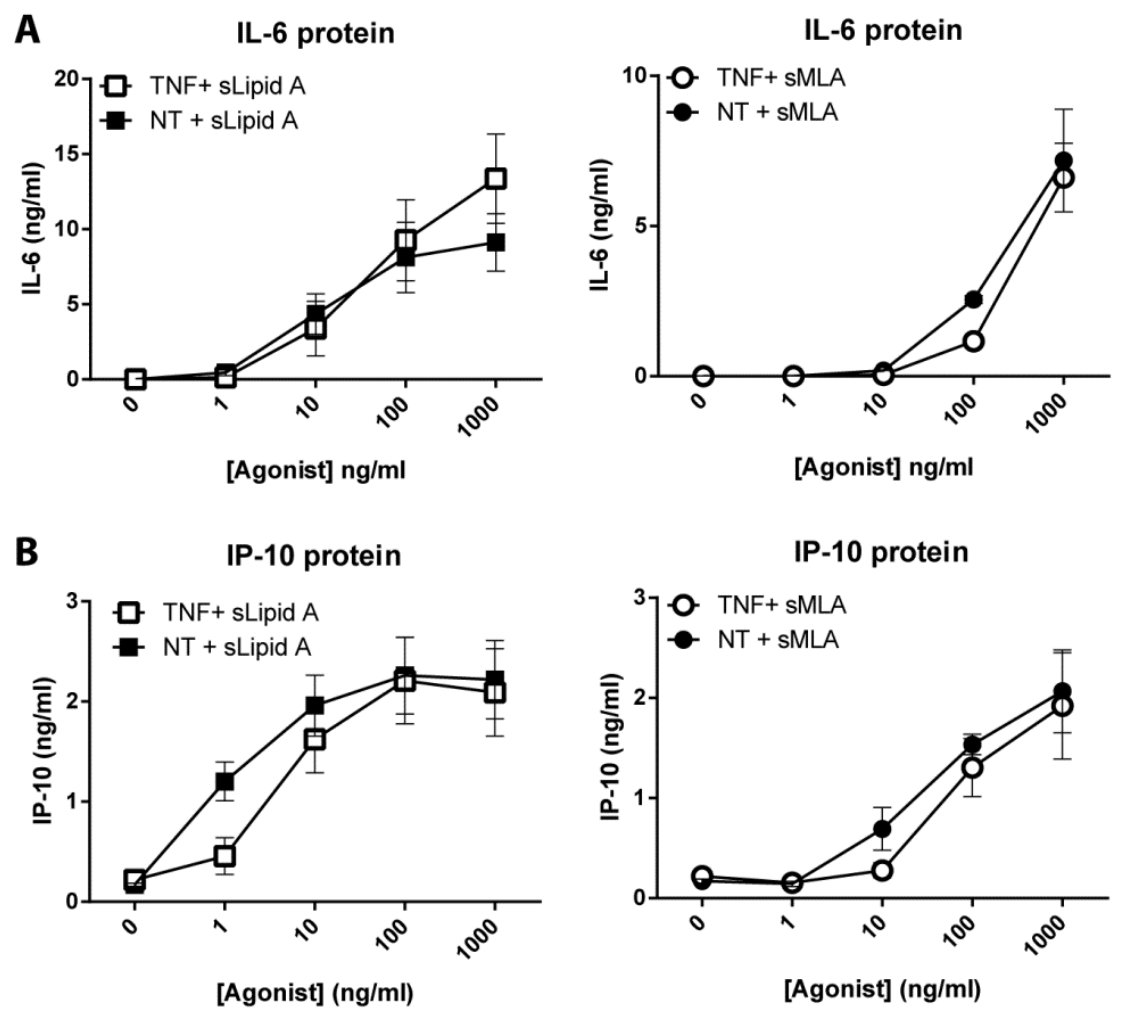

Fig. 10. Increased surface expression of mCD14 does not preferentially enhance TRIF-dependent protein production. WT BMDC were treated with $10 \mathrm{ng} / \mathrm{ml} \mathrm{TNF} \alpha$ or left untreated for 18 to 19 hours and then activated with the indicated concentrations of sLipid A or sMLA for an additional 18 hours. (A) IL-6 and (B) IP-10 protein abundance was measured in culture supernatants by ELISA. Data are the mean \pm SD of two independent experiments. 


\section{CHAPTER IV}

\section{AUTOCRINE AND PARACRINE SIGNALING BY TYPE I INTERFERONS CONTRIBUTES TO TOLL-LIKE RECEPTOR 4 TRIF-BIAS}

\section{INTRODUCTION}

In general, the TRIF signaling pathway is more associated with the initiation of adaptive immune responses than is the MyD88 signaling pathway, which is more commonly associated with proinflammatory outcomes. For example, TRIF-deficiency in mice substantially impairs the induction of antigen-specific T cell proliferation by APCs, whereas MyD88-deficiency has little effect on this process $(77,103)$. This impairment arises partly because IFN- $\beta$ production absolutely requires the activation of IRF3 through TRIF (52, 55). IFN- $\beta$ is essential for the adjuvant effects of several TLR agonists on T cell priming, including TLR4 (103), which may be due to the ability of IFN- $\beta$ to drive upregulation of costimulatory molecules and MHCII on APCs $(104,105)$. In one study, the TLR3 agonist polyI:C was the best of a panel of adjuvants, including LPS, at inducing antigen-specific Th1 CD4 responses because it induced the most robust type I IFN response (106). In addition, type I IFN promotes antigen cross-presentation (107) and T cell survival (108). TRIF signaling is also linked to adaptive immunity through TRIF-dependent chemokines, such as IP-10 (CXCL10), which promote the recruitment of T cells to DC for priming (109). 
Because TLR4 is the only TLR to signal through both MyD88 and TRIF, it is the only TLR with the potential for adapter modulation, the ability to signal more strongly through one adapter compared to the other. Given the distinct processes primarily controlled by each pathway, we and other groups have studied whether defined differences in agonist structure can cause MyD88- or TRIF-biased responses at the level of producing distinctive gene profiles (77-79, 110-112). As noted above, we previously proposed that the success of MPL adjuvant was related to its ability to function as a TRIF-biased agonist of TLR4, which is favorable for vaccination by limiting proinflammatory endpoints more than it limits those involved in T cell priming (77). Those studies were performed with a research grade version of MPL adjuvant (MPLA). In addition to MPLA, which is a mixture of monophosphorylated Salmonella minnesota lipid A species differing in numbers of acyl chains (Fig. 2), we also studied synthetic MPLA (sMLA), a single hexa-acyl species based on the E. coli lipid A structure (Fig. 3). We concluded that sMLA was also TRIF-biased in mouse cell systems $(78,79)$.

TLR4 adapter modulation is a controversial topic. Some have questioned its existence citing the use of heterogeneous compounds and insufficient doses as confounding factors that make it impossible to draw useful conclusions about structureactivity relationships (113). Here, we compared the potencies of sMLA and its diphosphorylated counterpart synthetic Lipid A (sLipid A) (Fig. 3) in inducing the expression of a panel of TRIF-dependent or MyD88-associated genes (all of which are MyD88- and TRIF-co-dependent) in mouse BMDCs. None of the analytes we have tested to date appear to be truly TRIF-independent (MyD88-sufficient) (45, 59, 60). We evaluated IP-10, IFIT-1, and CD86 as representative TRIF-dependent gene products, 
because TRIF alone is sufficient to induce the expression of the corresponding genes, whereas we evaluated IL-6, Cox-2, and CD80 as MyD88- and TRIF-co-dependent gene products, because optimal expression of the corresponding genes require both adaptor pathways. We found that TRIF-bias was not unique to sMLA as judged by pharmacological potency. Instead, expression of TRIF-dependent genes was induced with substantially less agonist than was required for the expression of MyD88- and TRIFco-dependent genes. Together, these data suggest that the TLR4 signaling network is itself biased toward TRIF-dependent events.

\section{RESULTS}

sMLA is not a TRIF-biased agonist as assessed by pharmacological measurements

To quantitatively evaluate sMLA as a TRIF-biased agonist, we activated BMDC with an extensive dilution series of sMLA or sLipid A and measured these agonists' potencies using a panel of TRIF-dependent and MyD88- and TRIF-co-dependent gene products by $\log (\mathrm{EC} 50)$ calculation, a pharmacological method. As expected, sLipid A was more potent than sMLA at inducing the expression of the MyD88- and TRIF-codependent genes Il6 and Cox2 (Fig. 11A). However, sLipid A was also more potent than sMLA at inducing expression of the TRIF-dependent genes Ip10 and Ifit1 (Fig. 11A). We compared the $\log (\mathrm{EC} 50)$ values of sLipid A and sMLA for each analyte to determine whether adapter bias was present despite obvious differences in agonist potency. We found that sLipid A was approximately 10 fold more potent than sMLA at inducing the expression of both co-dependent and TRIF-dependent genes, regardless of whether they were measured early (steady-state mRNA at 4 hours) or late (secreted protein at 18 hours) 
(Fig. 11, A and B). Therefore, sMLA was not functioning as a true TRIF-biased agonist compared to sLipid A because sMLA's deficiencies in potency were the same for indicators of both adapter pathways.

To determine whether our experimental system (cells and agonists) had changed since our initial experiments using sMLA, we directly compared agonist concentrations similar to those explored in our previous studies of TRIF-bias (78). We found that sMLA-stimulated BMDC induced lower amounts of MyD88- and TRIF-co-dependent IL-6 and equivalent amounts of TRIF-dependent IP-10 in culture supernatants compared to sLipidA (Fig. 11C), consistent with TRIF-biased signaling occurring over these doses. Therefore, these results were not fundamentally different from those in our previous studies.

The expression of TRIF-dependent genes is activated with less agonist than is required to activate the expression of MyD88- and TRIF-co-dependent genes

Although sMLA was a weak agonist for both co-dependent and TRIF-dependent genes, as measured by $\log (\mathrm{EC} 50)$ s, Figures $11 \mathrm{~A}$ and $11 \mathrm{C}$ demonstrated that there were distinct concentrations at which sMLA was equivalent to sLipid A in induction of TRIFdependent genes, but that sMLA was also weaker in induction of co-dependent genes. One explanation for this trend is that TRIF-dependent genes are more "easily” triggered than co-dependent genes; more agonist is required to stimulate TLR4-induced codependent events than is required for TRIF-dependent events. To test this hypothesis, we compared the $\log (\mathrm{EC} 50)$ values of sMLA or sLipid for the activation of TRIF-dependent and co-dependent signaling events, and expected the $\log (\mathrm{EC} 50)$ values for TRIF- 
dependent events to be lower than those for co-dependent events. As expected, the $\log (\mathrm{EC} 50)$ values of sMLA or sLipid A for TRIF-dependent IP-10 protein production was lower than their corresponding $\log (\mathrm{EC} 50)$ values for co-dependent IL-6 protein production (Fig. 12A). Similarly, the log(EC50) values of sLipid A and sMLA for TRIFdependent mRNA responses were lower than the $\log (\mathrm{EC} 50)$ values for co-dependent mRNA responses (Fig. 12A). These results suggest that in mouse BMDC, weak TLR4 agonists such as sMLA can appear to be TRIF-biased because expression of TRIFdependent genes is induced more effectively with less agonist than is the expression of co-dependent genes.

Both sMLA and sLipid A are hexa-acylated lipid A molecules, differing only in the presence or absence of the 1-phosphate of the diglucosamine head group and by 2 carbons on one of the secondary acyl chains (Fig. 3). Because the potential for a lipid A molecule to elicit the production of various cytokines is affected by both the number and length of its acyl chains $(114,115)$, it is possible that efficient activation of TRIFdependent signaling events at low doses of agonist may be unique to these hexa-acylated molecules. To determine whether the relative ease of activating TRIF-dependent events was common to agonists with markedly different structures, we stimulated BMDCs with tetra-acylated molecule lipid IVa and measured the $\log ($ EC50) values for TRIF-dependent IP-10 and co-dependent IL-6 production. Lipid IVa is an agonist of mouse TLR4, but an antagonist of human TLR4 $(116,117)$. Similar to sMLA, Lipid IVa was less potent than sLipid A in stimulating production of both IP-10 and IL-6 (Fig. 12B). As was seen with hexa-acylated sMLA and sLipid A, lipid IVa induced TRIF-dependent IP-10 production with a $\log ($ EC50) value that was significantly lower than its co-dependent IL-6 $\log (\mathrm{EC} 50)$ 
value (Fig. 12B). This result suggests that robust activation of TRIF-dependent events at low agonist doses may be intrinsic to TLR4 and less dependent on TLR4 agonist structure.

Cd86 mRNA expression is increased with less agonist than is required to increase Cd80 mRNA expression

Our characterization of TLR4 agonist potencies for TRIF and MyD88- and TRIFco-dependent event induction was initially focused on genes encoding proinflammatory cytokines and chemokines. In addition to the release of these mediators, DC function is inextricably linked to the upregulation of costimulatory molecules that promote adaptive immunity via T cell priming. We and others described previously the TLR4 adapter requirements for the upregulation of the costimulatory molecules CD80 and CD86 in mouse DC subsets in vivo, with CD86 upregulation appearing to be dependent on TRIF alone and CD80 upregulation dependent on both MyD88 and TRIF $(103,118)$. To confirm the specific adapter dependence of CD86 and CD80 in BMDCs, we generated BMDC from WT, TRIF ${ }^{\text {Lps2/Lps2 }}$ (which contain a non-functional mutation in the TRIF protein), or MyD88 ${ }^{--}$mice, treated them with sLipid A, and measured increases in Cd80 and Cd86 mRNA abundance by qPCR analysis. The ability of sLipid A to induce increases in Cd86 mRNA abundance was reduced in cells in which TRIF signaling was inhibited, whereas its ability to induce increases in Cd80 mRNA abundance was reduced by the absence of either TRIF or MyD88 signaling (Fig. 13A). These results confirm that in BMDCs the expression of Cd86 is TRIF-dependent, while the expression of Cd80 is MyD88- and TRIF-co-dependent. 
Because TLR4 signaling-induced increases in Cd86 mRNA abundance are strictly TRIF-dependent, whereas increases in Cd80 mRNA are MyD88- and TRIF-codependent, we hypothesized that sLipid A would have a higher potency for induction of Cd86 expression than for Cd80 expression. When BMDC were treated with increasing concentrations of sLipid A, the $\log (\mathrm{EC} 50)$ value for increased Cd86 mRNA abundance was significantly lower than that for Cd80 mRNA (Fig. 13B), suggesting that the TRIFdependent expression of Cd86 was more easily induced than was the co-dependent expression of $C d 80$. Therefore, the enhanced potency of TLR4 agonists for TRIFdependent gene expression may pertain to a variety of gene subsets with different roles in the immune response.

The low $\log (E C 50)$ values of sLipid A for the expression of TRIF-dependent genes are not explained by TRIF adaptor selectivity

One potential explanation for the low $\log (\mathrm{EC} 50)$ values of TLR4 agonsits for TRIF-dependent genes is that comparatively more TRIF adapter engagement than MyD88 engagement is triggered immediately downstream of TLR4 dimerization at limiting doses of agonist. To test this hypothesis, we measured the potency of sLipid A to activate IRF3 and IRAK1 (Fig. 14A), two signaling proteins that mediate the TRIF and MyD88 pathways, respectively $(36,48)$. The $\log ($ EC50) values for IRF3 activating phosphorylation and IRAK1 disappearance, which is due to an increase in molecular weight from Lys ${ }^{63}$ polyubiquitination upon signaling $(38,119)$, were not significantly different when measured in 4 independent experiments (Fig. 14B). In two paired experiments, the $\log (\mathrm{EC} 50)$ values for IRF3 phosphorylation were greater than those for 
IRAK1 disappearance (Fig. 14B). These data suggest that initial TRIF signaling is not induced more efficiently than initial MyD88 signaling at suboptimal TLR4 agonist concentrations; indeed, MyD88 signaling may be triggered more easily than TRIF signaling. Therefore, the low $\log (\mathrm{EC} 50)$ values of TLR4 agonists for the production of TRIF-dependent gene products cannot be explained by dose-dependent TRIF selectivity at the level of initial adapter engagement.

The $\log (E C 50)$ values of sLipid A for the activation of MAPKs and NF- $\kappa B$ are different

Because simple TLR4 TRIF adapter bias did not seem to explain the low $\log ($ EC50) values of TLR4 agonists for TRIF-dependent events, we explored signaling mediators that are activated through both the TRIF and MyD88 pathways. TLR4induced gene expression is controlled by NF-kB and transcription factors activated by MAPK signaling cascades, and considerable crosstalk exists between the MyD88 and TRIF signaling pathways in their activation. For example, TRIF signaling enhances NF$\kappa \mathrm{B}$ activity, a canonical MyD88-dependent event, through a Rip1-mediated pathway (57). In addition, signaling through both TRIF and MyD88 contribute to MAPK activation (44, 46). TLR4-induced genes have varying MAPK and NF- $\mathrm{BB}$ requirements for optimal expression, but the strength of TLR4 signal needed to efficiently activate these mediators is unknown. We determined the $\log (\mathrm{EC} 50)$ values for the activation of p38, c-Jun Nterminal kinase (JNK), extracellular signal-regulated kinase 1/2 (ERK1/2), and IאB $\alpha$ by treating BMDC with a series of doses of sLipid A and quantifying relative protein abundance by Western blotting (Fig. 15A). Significantly less sLipid A was needed to induce half-maximal I $\kappa \mathrm{B} \alpha$ degradation, as an indicator of NF- $\kappa \mathrm{B}$ activation, and $\mathrm{p} 38$ 
activating phosphorylation [low log(EC50) values] compared to JNK and ERK1/2 activating phosphorylation [high $\log ($ EC50) values] (Fig. 15B). We were not surprised that NF- $\mathrm{KB}$ activation required very little agonist given its prominence as a readily triggered component of proinflammatory gene regulation, but the low potency with which the MAPKs JNK and ERK1/2 were activated was striking. Thus, although MAPKs are influenced by both TRIF and MyD88 pathways, there are considerable differences in the ease with which they are activated.

The high $\log (E C 50)$ values of sLipid A for MyD88- and TRIF-co-dependent events correlate with a dependence on JNK

We and others published previously that MAPKs differ in their involvement in transcription factor activation and gene expression downstream of TLR4 (78, 120-124). Although substantial overlap and redundancy in MAPK requirements for gene expression exist, specific TLR4-induced genes may have a greater requirement for certain MAPKs. It is unclear whether specific MAPKs preferentially control the expression of TRIFdependent versus co-dependent genes. We hypothesized that the high $\log ($ EC50) values of agonists for the expression of co-dependent genes may be, in part, a result of their strong dependence on JNK, which is also associated with high $\log (\mathrm{EC} 50)$ values. Conversely, the low $\log (\mathrm{EC} 50)$ values of agonists for TRIF-dependent genes may be because their expression depends on p38 activity, which is characterized by a low $\log ($ EC50) value.

To test this hypothesis, BMDC were pretreated with specific chemical inhibitors of JNK and p38 before measuring the effects of a range of concentrations of sLipid A on 
TRIF- and co-dependent gene expression. The efficacy (maximum amount) of MyD88dependent IL-6 protein production was reduced by JNK inhibition but not by p38 inhibition (Fig. 16A), but neither inhibitor significantly changed the potency of sLipid A in stimulating IL-6 production (Fig. 16B). The efficacy of the TRIF-dependent production of IP-10 protein was unchanged by JNK and p38 inhibitors (Fig. 16A). Both inhibitors slightly reduced IP-10 production at doses of sLipid A below $1 \mathrm{nM}$ (Fig. 16A). The JNK inhibitor caused a statistically significant increase in the $\log (\mathrm{EC} 50)$ value of sLipid A for IP-10 production, whereas the p38 inhibitor caused an increase in the $\log$ (EC50) for IP-10 that approached statistical significance (Fig. 16B). Neither inhibitor increased the $\log (\mathrm{EC} 50)$ for IP-10 to match that for IL-6 production. These data suggest that a varying dependence on specific MAPKs is unlikely to be the cause of the differences in $\log (\mathrm{EC} 50)$ values between co-dependent and TRIF-dependent events.

Because the efficacy of sLipid A for the production of co-dependent IL-6, but not TRIF-dependent IP-10, was decreased by JNK inhibition, we explored the role of JNK signaling in expression of other TRIF-dependent or co-dependent genes. JNK inhibition reduced the sLipid A-stimulated increases in MyD88-dependent Il6 and Cd80 mRNA at 4 hours, but had no effect on TRIF-dependent Ip10 mRNA abundance (Fig. 16C). JNK inhibition did significantly reduce the TRIF-dependent increase in Cd86 mRNA abundance at 4 hours, but less effectively than it inhibited increased Cd80 mRNA abundance (Fig. 16C). Unexpectedly, inhibition of p38 had no significant effect on the expression of any genes (Fig. 16C), despite confirmation that SB202190 had been effectively delivered (Fig. 17). Therefore, the expression of MyD88- and TRIF-co- 
dependent genes, such as Il6 and Cd80, correlates with a dependence on the JNK signaling pathway for full induction.

The high $\log (E C 50)$ value of sLipid A for Ifnb mRNA expression correlates with a dependence on JNK

IFN- $\beta$ production in response to TLR4 stimulation absolutely requires TRIF signaling and is downstream of the activation of IRF3 $(48,55,125)$. In addition, optimal IFN- $\beta$ production requires intact MyD88 signaling (118), because the activity of the Ifnb promoter requires the activation of MyD88-associated transcription factors such as AP-1, which is activated downstream of JNK and NF-kB $(126,127)$. Because JNK-dependence was correlated with co-dependent genes characterized by logEC50s, we wondered whether the $\log (\mathrm{EC} 50)$ value for the induction of Ifnb expression was also high. We measured Ifnb mRNA abundance in BMDCs activated with a dose series of sLipid A and calculated the $\log (\mathrm{EC} 50)$ values at 1 hour, the time at which Ifnb mRNA was maximally expressed. The $\log ($ EC50) value of sLipid A for Ifnb expression was substantially higher than that for TRIF-dependent Ip10 and was as high as that for co-dependent Il6 (Fig. 18A). To confirm that sLipid A-induced Ifnb expression was JNK-dependent, we pretreated BMDCs with JNK inhibitor and measured Ifnb mRNA abundance over time. As expected from previous reports $(128,129)$, Ifnb mRNA expression was markedly decreased in the absence of JNK signaling (Fig. 18B). In contrast, p38 inhibition had relatively little influence on Ifnb expression, only slightly decreasing it at 1 hour (Fig. 18B). These data demonstrate that the TLR4-dependent expression of Ifnb is characterized by a high $\log (\mathrm{EC} 50)$, consistent with it being a co-dependent event. 
Autocrine and paracrine signaling by type I interferon determines the low log(EC50) values of sLipid A for TRIF-dependent responses

Although we observed a correlation between JNK-dependence and MyD88- and TRIF-co-dependence, differential MAPK-dependence could not completely explain either the high $\log (\mathrm{EC} 50)$ values of TLR4 agonists for the expression of co-dependent genes or the low $\log$ (EC50) values for the expression of TRIF-dependent genes (Fig. 16). Alternatively, the lower $\log (\mathrm{EC} 50)$ values of agonists for TRIF-dependent events could be caused by crosstalk or synergy between TLR4 and other receptors. In addition to inputs directly from TLR4, signaling through the IFN- $\alpha / \beta$ receptor (IFNAR) by secreted type I IFN enhances the expression of TRIF-dependent genes through the activation of the IFN-stimulated gene factor 3 (ISGF3) complex, which binds to and activates interferon stimulated response elements (ISREs) in gene promoters $(130,131)$.

We found that sLipid A induced robust Ifnb expression in BMDCs (Fig. 18). Therefore, we hypothesized that the relatively low $\log (\mathrm{EC} 50)$ values of sLipid A for TRIF-dependent gene expression were caused by enhancement of TRIF-dependent responses through secondary IFNAR signaling. To determine the extent to which IFN- $\beta$ alone could induce expression of TLR4-regulated genes, we exposed BMDCs to recombinant IFN- $\beta$ or sLipid A and measured increases in steady-state TRIF-dependent Ip10 and Cd86 mRNA abundance, and compared them to changes in co-dependent Il6 and Cd80 mRNA abundance. As expected, the abundances of TRIF-dependent Cd86 and Ip10 mRNAs were increased by IFN- $\beta$ treatment (Fig 19A). In fact, the increases in steady-state mRNA abundance by IFN- $\beta$ were comparable to those with sLipid A 
stimulation, indicating that IFN- $\beta$ is sufficient to induce the expression of $C d 86$ and Ip10 (Fig. 19A). In contrast, IFN- $\beta$ stimulation caused no measurable increases in Cd80 mRNA abundance and relatively small increases in Il6 mRNA abundance when compared to sLipid A stimulation (Fig. 19B). Although both Cd80 and Il6 are type I IFN-responsive genes in certain contexts (130, 132-134), IFN- $\beta$ was insufficient to induce their expression in BMDCs.

To determine whether autocrine and paracrine signaling by IFN- $\beta$ was responsible for the low $\log (\mathrm{EC} 50)$ values of sLipid A for the expression of Ip10 and Cd86, we blocked IFNAR signaling by pre-treating BMDCs with the IFNAR1 antagonistic antibody MAR1-5A3, or isotype control, and measured the $\log ($ EC50) values of sLipid A. We demonstrated that MAR1-5A3 was effective at blocking STAT1 phosphorylation downstream of IFNAR in response to sLipid A-induced type I IFN production at a concentration of $10 \mathrm{ug} / \mathrm{ml}$ (Fig. 20). The efficacy, or maximal responses, of both TRIFdependent Ip10 and co-dependent Il6 mRNA expression were decreased in MAR1-5A3 treated cells (Fig. 21A), consistent with both of these genes being type I IFN-inducible (Fig. 19A and B). Despite dampening of global Il6 and Ip10 expression, the $\log (\mathrm{EC} 50)$ value of sLipid A for Ip10 was significantly increased, whereas the $\log (\mathrm{EC} 50)$ value for Il6 was unchanged (Fig. 21A). Similarly, increases in Cd80 and Cd86 mRNA abundance were dampened by the addition of MAR1-5A3, but only the $\log (\mathrm{EC} 50)$ value of sLipid A for TRIF-dependent Cd86 was significantly increased (Fig. 21B). Furthermore, the $\log ($ EC50) values of sLipid A for both TRIF-dependent Ip10 and Cd86 mRNA expression were increased to values similar to those for co-dependent Il6 and Cd80 mRNA, suggesting that secondary signaling by IFN $\beta$ through IFNAR enhances the 
potency of TLR4 agonists like sLipid A for TRIF-dependent gene expression (Fig. 21A and B). We also tested whether secondary type I IFN signaling was responsible for the low $\log ($ EC50) values of sLipid A for TRIF-dependent protein production downstream of mRNA. MAR1-5A3 treatment increased the $\log ($ EC50) values for IP-10 production, but not for IL-6 production, when compared to those in stimulated control cells (Fig. 21C). Together, these results show that autocrine and paracrine signaling via IFNAR is a determinant of the low $\log$ (EC50) values of sLipid A for TRIF-dependent gene expression.

\section{DISCUSSION}

We and others have proposed that TLR4 adapter modulation is a function of an agonist's structural characteristics. Zughaier et al. (111) reported that LPSs from E. coli and Vibrio cholerae were MyD88-biased while LPSs from Salmonella species were TRIF-biased over a range of doses when compared to a Neisseria meningitidis lipooligosaccharide reference. We later proposed that MPLA functions as a TRIF-biased agonist of mouse TLR4, relative to the LPS from which it is derived, in an effort to understand how MPLA maintains immunostimulatory activity in spite of losing approximately $99.9 \%$ of its inflammatory activity (77). Bowen et al. (110) also reported TRIF-bias in demonstrating that the lipid A mimetic CRX-547 was significantly less efficacious than a stereoisomeric compound, CRX-527, in eliciting NF- $\mathrm{kB}$ activation and MyD88- and TRIF-co-dependent TNF $\alpha$ production, but was comparable in inducing TRIF-dependent IP-10 and RANTES. 
Despite this evidence for TLR4 TRIF-bias, other data called its existence into question. Earlier dose response experiments with mouse peritoneal macrophages demonstrated that MPL adjuvant was much less potent than LPS in activating both TRIFdependent IP-10 and co-dependent TNF- $\alpha$ and IL-1 $\beta$ (73). More recently, Gaekwad et al. (113) tested preparations of a variety of lipid A structures proposed to modulate TLR adapter signaling. Using mouse macrophage cell lines, they found no evidence for adapter modulation; instead cytokine and transcript potency data conformed to an additive model in which changes in agonist structure affect the potency for all genes equally regardless of their adapter association. In addition, TLR4 mutagenesis studies were inconsistent with a clear structural basis for TRIF-biased signaling by monophosphorylated agonists (135).

Our results support the conclusion that sMLA is not a TRIF-biased agonist of TLR4 relative to sLipid A because sMLA was approximately 10\% as potent as sLipid A for both the TRIF- and MyD88- and TRIF-co-dependent genes we tested (Fig. 11). However, by comparing $\log (\mathrm{EC} 50)$ values, we found that TRIF-dependent genes are activated with significantly less TLR4 agonist than are MyD88- and TRIF-co-dependent genes (Fig. 12 and Fig. 13). This characteristic seemed to be independent of TLR4 agonist structure and potency because sMLA and Lipid IVa, two weaker agonists that differ in phosphorylation status and acyl chain number, also induced TRIF-dependent genes more effectively. As we have only tested three different agonists, we have not definitively ruled out the possibility that other agonists may be incapable of this process. We demonstrated that the $\log (\mathrm{EC} 50)$ value of sLipid A for the increase in abundance of mRNA of the TRIF-dependent T cell costimulatory molecule Cd86 was 
also low compared to the $\log (\mathrm{EC} 50)$ s for co-dependent genes such as Il6, Cox2 (Fig. 12), and $C d 80$ (Fig. 13), supporting the idea that enhancement of $\mathrm{T}$ cell priming can proceed without high amounts of MyD88-associated proinflammatory cytokine production, as was seen in our first in vivo adjuvant tests with MPLA (77). Because all TRIF-dependent outcomes were characterized by low log(EC50) values compared to MyD88- and TRIFco-dependent outcomes, we propose that TLR4 itself, not sMLA, can be considered to be TRIF-biased.

We were able to discard several possible mechanisms for TLR4 TRIF-bias. TRIF adaptor engagement was not likely induced at lower doses of TLR4 agonist than was MyD88 adaptor engagement because the $\log (\mathrm{EC} 50)$ values of sLipid A for TRIFdependent activating phosphorylation of IRF3 and for MyD88-dependent polyubiquitination of IRAK1 were not significantly different (Fig. 14). In fact, two paired experiments seemed to indicate that TRIF signaling was initially more difficult to induce, which is not surprising given that MyD88 signaling occurs at the plasma membrane whereas TRIF signaling requires comparatively more complex CD14dependent endocytosis of TLR4 (47). In addition, differential requirements for JNK are unlikely to explain TRIF-biased signaling because inhibition of JNK had little effect on the $\log (\mathrm{EC} 50)$ values of sLipid A in its stimulation of the expression of either TRIFdependent or co-dependent genes (Fig. 16).

Many TRIF-dependent genes are also type I IFN-inducible and their activation in response to TLR4 stimulation decreases dramatically in the absence of IFN- $\beta$ within a 3 hour timeframe (130) indicating that autocrine and paracrine signaling by type I IFN may be involved in TLR4 TRIF-bias. When we blocked type I IFN signaling, we found that 
the $\log (\mathrm{EC} 50)$ values for the expression of TRIF-dependent genes increased to values similar to those of co-dependent genes, suggesting that the TRIF-biased nature of TLR4 depends on IFNAR (Fig. 21). In contrast, blocking IFNAR did not change the $\log ($ EC50) values for the MyD88- and TRIF-co-dependent production of IL-6 and increase in Cd80 mRNA abundance; however, IFNAR inhibition led to a decrease in their maximum abundance, suggesting that IFNAR signaling enhances the expression of their respective genes. TRIF-dependent, IFN- $\beta$-sufficient genes appear to be characterized by low $\log (\mathrm{EC} 50)$ values because they are regulated primarily by transcription factors that are activated by autocrine and paracrine IFNAR signaling stimulated by type I IFN released in response to TLR4 activation (130).

Though many consider IFN- $\beta$ to be the canonical TRIF-dependent gene, it may be characterized more accurately as MyD88- and TRIF-co-dependent because its production is reduced in the absence of MyD88 signaling (118). Like other co-dependent genes, the $\log (\mathrm{EC} 50)$ values of sLipid A for Ifnb mRNA expression is high compared to those of TRIF-dependent genes. Moreover, its expression is JNK-dependent, in line with codependent genes (Fig. 18). Compared to other genes which absolutely require TRIF signaling to be expressed, the promoter complexity of Ifnb is high, requiring inputs from AP1, NF-kB, and IRF3 $(126,127)$. In contrast, the promoter of TRIF-dependent IFIT-1 has been shown to only contain ISREs (136). Therefore, differences in promoter complexity likely contribute to the relatively high $\log (\mathrm{EC} 50)$ of agonists for Ifnb expression.

It is unclear how TRIF-dependent responses characterized by low log(EC50) values could be caused by IFN- $\beta$, a gene product characterized by high $\log (\mathrm{EC} 50)$ values. 
One possibility is that IFN- $\beta$ is a potent inducer of the expression of TRIF-dependent genes. Additionally, locally high concentrations of secreted IFN- $\beta$ may be present around the responding cell, which may enhance the effective potency of this cytokine. We have also not ruled out contributions from IFN- $\alpha$, which may be produced in response to TLR4 stimulation in certain contexts (137). From a teleological perspective, the high $\log (\mathrm{EC} 50)$ value for IFN- $\beta$ production may be beneficial to the host during infection, because type I IFNs can contribute to endotoxic shock and the production of proinflammatory IL-1 $\beta$ through the activation of caspase-11 $(138,139)$. These observations suggest that IFN- $\beta$ may have biphasic functionality, supporting adaptive immune priming at low concentrations and becoming more proinflammatory at high concentrations.

In conclusion, our results provide a new understanding of TLR4 TRIF-bias. In our culture system, monophosphorylation of lipid A did not cause TRIF-bias; rather, TLR4 itself signaled in a TRIF-biased manner in which TRIF-dependent, IFN- $\beta$ sufficient genes associated with $\mathrm{T}$ cell priming were induced with less agonist than codependent genes associated with proinflammatory outcomes. The extent to which TRIFbias can occur will likely depend upon a cell type's ability to respond to type I IFN within the system and to the characteristics of type I IFN-inducible gene regulation within that cell. These results are relevant to ongoing translational efforts because sMLA is the active component of GLA (glucopyranosyl lipid adjuvant) formulations that are being tested clinically (140). Future studies are needed to determine whether cell types other than mouse BMDC, including human cells, are capable of agonist-independent TRIF-bias. We have also not ruled out the ability of other species or cell types to 
undergo true TRIF-biased agonism based on agonist structural features, which may depend upon unique engagement of TLR4:MD-2. 
A
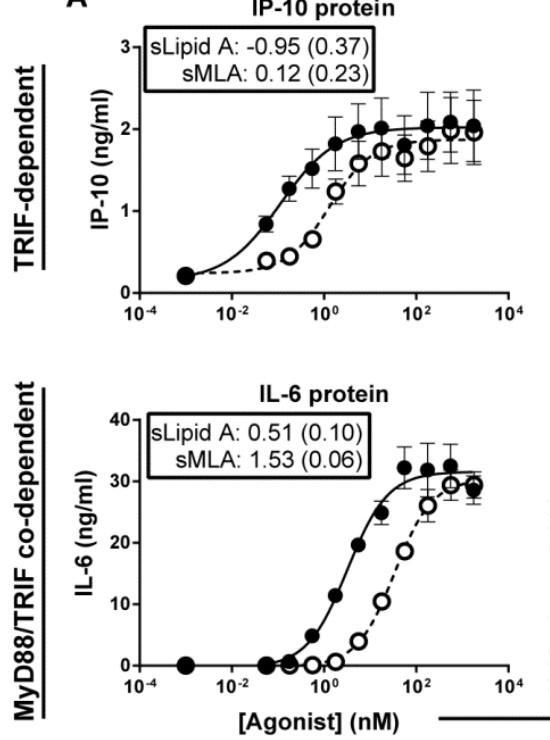

B

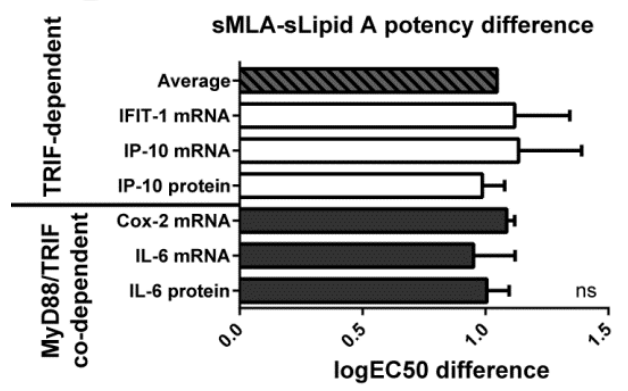

sLipid A O sMLA

Ip10 mRNA
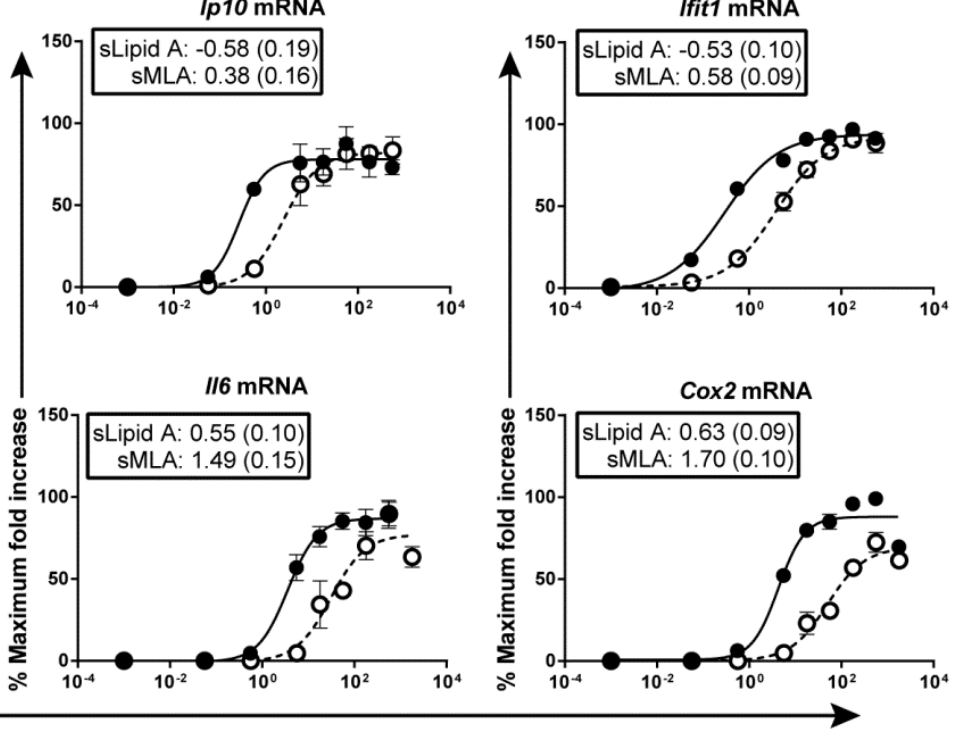

C

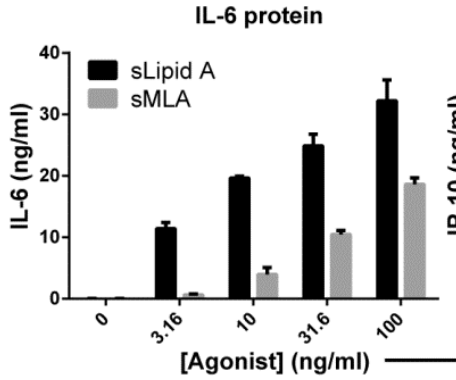

IP-10 protein

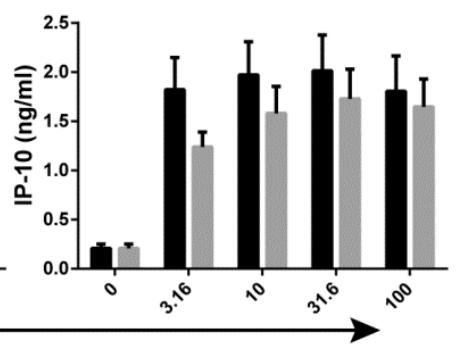

Fig. 11. sMLA is not a TRIF-biased TLR4 agonist. (A) BMDCs from C57BL/6 mice were treated with the indicated concentrations of sMLA or sLipid A. After 4 hours, increases in the steady-state abundances of the indicated mRNAs in agonist-treated cells compared to those in vehicle-treated cells were determined by qPCR analysis. After 18 hours, the amounts of the indicated proteins that were secreted into the culture media were determined by ELISA. Fold increases in mRNA abundance were converted to percentages of the maximal response measured in each experiment. Data are means \pm SEM of three independent experiments. Insets show $\log \left(\mathrm{EC}_{50}\right)$ values (with SE values in parentheses) derived from the goodness of the fit of the nonlinear regression calculation. (B) The sLipid A logEC50 values were subtracted from the sMLA logEC50 values for 
each analyte measured in (A) within each independent experiment, and then graphed. The logEC50 difference represents the potency difference between sMLA and sLipid A. Solid grey bars represent MyD88- and TRIF-co-dependent gene products and white bars represent TRIF-dependent gene products. The striped bar represents the average logEC50 difference between sMLA and sLipid A calculated for all analytes within each independent experiment. Data are mean $\log (\mathrm{EC} 50)$ differences \pm SEM from three independent experiments. Differences between the means were not statistically significant when analyzed by one-way ANOVA $(P>0.05)$. (C) The amounts of IL-6 and IP-10 proteins secreted by BMDCs in response to the indicated concentrations of sLipid A and sMLA from the experiments shown in (A) are plotted to show the appearance of TRIF-bias at low concentrations. 
A
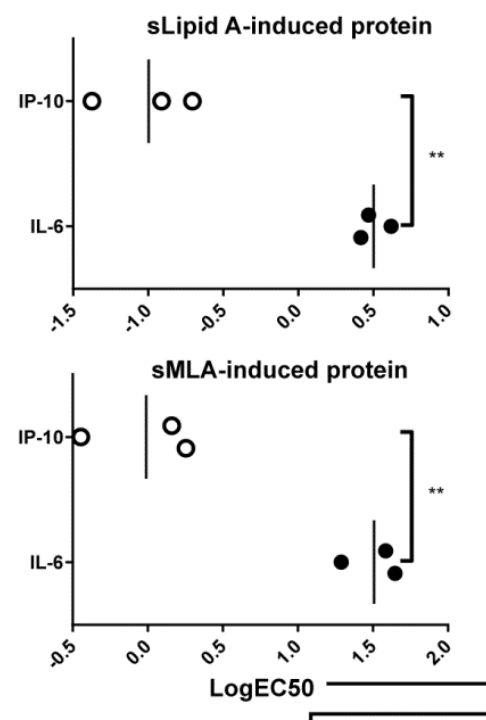

- Co-dependent
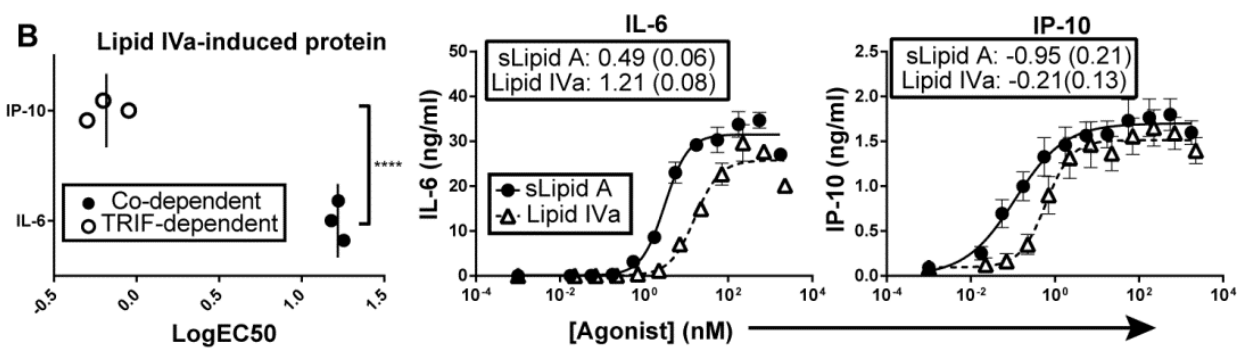

Fig. 12. The expression of TRIF-dependent genes is activated with lower concentrations of TLR4 agonists than are required for the expression of MyD88and TRIF-co-dependent genes. (A) Log(EC50) values of the sLipid A- and sMLAstimulated changes in the abundances of the indicated proteins and mRNAs from the experiments shown in Fig. 1A. Individual $\log (\mathrm{EC} 50)$ values and mean values from three independent experiments (vertical bars) are shown. (B) BMDCs from C57BL/6 mice were activated with half-log dilutions of Lipid IVa or sLipid A for 18 hours, after which IP-10 and IL-6 concentrations in culture media were measured by ELISA. Left: Individual $\log (\mathrm{EC} 50)$ values from three independent experiments were compared. Nonlinear regression analysis of the means \pm SEM of those experiments is shown for IL6 (middle) and IP-10 (right). Insets show $\log ($ EC50) values with SE values given in 
parentheses. Statistical differences were analyzed for the data in (A) and (B) by an unpaired, two-tailed t test or by one-way ANOVA with Tukey's post-test. ${ }^{*} P<0.05$; ${ }^{* *} P$ $<0.01 ; * * * * P<0.0001$; NS, not significantly different $(P>0.05)$. 
A
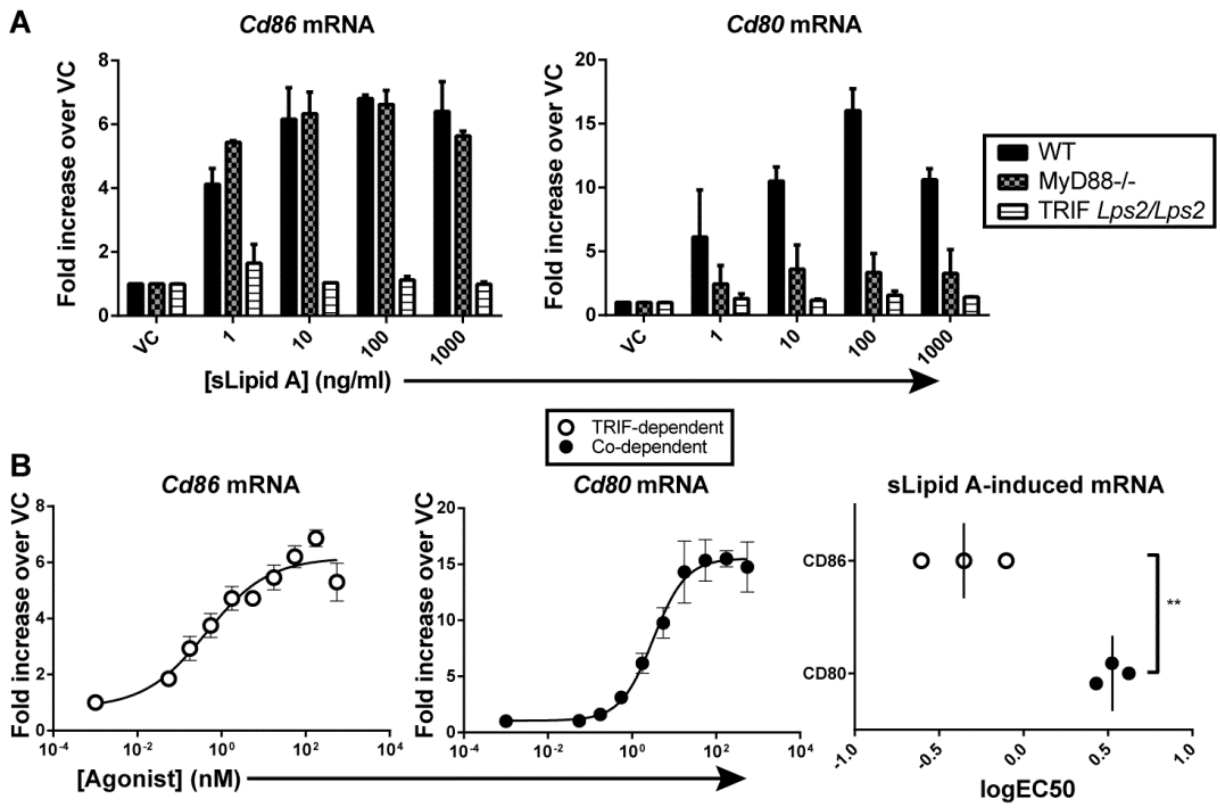

Fig. 13. The TRIF-dependent expression of Cd86 is activated with lower TLR4 agonist concentrations than are required for the MyD88- and TRIF-co-dependent expression of Cd80. (A) BMDCs from wild-type (WT), MyD88 ${ }^{-/}$, or $T R I F^{L p s 2 / L p s 2}$ mice were treated with vehicle control (VC) or were stimulated with the indicated concentrations of sLipid A for 4 hours. The steady-state abundances of Cd80 and Cd86 mRNAs were then analyzed by qPCR. Data are the mean fold-increases in mRNA abundance in sLipid A-stimulated cells compared to those in vehicle-treated cells and are combined from two independent experiments. (B) $\log (\mathrm{EC} 50)$ values were determined for the sLipid A-stimulated increases in the abundances of Cd80 and Cd86 mRNAs after 4 hours by nonlinear regression analysis. Data are means \pm SEM from three independent experiments. Right: Log(EC50) values from individual experiments. Statistical differences were determined with an unpaired, two-tailed t test. ${ }^{* *} P<0.01$. 
A
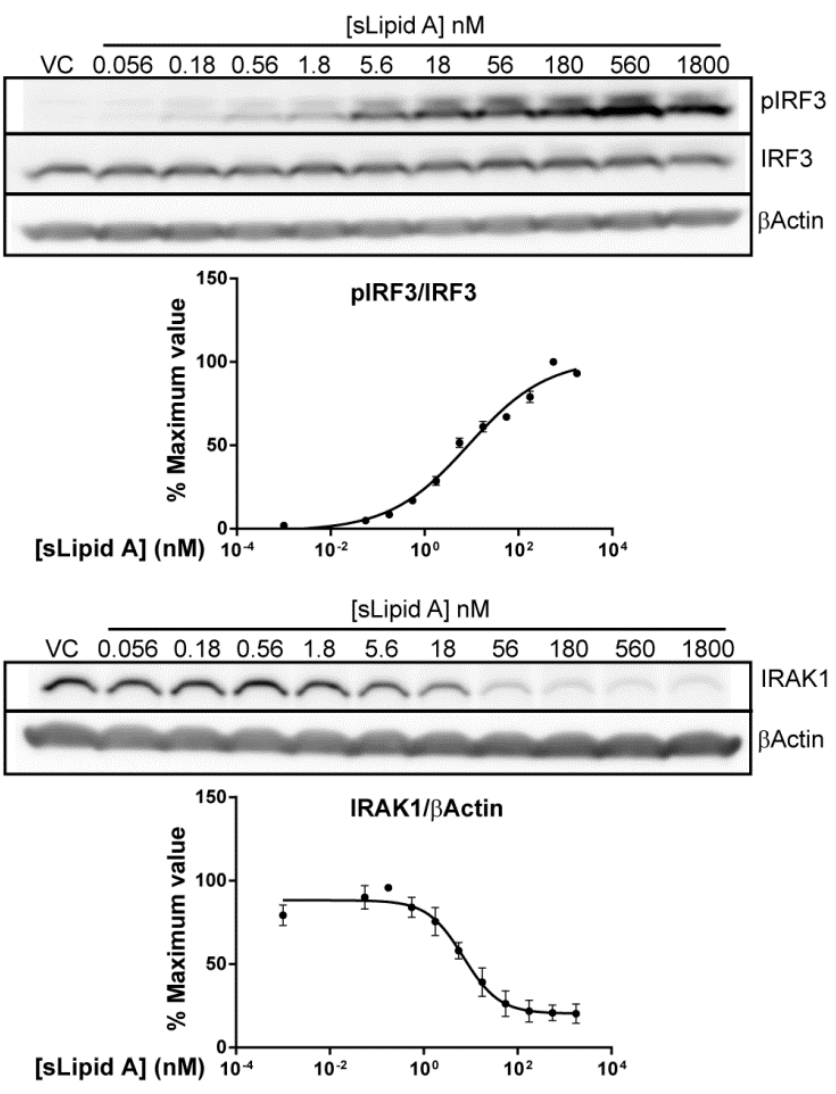

B

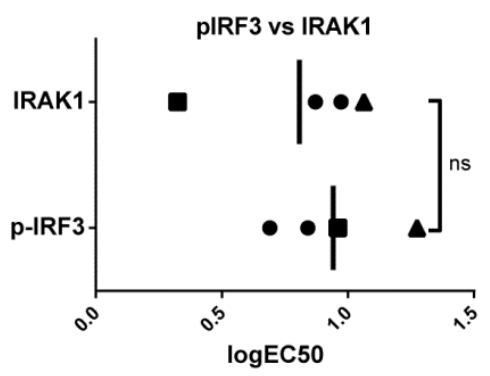

Fig. 14. Low $\log ($ EC50) values for TRIF-dependent genes are not explained by

biased adaptor use. (A) BMDCs from WT mice were treated with vehicle (VC) or were stimulated with a half-log dilution series of sLipid A for 1 hour. Samples were then analyzed by Western blotting with antibodies specific for the indicated proteins. The abundances of IRAK1 and pIRF3 (Ser ${ }^{396}$ ) were quantified by densitometric analysis and normalized to those of $\beta$-actin and total IRF3, respectively. Representative blots are shown. Normalized values from densitometric analysis were converted to percentage maximal responses for each experiment. Data in graphs are means \pm SEM from four 
independent experiments. (B) Individual $\log (\mathrm{EC} 50)$ values (squares and triangles indicate matched experiments) and means from the experiments shown in (A) were plotted and compared by an unpaired, two-tailed t test. NS, not statistically different $(P>0.05)$. 
A
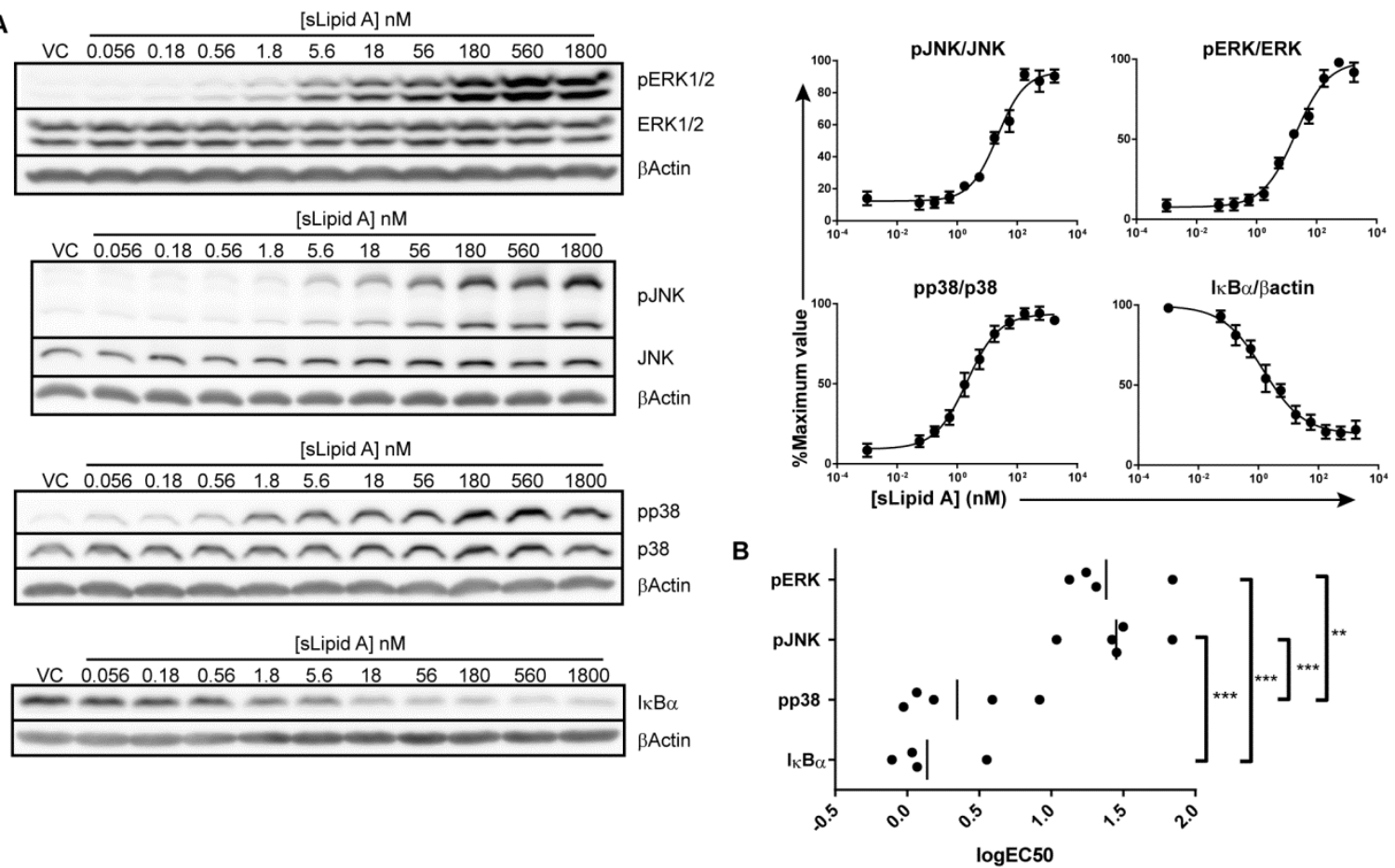

Fig. 15. The logEC50s of sLipid A for MAPKs and NF-кB are distinct. (A) BMDCs

from WT mice were treated with vehicle as a control (VC) or were stimulated with a halflog dilution series of sLipid A for 15 min. Samples were then subjected to Western blotting analysis to determine the relative extents of phosphorylation of JNK (Thr $\left.{ }^{183} / \mathrm{Tyr}^{185}\right)$, p38 (Thr $\left.{ }^{180} / \mathrm{Tyr}^{182}\right)$, and ERK1/2 $\left(\mathrm{Thr}^{202} / \mathrm{Tyr}^{204}\right)$, as well as of the

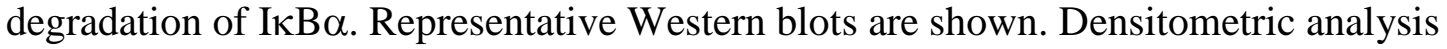
was performed to determine the relative abundances of the indicated phosphorylated proteins normalized to the abundances of their respective total proteins, whereas $\mathrm{I} \kappa \mathrm{B} \alpha$ abundance was normalized to that of $\beta$-actin. Normalized values were converted to percentage maximal responses for each experiment. Data are means \pm SEM from the nonlinear regression analysis of at least four independent experiments. (B) Log(EC50) values from the independent experiments shown in (A). Statistical differences were analyzed by one-way ANOVA with Tukey’s post-test. ${ }^{* *} P<0.01 ;{ }^{* * *} P<0.001$. 

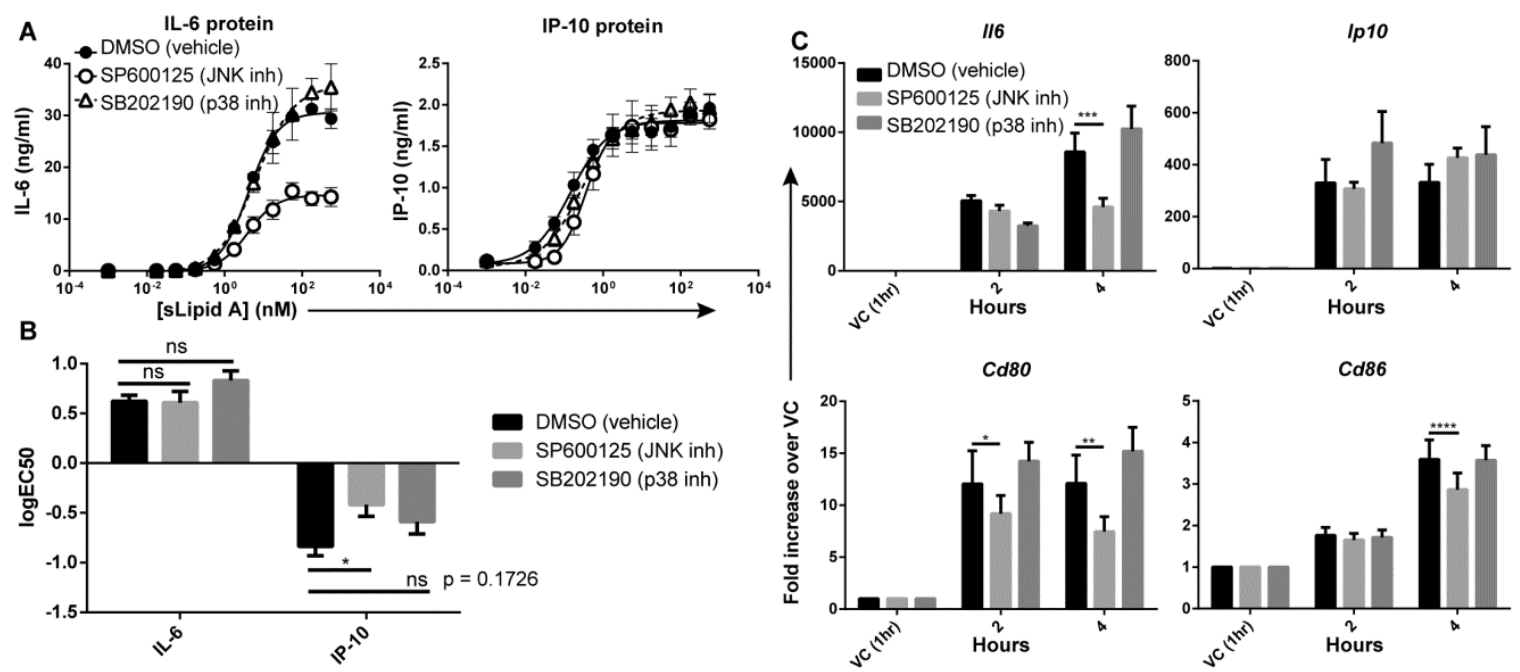

Fig. 16. MyD88- and TRIF-co-dependent genes with high $\log (\mathrm{EC50})$ values have a greater dependence on JNK for their expression than do TRIF-dependent genes. (A) BMDCs from WT mice were pretreated with the JNK inhibitor SP600125, the p38 inhibitor SB202190, or DMSO (vehicle) for 30 min before being stimulated with a halflog dilution series of sLipid A for 18 hours. The concentrations of secreted IL-6 and IP10 proteins in the culture media were then measured by ELISA. Data are means \pm SEM from the nonlinear regression analysis of at least three independent experiments. (B) Log(EC50) values were calculated from the dose-response curves of the independent experiments shown in (A) and then were compared by two-way ANOVA with Sidak's post-test. ${ }^{*} P<0.05$; ns, not statistically significant. (C) BMDCs from WT mice were pretreated with DMSO or the indicated inhibitors for 30 min before being treated with vehicle (VC) or sLipid A (100 ng/ml) for the indicated times. Increases in the steady-state abundances of the indicated mRNAs in sLipid A-treated cells compared to those in vehicle-treated cells were determined by qPCR analysis. Data are means \pm SEM from four independent experiments. Statistical differences between agonist-treated samples 
and DMSO-treated samples were analyzed with repeated measures two-way ANOVA with Dunnett's post-test. ${ }^{*} P<0.05 ;{ }^{* *} P<0.01,{ }^{* * *} P<0.001,{ }^{* * * *} P<0.0001$. 


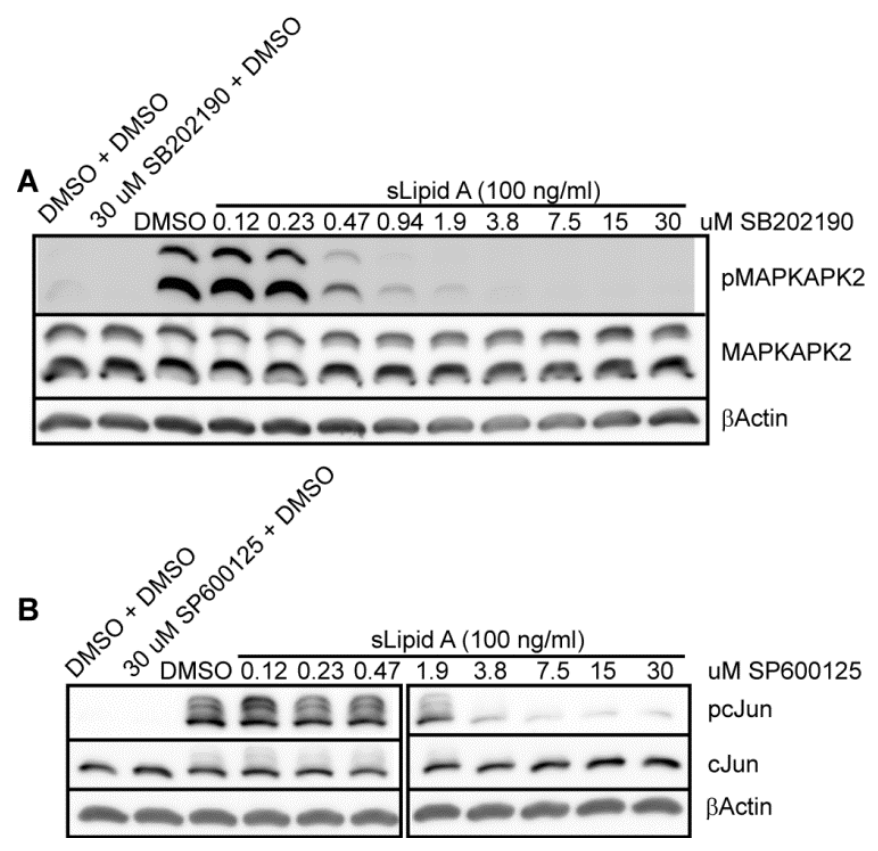

Fig. 17. SB202190 and SP600125 inhibit p38 MAPK and JNK signaling,

respectively. (A and B) BMDCs from wild-type mice were pre-incubated with DMSO (vehicle control) or increasing concentrations of (A) SB202190 (a p38 inhibitor) or (B) SP600125 (a JNK inhibitor) for 30 min. Cells were then treated with DMSO (vehicle control) or were stimulated with sLipid A (100 ng/ml) for $15 \mathrm{~min}$. Samples were then subjected to Western blotting analysis with antibodies specific for the indicated proteins. Representative Western blots from two independent experiments are shown. 
A
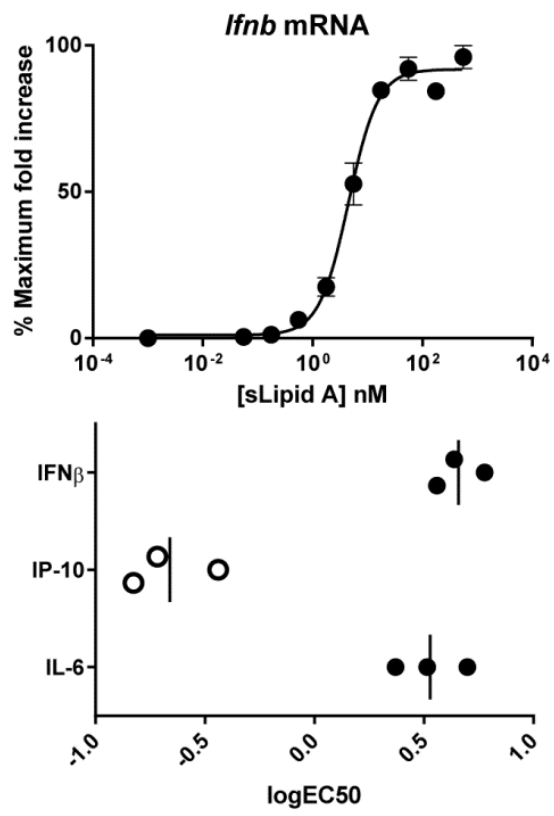

B

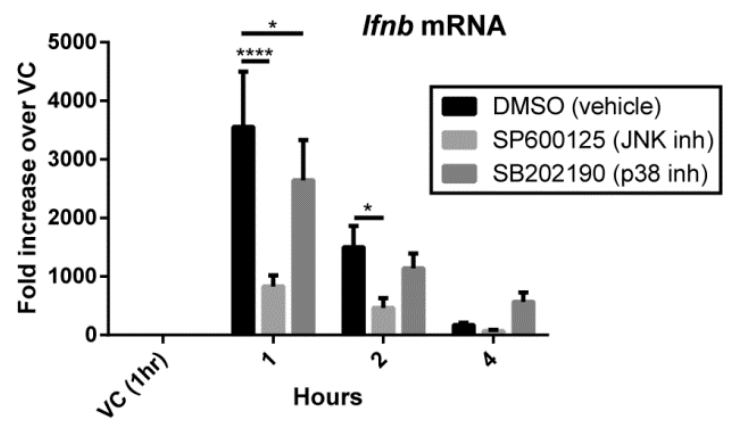

Fig. 18. The high $\log (\mathrm{EC} 50)$ values for the expression of Ifnb correlate with a dependence on JNK signaling. (A) BMDCs from WT mice were stimulated with a halflog dose series of sLipid A for 1 hour. The steady-state abundance of Ifnb mRNA in each of the samples was determined by qPCR analysis, and fold-increases in mRNA abundance in agonist-treated cells compared to that in vehicle-treated cells were calculated and then converted to percentage maximal responses for each experiment. Top: Data are means \pm SEM of three independent experiments that were subjected to nonlinear regression analysis. Bottom: One hour Ifnb logEC50s are compared to those of Il6 and Ip10 (reproduced from Fig. 2A), both measured at 4 hours (bottom). (B) BMDCs from WT mice were pretreated with the indicated inhibitors or DMSO for 30 min before 
being treated with vehicle (VC) for 1 hour or with sLipid A (100 ng/ml) for the indicated times. The abundance of Ifnb mRNA in each sample was determined by qPCR analysis. Data are means \pm SEM in the fold increase in Ifnb mRNA in agonist-treated cells compared to that in vehicle-treated cells and are from three independent experiments. Statistical differences between agonist-treated and DMSO-treated samples were determined by repeated measures two-way ANOVA with Dunnett's post-test. $* P<0.05$; $* * * * P<0.0001$. 

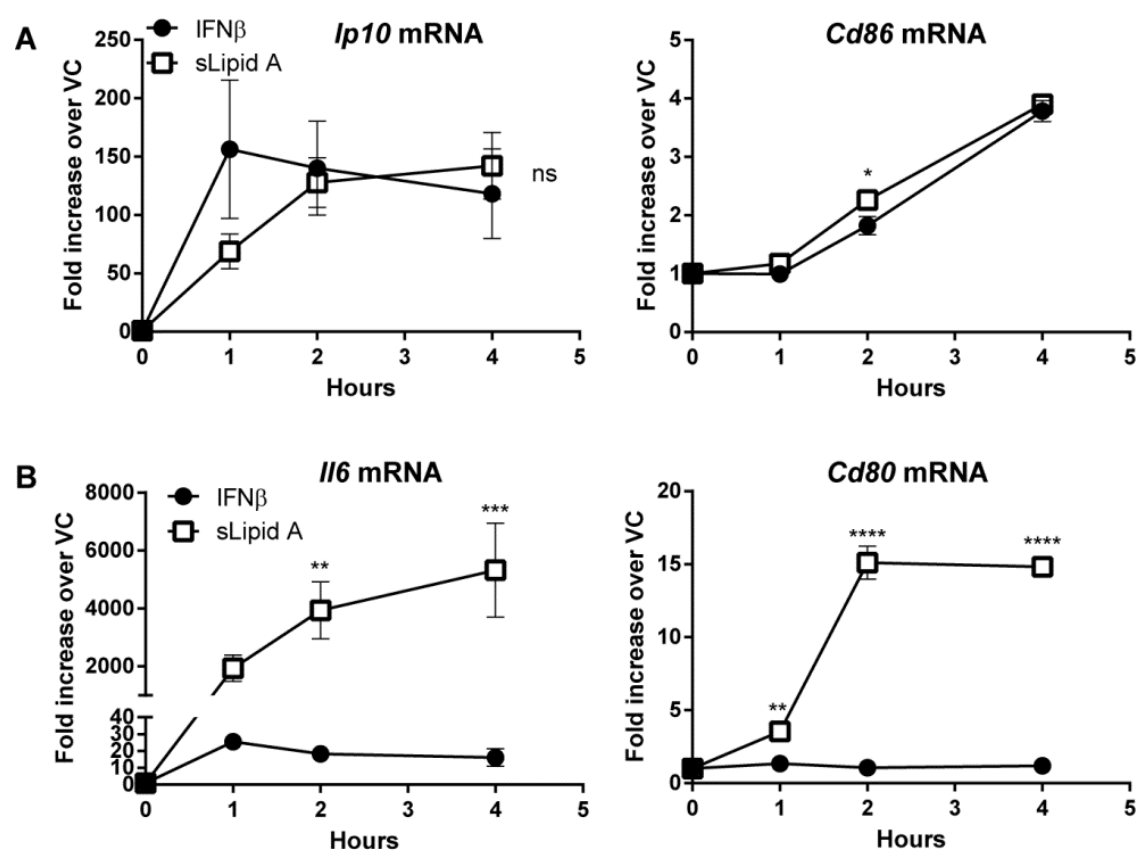

Fig. 19. IFN- $\beta$ is sufficient to induce the maximal expression of genes with low $\log ($ EC50) values. (A and B) BMDCs from WT mice were activated with either IFN- $\beta$ (1000 U/ml) or sLipid A (100 ng/ml) for the indicated times. Samples were then analyzed by qPCR, and the relative fold-increases in the abundances of the mRNAs of (A) TRIFdependent and (B) MyD88- and TRIF-co-dependent genes in stimulated cells compared to those in DMSO-treated cells were determined. Data are means \pm SEM from at least three independent experiments. Statistical differences between sLipid A- and IFN- $\beta$ stimulated mRNA abundances at each time point were determined by two-way ANOVA with Sidak's post-test. ${ }^{*} P<0.05$; ${ }^{* *} P<0.01$, ${ }^{* * *} P<0.001,{ }^{* * * *} P<0.0001$; NS, not statistically significant $(P>0.05)$. 


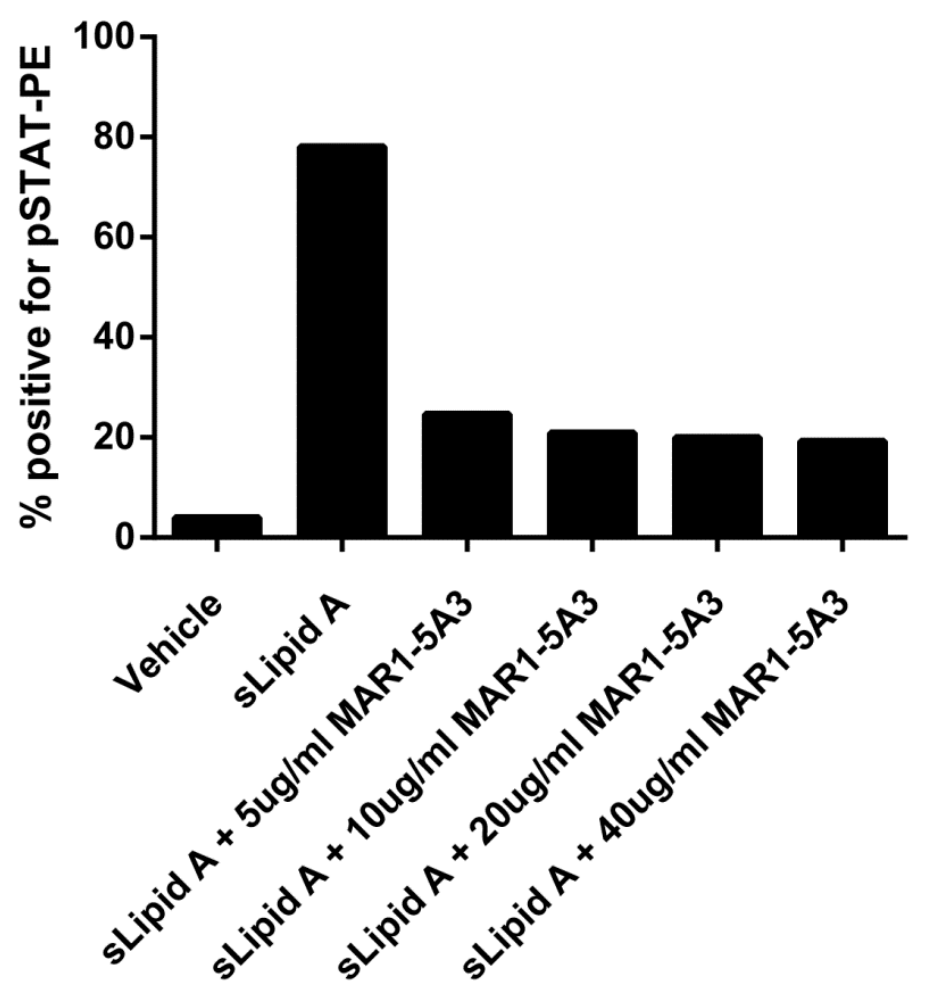

Fig. 20. MAR-5A3 effectively blocks IFNAR signaling. WT BMDC were

preincubated with the indicated concentrations of MAR1-5A3 or media alone for 1 hour. The cells were then activated with $100 \mathrm{ng} / \mathrm{ml}$ sLipid A for 1 hour. Intracellular staining for PSTAT1 was performed. Data were collected on a FACScalibur. The percentage of cells staining positive for pSTAT1-PE is presented. 

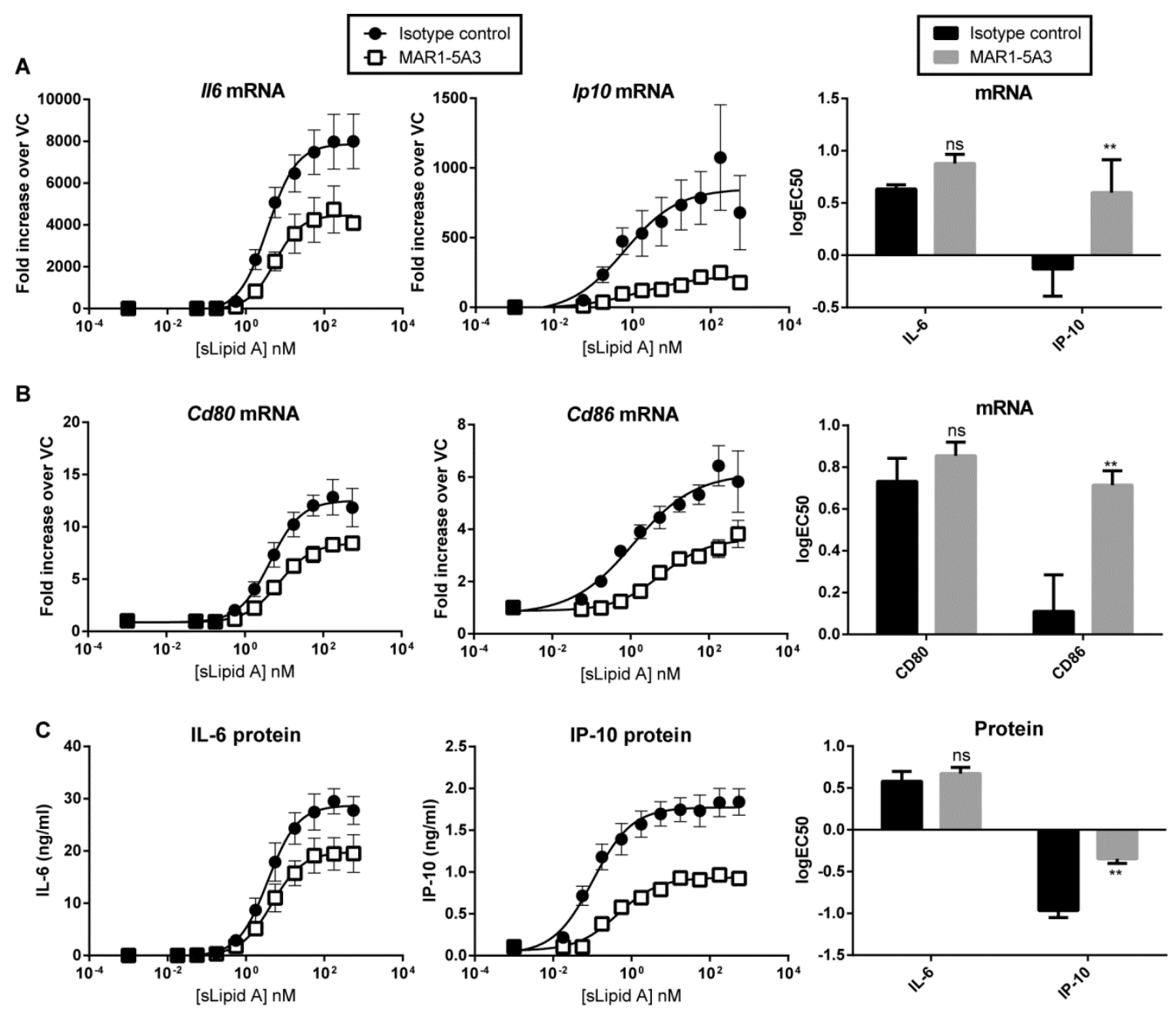

Fig. 21. Autocrine and paracrine signaling by IFN- $\beta$ contributes to the low

$\log$ (EC50) values of TRIF-dependent genes. (A to C) BMDCs from WT mice were pre-treated with MAR1-5A3 (an anti-IFNAR1 antibody) or isotype control antibody for 2 hours before being stimulated with a half-log dose series of sLipid A for 4 or 18 hours. (A and B) After 4 hours, samples were analyzed by qPCR to measure the steady-state abundances of the indicated mRNAs in stimulated cells relative to those of vehicletreated cells. (C) After 18 hours, the concentrations of the indicated proteins in the culture media were determined by ELISA. Data are means \pm SEM from the nonlinear regression analysis of at least three independent experiments. Right: The log(EC50) values derived from each experiment were averaged and are compared in bar graphs. Statistical 
differences between the $\log (\mathrm{EC} 50)$ values of isotype -treated and MAR1-5A3-treated cells were determined by repeated measures two-way ANOVA with Sidak's post-test. ${ }^{* *} P<0.01 ; \mathrm{NS}$, not statistically significant $(P>0.05)$. 


\section{CHAPTER V}

\section{CONCLUSION}

\section{CD14 DOES NOT PLAY A SPECIAL ROLE IN TLR4 SIGNALING IN RESPONSE TO MONOPHOSPHORYL LIPID A}

Following our proposal that MPLA induced a TRIF-biased response by TLR4, our search for potential mechanisms led us to consider the coreceptor CD14. Although CD14 is well known to enhance the expression of MyD88-associated genes in response to TLR4 agonists, its primary role in driving endocytosis of TLR4-MD2 signaling complexes to initiate TRIF signaling has only recently come to light (47). We reasoned that a TRIF-biased agonist may utilize CD14 in a different manner than a MyD88- and TRIF-balanced agonist.

Although CD14 promotes endocytosis of TLR4 through a Syk- and PLC $\gamma 2-$ dependent pathway, the exact mechanism by which it activates this pathway is unknown. For example, it is unknown whether CD14 must bind its ligand directly, or if its mere presence on the cell surface promotes internalization. It is likely that in the process of transferring ligands to TLR4-MD2, the dimeric CD14 molecule promotes heterotetramerization of TLR4-MD2 by physically bringing together the two complexes. In fact, the distance between the ligand-binding domains of CD14 corresponds closely to the distance between adjacent MD2 molecules in the heterotetramer (141). Perhaps this transient interaction with TLR4-MD2 promotes the endocytic pathway. 
The ligand-binding pocket of CD14 is large and hydrophobic with charged residues around its rim (85). These charged residues are thought to interact with the hydrophilic headgroup of lipid A. Because MPLA contains one less phosphate, it is conceivable that its interaction with CD14 may be different than that of lipid A, but we found little evidence to suggest that MPLA utilizes CD14 differently than lipid A. Our data suggest that CD14 ablation decreases the potency of lipid A and MPLA to the same extent. This is not surprising given the ability of CD14 to bind molecules with significantly different structures.

Our results also confirm the importance of CD14 in the initiation of the TRIF pathway because the efficacy of lipid A was reduced by $50 \%$ for induction of TRIFdependent Ifit1 expression. The efficacy of lipid A for MyD88-associated events, on the other hand, was not decreased. Interestingly, Tanimura et al. (93) have shown that CD86 upregulation on BMDCs in response to lipid A and MPLA is unaffected by CD14 ablation, despite the fact that this process is TRIF-dependent. This group suggests that in the absence of CD14, some TRIF-dependent signaling may originate from the cell membrane, which is sufficient to induce certain TRIF-dependent responses. Therefore, TRIF-dependence and CD14-dependence should not be considered one in the same. Perhaps alternative methods exist to initiate TRIF signaling independent of endocytosis of TLR4-MD2 heterotetramers.

\section{IMPLICATIONS FOR VACCINE ADJUVANTS}

Observation of "biased agonism" is not unique to TLR4. This phenomenon has long been recognized to occur with members of the G protein-coupled receptor (GPCR) 
family, the largest class of receptors in the human genome (142). GPCR signaling is mediated by two groups of adaptor proteins, the heterotrimeric $\mathrm{G}$ proteins and the arrestins, the most common of which are the $\beta$-arrestins (143). Similar to the TLR4 adaptor proteins MyD88 and TRIF, G proteins and $\beta$-arrestins mediate different downstream signaling events. Exchange of GDP for GTP by the Ga subunit induces signaling through second messenger systems such as cyclic AMP (143). The $\beta$-arrestins are involved in GPCR desensitization and internalization, MAPK activation, and can also serve as cofactors during transcription (143). Initially, it was thought that GPCR ligands induced balanced signaling through $\mathrm{G}$ proteins and $\beta$-arrestins, but there are now many studies confirming that certain ligands can induce biased signaling through either pathway, which may be caused by the existence of multiple active receptor conformations (144). For example, SII angiotensin, a synthetically modified agonist of the angiotensin II type IA receptor, is unable to activate $\mathrm{G} \alpha_{q}$ signaling, but retains activation of $\beta$-arrestin 2 which leads to ERK activity $(145,146)$.

Similar to modification of LPS to reduce its toxicity while maintaining adjuvanticity, GPCR agonists are being developed to selectively target therapeutically beneficial signaling pathways. Stimulation of the $\mu$-opioid receptor by morphine induces clinically beneficial analgesic affects but is also associated with detrimental side-effects such as constipation and respiratory depression (147). These side-effects have been linked to $\beta$-arrestin 2 signaling (147). A morphine derivative called TRV130 has recently been shown to be better tolerated by patients because it induces signaling biased toward the G protein pathway $(148,149)$. Therefore, a strong precedent has been set for harnessing biased receptor signaling to target clinically useful outcomes more effectively. 
Unexpectedly, this dissertation provides evidence that neither MPLA nor sMLA are bona fide TRIF-biased agonists. In fact, they were less potent than their corresponding diphosphorylated agonist (lipid A or sLipid A) by the same magnitude for the expression of both TRIF-dependent and MyD88- and TRIF-co-dependent genes (Chapters III and IV). Instead, we provide evidence to suggest that TLR4 itself can behave as a TRIF-biased receptor. When using synthetic agonists, the amount of agonist required to induce half-maximal TRIF-dependent gene expression was significantly less than the amount of agonist needed to induce that of MyD88- and TRIF-co-dependent gene expression. TRIF-bias by TLR4 was not at the level of early adaptor engagement because there was no significant difference between the $\log (\mathrm{EC} 50)$ values of sLipid A for MyD88-dependent IRAK1 disappearance and TRIF-dependent IRF3 phosphorylation. The $\log (\mathrm{EC} 50)$ values of sLipid A for the downstream activation of MAPKs and NF- $\mathrm{BB}$ began to diverge, even though these events are MyD88- and TRIF-co-dependent. The strikingly consistent difference between the $\log (\mathrm{EC} 50)$ values for TRIF- and codependent events occurred at the level of gene expression and protein secretion. According to our model, autocrine and paracrine signaling by type I IFN produced in response to TLR4 activation contributes to the relative ease with which TRIF-dependent genes are activated (Fig. 22).

We have yet to fully explain the paradox whereby the expression of a gene characterized by a high $\log (\mathrm{EC} 50)$ value, Ifnb, can promote the low $\log (\mathrm{EC} 50)$ values of agonists for TRIF-dependent genes. In this work, we have only characterized the $\log (\mathrm{EC} 50)$ value for increases in steady-state Ifnb mRNA abundance. The $\log (\mathrm{EC} 50)$ value for the secretion of IFN- $\beta$ protein may in fact be lower which would support our 
hypothesis that an autocrine and paracrine signaling loop through IFNAR promotes TLR4 TRIF-bias. These tests are underway. As discussed in Chapter IV, the potency of IFN- $\beta$ may also be sufficient to promote TRIF-bias, even when the IFN- $\beta$ concentration is relatively low.

Other non-mutually exclusive mechanisms may also be involved in TLR4 TRIFbias. One hypothesis is that gene promoter complexity may promote a TLR4 TRIFbiased gene expression profile. In general, genes which require MyD88-dependent signaling for full activation (i.e. co-dependent genes) may have more complex promoters with multiple NF- $\mathrm{BB}$ and AP1 binding sites. TRIF-sufficient genes likely have less complex promoters which require fewer cofactor inputs for sufficient expression. For example, TRIF-dependent Ifit1 has only two ISREs in its promoter (136) and Ip10 expression requires either two NF- $\mathrm{kB}$ binding sites or one NF- $\mathrm{kB}$ binding site and one ISRE (150). Therefore, it is plausible that TRIF-dependent genes may simply be more easily activated because less TLR4 agonist is needed to induce the transcriptional inputs required to express these genes.

It should be noted that neither MPLA nor lipid A seemed to conform to our model of TLR4 TRIF-bias in the experiments presented in Figure 4. In these experiments, the $\log$ (EC50) values for MPLA and lipid A for Ifit1 mRNA expression were not lower than those for co-dependent IL-6 and Cox2 mRNA. A direct comparison of the log(EC50) values of sLipid A and lipid A, under the same conditions, for TRIF-dependent and codependent gene expression will need to be completed before we can confirm that TLR4 TRIF-bias is not exhibited with these biological compounds. 
A major limitation to the studies presented herein is that they were all assessed in vitro. Therefore, they do not take into account the complex interplay between different cell types that occurs during vaccination or infection. We chose to perform this work using BMDC because DC are expected to be the most important cells in the context of immunization. But other cell types, such as monocytes and macrophages certainly respond during immunization as well. Whether or not these cell types exhibit TLR4 TRIF-bias must be determined in the future.

Although we have not directly tested this hypothesis in vivo, work by Mata-Haro et al. (77) does suggest that TLR4 TRIF-bias may occur within a living host. In this study, both serum cytokine and spleen cell mRNA measurements after immunization with LPS or MPLA demonstrated that the weak agonist MPLA was TRIF-biased relative to LPS. This observation could very well be explained by inherent TRIF-bias by TLR4 itself, especially since a higher dose of MPLA than LPS was used in these studies. A definitive test of this hypothesis would be to perform immunizations with a series of dilutions of a potent agonist, like LPS or lipid A, and compare TRIF- and co-dependent outcomes. Our hypothesis predicts that a dose of LPS or lipid A exists that mirrors the response induced by MPLA, both in T cell priming and cytokine production. While our results clearly show that the potency of TLR4 agonists for TRIF-dependent events is higher than that of co-dependent events, they do not inform us of the actual levels of TLR4 signaling events needed to induce sufficient T cell priming. By studying limiting doses of agonists in vivo, we can bypass issues of the physiological relevance of pharmacological potency and efficacy measured in vitro. 
Our findings have direct implications for the use of TLR4 agonists as vaccine adjuvants. A paradigm has emerged in which TRIF-dependent gene activation is associated with events necessary for adaptive T cell priming and MyD88-associated gene activation is linked to proinflammatory cytokine release and toxicity. Safe and efficacious vaccine adjuvants should induce maximal beneficial effects with the least amount of toxicity. We speculate that TLR4's TRIF-biased gene activation profile effectively widens the therapeutic window in which TLR4 agonists may be used as clinical adjuvants (Fig. 23). In other words, there may be a broad range of doses at which a TLR4 agonist may be administered where adjuvanticity is retained and toxicity remains low. Inherently less potent adjuvants like MPLA and sMLA may be better able to fit within this therapeutic window when administered in vivo. At their effective doses, these agonists may also retain sufficient levels of MyD88-associated proinflammatory cytokine production which is likely important to promote long term immunity through effects on regulatory T cells (Tregs) and retention of memory T cells $(151,152)$.

Our observation that type I IFN production was responsible for much of the TLR4 TRIF-biased gene expression may also provide insight into the development of more effective adjuvants. There is currently much interest in the combination of vaccine adjuvants to promote more robust immunity (153). Specifically, combining TLR4 with TLR7, TLR8, or TLR9 agonists was shown to synergistically enhance production of IL12 and IL-23 in human and mouse DC, which promoted Th1 immunity (154). TLR7 and TLR9 are expressed on plasmacytoid DC (pDC) and their activation induces production of large quantities of type I IFN (155), which induces many effects including APC maturation and migration, and B cell isotype switching (156). We speculate that the 
efficacy of combining TLR4-based adjuvants with those that target pDC may lie in the enhanced production of type I IFN. In fact, a candidate clinical vaccine against a Mycobacterium tuberculosis antigen was recently shown to be more effective at inducing a Th1 response when adjuvanted with GLA (a formulation of sMLA) and CpG (a TLR9 agonist) as opposed to GLA alone (157). Adjuvant synergy between GLA and CpG was independent of TRIF signaling, but the adjuvant effects of GLA alone were TRIFdependent. This result could be explained by rescue of TRIF-dependent, type I IFNinducible gene expression by the TLR9 signaling component. Type I IFN signaling through IFNAR, either before or during TLR4 activation on conventional DC, may promote an even greater bias toward TRIF-dependent gene activation and further enhance adaptive immune priming and optimal $\mathrm{T}$ cell differentiation.

Preliminary studies in our lab using the human monocytic cell line THP1 and human peripheral blood mononuclear cells suggest that inherent TLR4 TRIF-bias is likely relevant to clinical medicine, but additional work needs to be performed to determine whether autocrine and paracrine signaling by type I IFN drives this response. Certain TLR4 agonist structures may also be TRIF-biased (i.e. ligand bias rather than receptor bias) in the human system as was demonstrated by Bowen et al. (110). Current studies in our lab have shown that the biological mixture MPLA has a lower efficacy than lipid A for MyD88-associated gene expression in human cells. In contrast, the efficacy of sMLA for these events is equivalent to that of sLipid A. The lower efficacy of MPLA compared to sMLA may be explained by the presence of hypo-acylated congeners within the MPLA mixture that either act as antagonists or partial agonists of TLR4. Interestingly, studies performed by the Infectious Disease Research Institute (IDRI) 
demonstrated that GLA was generally stronger than MPLA at inducing co-dependent and TRIF-dependent cytokines in human DC, including those implicated in adverse events such as TNF $\alpha$ and IL-6 (158). Therefore, the fact that GLA is a homogeneous preparation of hexa-acylated molecules may be a barrier to its incorporation into clinical vaccines. MPLA, on the other hand, may be a more tolerable vaccine adjuvant due to its heterogeneity which serves to tone down TLR4 activity.

\section{IMPLICATIONS FOR COEVOLUTION OF COMMENSAL BACTERIA AND INNATE IMMUNITY}

It is tempting to speculate on the selective pressures that would have promoted the evolution of bias toward the TRIF pathway of TLR4. An answer may lie in the interaction between the host and its resident gut microbiota, which is essential for competent host immune system development, nutrition, and for maintenance of the mucosal barrier (159). Trillions of bacteria colonize the host mucosal surfaces. These bacterial colonies, although essential to host health, must be held in check by the host immune system. An overly vigorous response to commensal bacteria may promote disease states such as colitis. On the other hand, an inadequate immune response can promote infection by normally benign microbes. The importance of gut microbiota homeostasis is demonstrated by the fact that disruption of commensal populations by antibiotic use promotes susceptibility to pathogenic Clostridium difficile infection (160).

Intestinal $\mathrm{CD}_{103^{+}} \mathrm{DC}$ play an essential role in the maintenance of gut microbiota homeostasis (161). These cells reside in the lamina propria and the gut-associated lymphoid tissue, and extend dendrites between intestinal epithelial cells to sample 
commensal antigens within the lumen $(161,162)$. Commensal bacteria themselves also relay signals to immune cells and lymphoid tissues through the release of PAMPcontaining membrane microvesicles that transverse the gut epithelium $(163,164)$. To prevent an overly robust immune response to commensal bacteria, $\mathrm{CD}_{103}{ }^{+} \mathrm{DC}$ promote the differentiation of commensal-specific induced T regulatory cells (Treg) through production of retinoic acid and TGF- $\beta$ (161). These Treg then promote commensal tolerance.

Although tolerance to gut antigens is important, a mechanism must be in place to limit commensal loads and elicit immunity in the case of infection. Intestinal DC support Th17 effector cell differentiation through production of IL-23 and IL-6 $(161,165)$. Th17 cells play an important role in controlling gut microbiota. They promote the production of IgA (166), which limits commensal escape into the periphery (167), and have been implicated in lessening the severity of T cell-mediated colitis (168).

Interestingly, many commensal bacteria express weak TLR4 agonists characterized by hypo-acylation or monophosphorylation (169-171). In addition, intestinal alkaline phosphatase (IAP) concentrated in the intestinal brush border and produced in response to bacterial colonization has been proposed to promote tolerance to commensal Gram-negatives by decreasing the potency of their LPS through the removal of the lipid A 1-phosphate group (172). IAP-deficient zebrafish exhibited severe gut inflammation characterized by heightened infiltration of neutrophils (172). We speculate that commensal bacteria may express weakened forms of LPS, produced either endogenously or by chemical modification by the host, to prevent strong TLR4 activity in intestinal DC that may promote Th17 mediated immunity over Treg mediated tolerance. 
Weak activation of TLR4 on intestinal DC would be expected to induce a higher level of TRIF-dependent versus co-dependent gene activation in the context of our model of TRIF-bias. Whether or not TRIF signaling plays a predominant role in maintenance of Tregs and tolerance is uncertain, but one study showed that TRIF signaling by gut DC in response to intestinal Candida albicans infection was required for Treg induction through the production of indoleamine dioxygenase (173).

In cases where the $\mathrm{T}$ effector to Treg ratio should increase, such as infection by a pathogen, higher levels of TLR4 stimulation may occur through exposure of DC to higher bacterial loads or to more potent LPS chemotypes. In this scenario, MyD88-associated genes would be more efficiently induced and promote conversion of tolerogenic DC to those which promote inflammation and immunity. For example, stronger stimulation of gut DC through TLR4 may induce more robust production of co-dependent IL-6 which promotes Th17 differentiation $(161,174)$. We speculate that commensal bacteria may have been selected to express low potency LPS structures in order to minimize clearance by the host immune system. In addition, differential ease of activating TRIF- versus MyD88-associated gene expression by host APC may have coevolved with the microbiota to strike a balance between tolerance and immunity, which allows these beneficial bacteria to persist without damage to the gut, or other host-environment interfaces such as the skin and respiratory tract. 


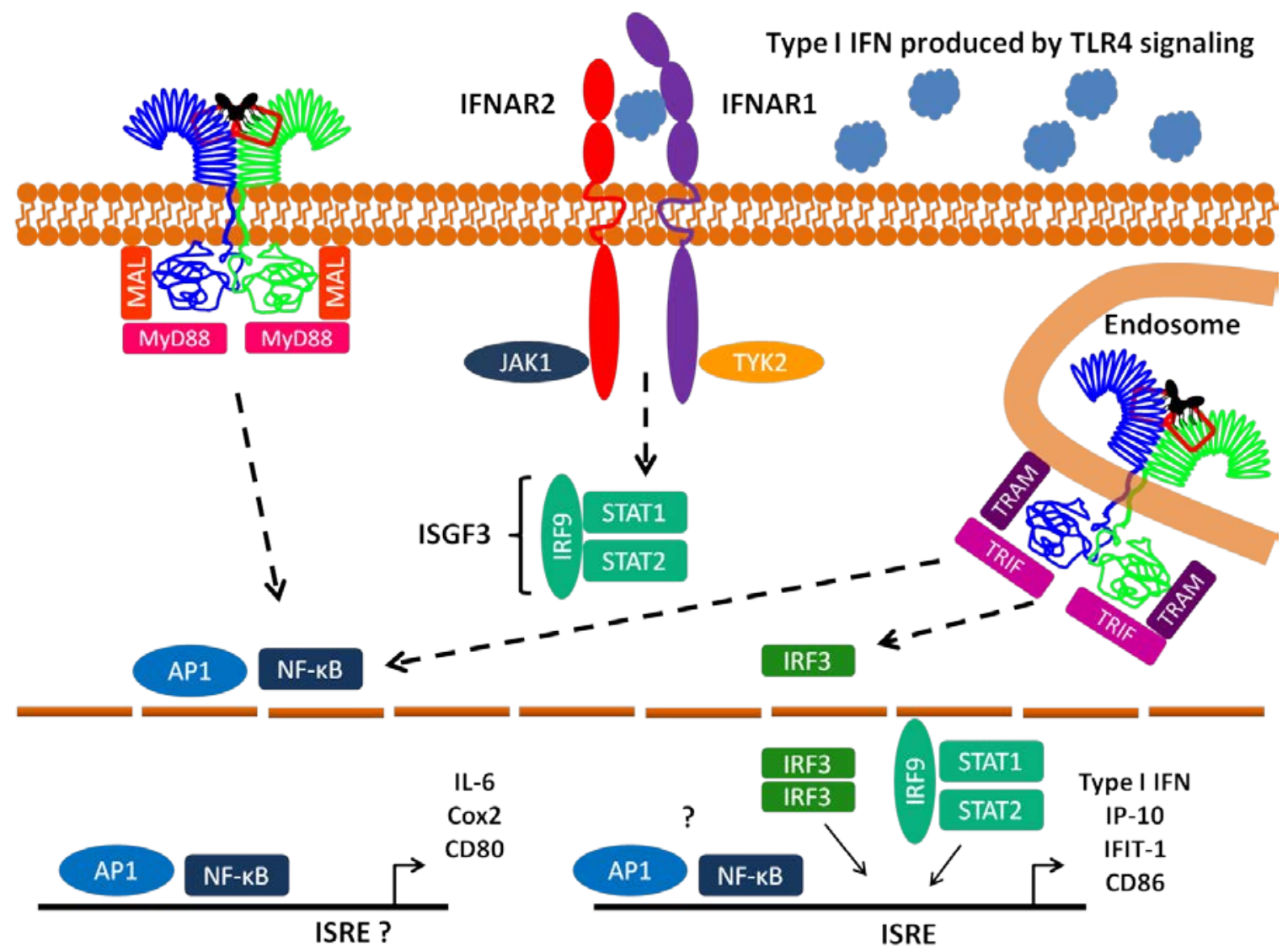

Fig. 22. The proposed mechanism for TRIF-biased TLR4 signaling. TLR4

activation induces the expression of MyD88- and TRIF-co-dependent genes which require the activation of NF- $\mathrm{kB}$ and AP1 transcription factors. TRIF dependent signaling activates IRF3, which, together with NF-kB and AP1, promotes type I IFN expression and low levels of type I IFN-inducible gene expression. Type I IFN secreted by the cell activates ISGF3 through IFNAR signaling. ISGF3 then promotes the expression of type I IFN-inducible genes. The combined action of IRF3 and ISGF3, as well as other transcription factors, may increase the potency of TLR4 agonists for the induction of TRIF-dependent genes. Though optimal co-dependent gene expression may require ISGF3 activity, the potency of agonists for the induction of these genes is unaffected. 


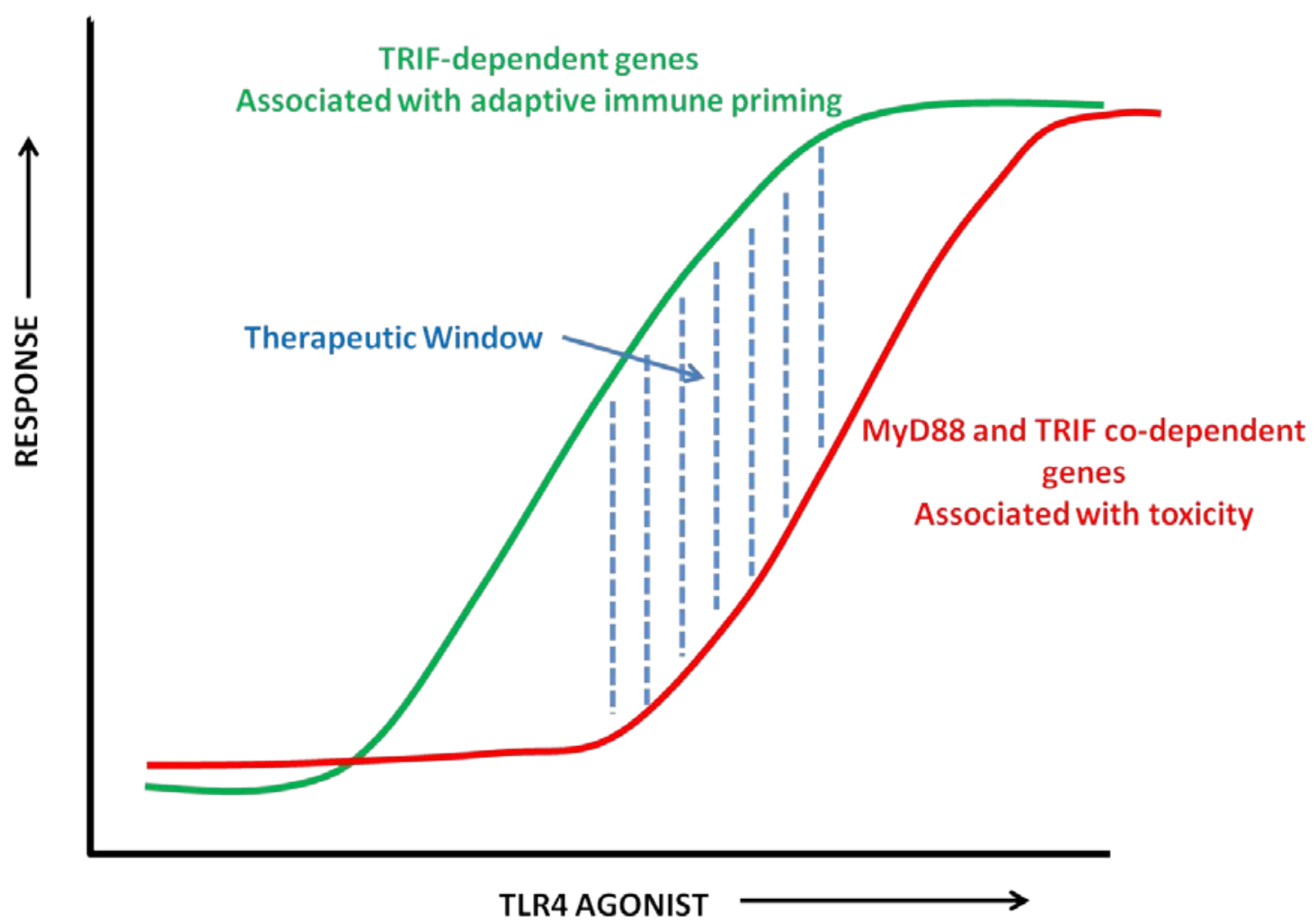

Fig. 23. TLR4 TRIF-bias opens a therapeutic window for vaccine adjuvants. The therapeutic window shaded in blue represents doses of a TLR4 agonist that induce TRIFdependent responses sufficient for robust adjuvanticity with minimal toxicity. 


\section{REFERENCES}

1. Janeway, C. A., Jr. 1989. Approaching the asymptote? Evolution and revolution in immunology. Cold Spring Harb Symp Quant Biol 54 Pt 1:1-13.

2. Rietschel, E. T., U. Seydel, U. Zahringer, U. F. Schade, L. Brade, H. Loppnow, W. Feist, M. H. Wang, A. J. Ulmer, H. D. Flad, and et al. 1991. Bacterial endotoxin: molecular relationships between structure and activity. Infect Dis Clin North Am 5:753-779.

3. Rietschel, E. T., and J. M. Cavaillon. 2003. Richard Pfeiffer and Alexandre Besredka: creators of the concept of endotoxin and anti-endotoxin. Microbes Infect 5:1407-1414.

4. Beeson, P. B. 1946. Development of tolerance to typhoid bacterial pyrogen and its abolition by reticulo-endothelial blockade. Proc Soc Exp Biol Med 61:248-250.

5. Andersson, J., O. Sjoberg, and G. Moller. 1972. Induction of immunoglobulin and antibody synthesis in vitro by lipopolysaccharides. Eur J Immunol 2:349-353.

6. Peavy, D. L., W. H. Adler, and R. T. Smith. 1970. The mitogenic effects of endotoxin and staphylococcal enterotoxin B on mouse spleen cells and human peripheral lymphocytes. J Immunol 105:1453-1458.

7. Sultzer, B. M. 1969. Genetic factors in leucocyte responses to endotoxin: further studies in mice. J Immunol 103:32-38.

8. Tobias, P. S., K. Soldau, and R. J. Ulevitch. 1986. Isolation of a lipopolysaccharide-binding acute phase reactant from rabbit serum. $J$ Exp Med 164:777-793.

9. Wright, S. D., R. A. Ramos, P. S. Tobias, R. J. Ulevitch, and J. C. Mathison. 1990. CD14, a receptor for complexes of lipopolysaccharide (LPS) and LPS binding protein. Science 249:1431-1433. 
10. Goyert, S. M., E. Ferrero, W. J. Rettig, A. K. Yenamandra, F. Obata, and M. M. Le Beau. 1988. The CD14 monocyte differentiation antigen maps to a region encoding growth factors and receptors. Science 239:497-500.

11. Pugin, J., I. D. Heumann, A. Tomasz, V. V. Kravchenko, Y. Akamatsu, M. Nishijima, M. P. Glauser, P. S. Tobias, and R. J. Ulevitch. 1994. CD14 is a pattern recognition receptor. Immunity 1:509-516.

12. Haziot, A., S. Chen, E. Ferrero, M. G. Low, R. Silber, and S. M. Goyert. 1988. The monocyte differentiation antigen, CD14, is anchored to the cell membrane by a phosphatidylinositol linkage. J Immunol 141:547-552.

13. Kitchens, R. L., and R. S. Munford. 1995. Enzymatically deacylated lipopolysaccharide (LPS) can antagonize LPS at multiple sites in the LPS recognition pathway. J Biol Chem 270:9904-9910.

14. Delude, R. L., R. Savedra, Jr., H. Zhao, R. Thieringer, S. Yamamoto, M. J. Fenton, and D. T. Golenbock. 1995. CD14 enhances cellular responses to endotoxin without imparting ligand-specific recognition. Proc Natl Acad Sci U S A 92:9288-9292.

15. Perera, P. Y., S. N. Vogel, G. R. Detore, A. Haziot, and S. M. Goyert. 1997. CD14-dependent and CD14-independent signaling pathways in murine macrophages from normal and CD14 knockout mice stimulated with lipopolysaccharide or taxol. J Immunol 158:4422-4429.

16. Lemaitre, B., E. Nicolas, L. Michaut, J. M. Reichhart, and J. A. Hoffmann. 1996. The dorsoventral regulatory gene cassette spatzle/Toll/cactus controls the potent antifungal response in Drosophila adults. Cell 86:973-983.

17. Vogel, S. N. 2012. How discovery of Toll-mediated innate immunity in Drosophila impacted our understanding of TLR signaling (and vice versa). $J$ Immunol 188:5207-5209.

18. Medzhitov, R., P. Preston-Hurlburt, and C. A. Janeway, Jr. 1997. A human homologue of the Drosophila Toll protein signals activation of adaptive immunity. Nature 388:394-397.

19. Poltorak, A., X. He, I. Smirnova, M. Y. Liu, C. Van Huffel, X. Du, D. Birdwell, E. Alejos, M. Silva, C. Galanos, M. Freudenberg, P. Ricciardi-Castagnoli, B. 
Layton, and B. Beutler. 1998. Defective LPS signaling in C3H/HeJ and C57BL/10ScCr mice: mutations in Tlr4 gene. Science 282:2085-2088.

20. Hoshino, K., O. Takeuchi, T. Kawai, H. Sanjo, T. Ogawa, Y. Takeda, K. Takeda, and S. Akira. 1999. Cutting edge: Toll-like receptor 4 (TLR4)-deficient mice are hyporesponsive to lipopolysaccharide: evidence for TLR4 as the Lps gene product. J Immunol 162:3749-3752.

21. Shimazu, R., S. Akashi, H. Ogata, Y. Nagai, K. Fukudome, K. Miyake, and M. Kimoto. 1999. MD-2, a molecule that confers lipopolysaccharide responsiveness on Toll-like receptor 4. J Exp Med 189:1777-1782.

22. Viriyakosol, S., P. S. Tobias, R. L. Kitchens, and T. N. Kirkland. 2001. MD-2 binds to bacterial lipopolysaccharide. J Biol Chem 276:38044-38051.

23. Hailman, E., H. S. Lichenstein, M. M. Wurfel, D. S. Miller, D. A. Johnson, M. Kelley, L. A. Busse, M. M. Zukowski, and S. D. Wright. 1994. Lipopolysaccharide (LPS)-binding protein accelerates the binding of LPS to CD14. J Exp Med 179:269-277.

24. Yu, B., and S. D. Wright. 1996. Catalytic properties of lipopolysaccharide (LPS) binding protein. Transfer of LPS to soluble CD14. J Biol Chem 271:4100-4105.

25. Bufler, P., G. Stiegler, M. Schuchmann, S. Hess, C. Kruger, F. Stelter, C. Eckerskorn, C. Schutt, and H. Engelmann. 1995. Soluble lipopolysaccharide receptor (CD14) is released via two different mechanisms from human monocytes and CD14 transfectants. Eur J Immunol 25:604-610.

26. da Silva Correia, J., K. Soldau, U. Christen, P. S. Tobias, and R. J. Ulevitch. 2001. Lipopolysaccharide is in close proximity to each of the proteins in its membrane receptor complex. transfer from CD14 to TLR4 and MD-2. J Biol Chem 276:21129-21135.

27. Erridge, C., E. Bennett-Guerrero, and I. R. Poxton. 2002. Structure and function of lipopolysaccharides. Microbes Infect 4:837-851.

28. Galanos, C., O. Luderitz, E. T. Rietschel, O. Westphal, H. Brade, L. Brade, M. Freudenberg, U. Schade, M. Imoto, H. Yoshimura, and et al. 1985. Synthetic and natural Escherichia coli free lipid A express identical endotoxic activities. Eur $J$ Biochem 148:1-5. 
29. Park, B. S., D. H. Song, H. M. Kim, B. S. Choi, H. Lee, and J. O. Lee. 2009. The structural basis of lipopolysaccharide recognition by the TLR4-MD-2 complex. Nature 458:1191-1195.

30. Ohto, U., K. Fukase, K. Miyake, and Y. Satow. 2007. Crystal structures of human MD-2 and its complex with antiendotoxic lipid IVa. Science 316:1632-1634.

31. Kim, H. M., B. S. Park, J. I. Kim, S. E. Kim, J. Lee, S. C. Oh, P. Enkhbayar, N. Matsushima, H. Lee, O. J. Yoo, and J. O. Lee. 2007. Crystal structure of the TLR4-MD-2 complex with bound endotoxin antagonist Eritoran. Cell 130:906917.

32. Nunez Miguel, R., J. Wong, J. F. Westoll, H. J. Brooks, L. A. O'Neill, N. J. Gay, C. E. Bryant, and T. P. Monie. 2007. A dimer of the Toll-like receptor 4 cytoplasmic domain provides a specific scaffold for the recruitment of signalling adaptor proteins. PLoS One 2:e788.

33. Latz, E., A. Visintin, E. Lien, K. A. Fitzgerald, T. Espevik, and D. T. Golenbock. 2003. The LPS receptor generates inflammatory signals from the cell surface. $J$ Endotoxin Res 9:375-380.

34. O'Neill, L. A., and A. G. Bowie. 2007. The family of five: TIR-domaincontaining adaptors in Toll-like receptor signalling. Nat Rev Immunol 7:353-364.

35. Kagan, J. C., and R. Medzhitov. 2006. Phosphoinositide-mediated adaptor recruitment controls Toll-like receptor signaling. Cell 125:943-955.

36. Lin, S. C., Y. C. Lo, and H. Wu. 2010. Helical assembly in the MyD88-IRAK4IRAK2 complex in TLR/IL-1R signalling. Nature 465:885-890.

37. Deng, L., C. Wang, E. Spencer, L. Yang, A. Braun, J. You, C. Slaughter, C. Pickart, and Z. J. Chen. 2000. Activation of the IkappaB kinase complex by TRAF6 requires a dimeric ubiquitin-conjugating enzyme complex and a unique polyubiquitin chain. Cell 103:351-361.

38. Conze, D. B., C. J. Wu, J. A. Thomas, A. Landstrom, and J. D. Ashwell. 2008. Lys63-linked polyubiquitination of IRAK-1 is required for interleukin-1 receptorand toll-like receptor-mediated NF-kappaB activation. Mol Cell Biol 28:35383547. 
39. Keating, S. E., G. M. Maloney, E. M. Moran, and A. G. Bowie. 2007. IRAK-2 participates in multiple toll-like receptor signaling pathways to NFkappaB via activation of TRAF6 ubiquitination. J Biol Chem 282:33435-33443.

40. Lamothe, B., A. Besse, A. D. Campos, W. K. Webster, H. Wu, and B. G. Darnay. 2007. Site-specific Lys-63-linked tumor necrosis factor receptor-associated factor 6 auto-ubiquitination is a critical determinant of I kappa B kinase activation. $J$ Biol Chem 282:4102-4112.

41. Wang, C., L. Deng, M. Hong, G. R. Akkaraju, J. Inoue, and Z. J. Chen. 2001. TAK1 is a ubiquitin-dependent kinase of MKK and IKK. Nature 412:346-351.

42. Kanayama, A., R. B. Seth, L. Sun, C. K. Ea, M. Hong, A. Shaito, Y. H. Chiu, L. Deng, and Z. J. Chen. 2004. TAB2 and TAB3 activate the NF-kappaB pathway through binding to polyubiquitin chains. Mol Cell 15:535-548.

43. Wu, C. J., D. B. Conze, T. Li, S. M. Srinivasula, and J. D. Ashwell. 2006. Sensing of Lys 63-linked polyubiquitination by NEMO is a key event in NF-kappaB activation [corrected]. Nat Cell Biol 8:398-406.

44. Kawai, T., O. Adachi, T. Ogawa, K. Takeda, and S. Akira. 1999. Unresponsiveness of MyD88-deficient mice to endotoxin. Immunity 11:115-122.

45. Bjorkbacka, H., K. A. Fitzgerald, F. Huet, X. Li, J. A. Gregory, M. A. Lee, C. M. Ordija, N. E. Dowley, D. T. Golenbock, and M. W. Freeman. 2004. The induction of macrophage gene expression by LPS predominantly utilizes Myd88independent signaling cascades. Physiol Genomics 19:319-330.

46. Kawai, T., O. Takeuchi, T. Fujita, J. Inoue, P. F. Muhlradt, S. Sato, K. Hoshino, and S. Akira. 2001. Lipopolysaccharide stimulates the MyD88-independent pathway and results in activation of IFN-regulatory factor 3 and the expression of a subset of lipopolysaccharide-inducible genes. J Immunol 167:5887-5894.

47. Zanoni, I., R. Ostuni, L. R. Marek, S. Barresi, R. Barbalat, G. M. Barton, F. Granucci, and J. C. Kagan. 2011. CD14 controls the LPS-induced endocytosis of Toll-like receptor 4. Cell 147:868-880.

48. Fitzgerald, K. A., D. C. Rowe, B. J. Barnes, D. R. Caffrey, A. Visintin, E. Latz, B. Monks, P. M. Pitha, and D. T. Golenbock. 2003. LPS-TLR4 signaling to IRF-3/7 
and NF-kappaB involves the toll adapters TRAM and TRIF. $J$ Exp Med 198:1043-1055.

49. Kagan, J. C., T. Su, T. Horng, A. Chow, S. Akira, and R. Medzhitov. 2008. TRAM couples endocytosis of Toll-like receptor 4 to the induction of interferonbeta. Nat Immunol 9:361-368.

50. Tanimura, N., S. Saitoh, F. Matsumoto, S. Akashi-Takamura, and K. Miyake. 2008. Roles for LPS-dependent interaction and relocation of TLR4 and TRAM in TRIF-signaling. Biochem Biophys Res Commun 368:94-99.

51. Tseng, P. H., A. Matsuzawa, W. Zhang, T. Mino, D. A. Vignali, and M. Karin. 2010. Different modes of ubiquitination of the adaptor TRAF3 selectively activate the expression of type I interferons and proinflammatory cytokines. Nat Immunol 11:70-75.

52. Hiscott, J., P. Pitha, P. Genin, H. Nguyen, C. Heylbroeck, Y. Mamane, M. Algarte, and R. Lin. 1999. Triggering the interferon response: the role of IRF-3 transcription factor. J Interferon Cytokine Res 19:1-13.

53. Hacker, H., V. Redecke, B. Blagoev, I. Kratchmarova, L. C. Hsu, G. G. Wang, M. P. Kamps, E. Raz, H. Wagner, G. Hacker, M. Mann, and M. Karin. 2006. Specificity in Toll-like receptor signalling through distinct effector functions of TRAF3 and TRAF6. Nature 439:204-207.

54. Fitzgerald, K. A., S. M. McWhirter, K. L. Faia, D. C. Rowe, E. Latz, D. T. Golenbock, A. J. Coyle, S. M. Liao, and T. Maniatis. 2003. IKKepsilon and TBK1 are essential components of the IRF3 signaling pathway. Nat Immunol 4:491-496.

55. Sakaguchi, S., H. Negishi, M. Asagiri, C. Nakajima, T. Mizutani, A. Takaoka, K. Honda, and T. Taniguchi. 2003. Essential role of IRF-3 in lipopolysaccharideinduced interferon-beta gene expression and endotoxin shock. Biochem Biophys Res Commun 306:860-866.

56. Chang, M., W. Jin, and S. C. Sun. 2009. Peli1 facilitates TRIF-dependent Tolllike receptor signaling and proinflammatory cytokine production. Nat Immunol 10:1089-1095. 
57. Cusson-Hermance, N., S. Khurana, T. H. Lee, K. A. Fitzgerald, and M. A. Kelliher. 2005. Rip1 mediates the Trif-dependent toll-like receptor 3- and 4induced NF-\{kappa\}B activation but does not contribute to interferon regulatory factor 3 activation. $J$ Biol Chem 280:36560-36566.

58. Ea, C. K., L. Deng, Z. P. Xia, G. Pineda, and Z. J. Chen. 2006. Activation of IKK by TNFalpha requires site-specific ubiquitination of RIP1 and polyubiquitin binding by NEMO. Mol Cell 22:245-257.

59. Yamamoto, M., S. Sato, H. Hemmi, K. Hoshino, T. Kaisho, H. Sanjo, O. Takeuchi, M. Sugiyama, M. Okabe, K. Takeda, and S. Akira. 2003. Role of adaptor TRIF in the MyD88-independent toll-like receptor signaling pathway. Science 301:640-643.

60. Hirotani, T., M. Yamamoto, Y. Kumagai, S. Uematsu, I. Kawase, O. Takeuchi, and S. Akira. 2005. Regulation of lipopolysaccharide-inducible genes by MyD88 and Toll/IL-1 domain containing adaptor inducing IFN-beta. Biochem Biophys Res Commun 328:383-392.

61. Yamamoto, M., S. Sato, H. Hemmi, S. Uematsu, K. Hoshino, T. Kaisho, O. Takeuchi, K. Takeda, and S. Akira. 2003. TRAM is specifically involved in the Toll-like receptor 4-mediated MyD88-independent signaling pathway. Nat Immunol 4:1144-1150.

62. Hoebe, K., X. Du, P. Georgel, E. Janssen, K. Tabeta, S. O. Kim, J. Goode, P. Lin, N. Mann, S. Mudd, K. Crozat, S. Sovath, J. Han, and B. Beutler. 2003. Identification of Lps2 as a key transducer of MyD88-independent TIR signalling. Nature 424:743-748.

63. Yaqub, O., S. Castle-Clarke, N. Sevdalis, and J. Chataway. 2014. Attitudes to vaccination: a critical review. Soc Sci Med 112:1-11.

64. Glenny, A. T. 1930. Insoluble Precipitates in Diphtheria and Tetanus Immunization. Br Med J 2:244-245.

65. Flach, T. L., G. Ng, A. Hari, M. D. Desrosiers, P. Zhang, S. M. Ward, M. E. Seamone, A. Vilaysane, A. D. Mucsi, Y. Fong, E. Prenner, C. C. Ling, J. Tschopp, D. A. Muruve, M. W. Amrein, and Y. Shi. 2011. Alum interaction with dendritic cell membrane lipids is essential for its adjuvanticity. Nat Med 17:479487. 
66. McKee, A. S., M. W. Munks, M. K. MacLeod, C. J. Fleenor, N. Van Rooijen, J. W. Kappler, and P. Marrack. 2009. Alum induces innate immune responses through macrophage and mast cell sensors, but these sensors are not required for alum to act as an adjuvant for specific immunity. J Immunol 183:4403-4414.

67. Johnson, D. A., D. S. Keegan, C. G. Sowell, M. T. Livesay, C. L. Johnson, L. M. Taubner, A. Harris, K. R. Myers, J. D. Thompson, G. L. Gustafson, M. J. Rhodes, J. T. Ulrich, J. R. Ward, Y. M. Yorgensen, J. L. Cantrell, and V. G. Brookshire. 1999. 3-O-Desacyl monophosphoryl lipid A derivatives: synthesis and immunostimulant activities. J Med Chem 42:4640-4649.

68. Ribi, E. 1984. Beneficial modification of the endotoxin molecule. J Biol Response Mod 3:1-9.

69. Einstein, M. H., M. Baron, M. J. Levin, A. Chatterjee, R. P. Edwards, F. Zepp, I. Carletti, F. J. Dessy, A. F. Trofa, A. Schuind, and G. Dubin. 2009. Comparison of the immunogenicity and safety of Cervarix and Gardasil human papillomavirus (HPV) cervical cancer vaccines in healthy women aged 18-45 years. Hum Vaccin 5:705-719.

70. Einstein, M. H., M. Baron, M. J. Levin, A. Chatterjee, B. Fox, S. Scholar, J. Rosen, N. Chakhtoura, D. Meric, F. J. Dessy, S. K. Datta, D. Descamps, and G. Dubin. 2011. Comparative immunogenicity and safety of human papillomavirus (HPV)-16/18 vaccine and HPV-6/11/16/18 vaccine: follow-up from months 12-24 in a Phase III randomized study of healthy women aged 18-45 years. Hum Vaccin 7:1343-1358.

71. Salkowski, C. A., G. R. Detore, and S. N. Vogel. 1997. Lipopolysaccharide and monophosphoryl lipid A differentially regulate interleukin-12, gamma interferon, and interleukin-10 mRNA production in murine macrophages. Infect Immun 65:3239-3247.

72. Ismaili, J., J. Rennesson, E. Aksoy, J. Vekemans, B. Vincart, Z. Amraoui, F. Van Laethem, M. Goldman, and P. M. Dubois. 2002. Monophosphoryl lipid A activates both human dendritic cells and T cells. J Immunol 168:926-932.

73. Henricson, B. E., C. L. Manthey, P. Y. Perera, T. A. Hamilton, and S. N. Vogel. 1993. Dissociation of lipopolysaccharide (LPS)-inducible gene expression in murine macrophages pretreated with smooth LPS versus monophosphoryl lipid A. Infect Immun 61:2325-2333. 
74. Henricson, B. E., W. R. Benjamin, and S. N. Vogel. 1990. Differential cytokine induction by doses of lipopolysaccharide and monophosphoryl lipid A that result in equivalent early endotoxin tolerance. Infect Immun 58:2429-2437.

75. Okemoto, K., K. Kawasaki, K. Hanada, M. Miura, and M. Nishijima. 2006. A potent adjuvant monophosphoryl lipid A triggers various immune responses, but not secretion of IL-1beta or activation of caspase-1. J Immunol 176:1203-1208.

76. Thompson, B. S., P. M. Chilton, J. R. Ward, J. T. Evans, and T. C. Mitchell. 2005. The low-toxicity versions of LPS, MPL adjuvant and RC529, are efficient adjuvants for CD4+ T cells. J Leukoc Biol 78:1273-1280.

77. Mata-Haro, V., C. Cekic, M. Martin, P. M. Chilton, C. R. Casella, and T. C. Mitchell. 2007. The vaccine adjuvant monophosphoryl lipid A as a TRIF-biased agonist of TLR4. Science 316:1628-1632.

78. Cekic, C., C. R. Casella, C. A. Eaves, A. Matsuzawa, H. Ichijo, and T. C. Mitchell. 2009. Selective activation of the p38 MAPK pathway by synthetic monophosphoryl lipid A. J Biol Chem 284:31982-31991.

79. Embry, C. A., L. Franchi, G. Nunez, and T. C. Mitchell. 2011. Mechanism of impaired NLRP3 inflammasome priming by monophosphoryl lipid A. Sci Signal 4:ra28.

80. Cekic, C., C. R. Casella, D. Sag, F. Antignano, J. Kolb, J. Suttles, M. R. Hughes, G. Krystal, and T. C. Mitchell. 2011. MyD88-dependent SHIP1 regulates proinflammatory signaling pathways in dendritic cells after monophosphoryl lipid A stimulation of TLR4. J Immunol 186:3858-3865.

81. Casella, C. R., and T. C. Mitchell. 2013. Inefficient TLR4/MD-2 heterotetramerization by monophosphoryl lipid A. PLoS One 8:e62622.

82. Lutz, M. B., N. Kukutsch, A. L. Ogilvie, S. Rossner, F. Koch, N. Romani, and G. Schuler. 1999. An advanced culture method for generating large quantities of highly pure dendritic cells from mouse bone marrow. J Immunol Methods 223:7792.

83. Ferrero, E., C. L. Hsieh, U. Francke, and S. M. Goyert. 1990. CD14 is a member of the family of leucine-rich proteins and is encoded by a gene syntenic with multiple receptor genes. J Immunol 145:331-336. 
84. Jersmann, H. P. 2005. Time to abandon dogma: CD14 is expressed by nonmyeloid lineage cells. Immunol Cell Biol 83:462-467.

85. Kim, J. I., C. J. Lee, M. S. Jin, C. H. Lee, S. G. Paik, H. Lee, and J. O. Lee. 2005. Crystal structure of CD14 and its implications for lipopolysaccharide signaling. $J$ Biol Chem 280:11347-11351.

86. Dziarski, R., R. I. Tapping, and P. S. Tobias. 1998. Binding of bacterial peptidoglycan to CD14. J Biol Chem 273:8680-8690.

87. Schroder, N. W., S. Morath, C. Alexander, L. Hamann, T. Hartung, U. Zahringer, U. B. Gobel, J. R. Weber, and R. R. Schumann. 2003. Lipoteichoic acid (LTA) of Streptococcus pneumoniae and Staphylococcus aureus activates immune cells via Toll-like receptor (TLR)-2, lipopolysaccharide-binding protein (LBP), and CD14, whereas TLR-4 and MD-2 are not involved. J Biol Chem 278:15587-15594.

88. Park, B. S., and J. O. Lee. 2013. Recognition of lipopolysaccharide pattern by TLR4 complexes. Exp Mol Med 45:e66.

89. Tsukamoto, H., K. Fukudome, S. Takao, N. Tsuneyoshi, and M. Kimoto. 2010. Lipopolysaccharide-binding protein-mediated Toll-like receptor 4 dimerization enables rapid signal transduction against lipopolysaccharide stimulation on membrane-associated CD14-expressing cells. Int Immunol 22:271-280.

90. Frey, E. A., D. S. Miller, T. G. Jahr, A. Sundan, V. Bazil, T. Espevik, B. B. Finlay, and S. D. Wright. 1992. Soluble CD14 participates in the response of cells to lipopolysaccharide. J Exp Med 176:1665-1671.

91. Pugin, J., C. C. Schurer-Maly, D. Leturcq, A. Moriarty, R. J. Ulevitch, and P. S. Tobias. 1993. Lipopolysaccharide activation of human endothelial and epithelial cells is mediated by lipopolysaccharide-binding protein and soluble CD14. Proc Natl Acad Sci U S A 90:2744-2748.

92. Jiang, Z., P. Georgel, X. Du, L. Shamel, S. Sovath, S. Mudd, M. Huber, C. Kalis, S. Keck, C. Galanos, M. Freudenberg, and B. Beutler. 2005. CD14 is required for MyD88-independent LPS signaling. Nat Immunol 6:565-570.

93. Tanimura, N., S. Saitoh, U. Ohto, S. Akashi-Takamura, Y. Fujimoto, K. Fukase, T. Shimizu, and K. Miyake. 2014. The attenuated inflammation of MPL is due to 
the lack of CD14-dependent tight dimerization of the TLR4/MD2 complex at the plasma membrane. Int Immunol 26:307-314.

94. Legat, A., S. Thomas, P. Hermand, M. Van Mechelen, M. Goldman, and D. De Wit. 2010. CD14-independent responses induced by a synthetic lipid A mimetic. Eur J Immunol 40:797-802.

95. Zanoni, I., C. Bodio, A. Broggi, R. Ostuni, M. Caccia, M. Collini, A. Venkatesh, R. Spreafico, G. Capuano, and F. Granucci. 2012. Similarities and differences of innate immune responses elicited by smooth and rough LPS. Immunol Lett 142:41-47.

96. Haziot, A., E. Ferrero, F. Kontgen, N. Hijiya, S. Yamamoto, J. Silver, C. L. Stewart, and S. M. Goyert. 1996. Resistance to endotoxin shock and reduced dissemination of gram-negative bacteria in CD14-deficient mice. Immunity 4:407414.

97. Lloyd-Jones, K. L., M. M. Kelly, and P. Kubes. 2008. Varying importance of soluble and membrane CD14 in endothelial detection of lipopolysaccharide. $J$ Immunol 181:1446-1453.

98. Haziot, A., G. W. Rong, V. Bazil, J. Silver, and S. M. Goyert. 1994. Recombinant soluble CD14 inhibits LPS-induced tumor necrosis factor-alpha production by cells in whole blood. J Immunol 152:5868-5876.

99. Troelstra, A., B. N. Giepmans, K. P. Van Kessel, H. S. Lichenstein, J. Verhoef, and J. A. Van Strijp. 1997. Dual effects of soluble CD14 on LPS priming of neutrophils. J Leukoc Biol 61:173-178.

100. Zanoni, I., and F. Granucci. 2010. Differences in lipopolysaccharide-induced signaling between conventional dendritic cells and macrophages. Immunobiology 215:709-712.

101. Ling, G. S., J. Bennett, K. J. Woollard, M. Szajna, L. Fossati-Jimack, P. R. Taylor, D. Scott, G. Franzoso, H. T. Cook, and M. Botto. 2014. Integrin CD11b positively regulates TLR4-induced signalling pathways in dendritic cells but not in macrophages. Nat Commun 5:3039. 
102. Dunzendorfer, S., H. K. Lee, K. Soldau, and P. S. Tobias. 2004. TLR4 is the signaling but not the lipopolysaccharide uptake receptor. J Immunol 173:11661170.

103. Gandhapudi, S. K., P. M. Chilton, and T. C. Mitchell. 2013. TRIF is required for TLR4 mediated adjuvant effects on T cell clonal expansion. PLoS One 8:e56855.

104. Hoshino, K., T. Kaisho, T. Iwabe, O. Takeuchi, and S. Akira. 2002. Differential involvement of IFN-beta in Toll-like receptor-stimulated dendritic cell activation. Int Immunol 14:1225-1231.

105. Hoebe, K., E. M. Janssen, S. O. Kim, L. Alexopoulou, R. A. Flavell, J. Han, and B. Beutler. 2003. Upregulation of costimulatory molecules induced by lipopolysaccharide and double-stranded RNA occurs by Trif-dependent and Trifindependent pathways. Nat Immunol 4:1223-1229.

106. Longhi, M. P., C. Trumpfheller, J. Idoyaga, M. Caskey, I. Matos, C. Kluger, A. M. Salazar, M. Colonna, and R. M. Steinman. 2009. Dendritic cells require a systemic type I interferon response to mature and induce CD4+ Th1 immunity with poly IC as adjuvant. $J$ Exp Med 206:1589-1602.

107. Le Bon, A., V. Durand, E. Kamphuis, C. Thompson, S. Bulfone-Paus, C. Rossmann, U. Kalinke, and D. F. Tough. 2006. Direct stimulation of T cells by type I IFN enhances the CD8+ T cell response during cross-priming. J Immunol 176:4682-4689.

108. Marrack, P., J. Kappler, and T. Mitchell. 1999. Type I interferons keep activated T cells alive. J Exp Med 189:521-530.

109. Yoneyama, H., S. Narumi, Y. Zhang, M. Murai, M. Baggiolini, A. Lanzavecchia, T. Ichida, H. Asakura, and K. Matsushima. 2002. Pivotal role of dendritic cellderived CXCL10 in the retention of T helper cell 1 lymphocytes in secondary lymph nodes. J Exp Med 195:1257-1266.

110. Bowen, W. S., L. A. Minns, D. A. Johnson, T. C. Mitchell, M. M. Hutton, and J. T. Evans. 2012. Selective TRIF-dependent signaling by a synthetic toll-like receptor 4 agonist. Sci Signal 5:ra13. 
111. Zughaier, S. M., S. M. Zimmer, A. Datta, R. W. Carlson, and D. S. Stephens. 2005. Differential induction of the toll-like receptor 4-MyD88-dependent and independent signaling pathways by endotoxins. Infect Immun 73:2940-2950.

112. van der Ley, P., L. Steeghs, H. J. Hamstra, J. ten Hove, B. Zomer, and L. van Alphen. 2001. Modification of lipid A biosynthesis in Neisseria meningitidis lpxL mutants: influence on lipopolysaccharide structure, toxicity, and adjuvant activity. Infect Immun 69:5981-5990.

113. Gaekwad, J., Y. Zhang, W. Zhang, J. Reeves, M. A. Wolfert, and G. J. Boons. 2010. Differential induction of innate immune responses by synthetic lipid a derivatives. J Biol Chem 285:29375-29386.

114. Zhang, Y., J. Gaekwad, M. A. Wolfert, and G. J. Boons. 2007. Modulation of innate immune responses with synthetic lipid A derivatives. J Am Chem Soc 129:5200-5216.

115. Teghanemt, A., D. Zhang, E. N. Levis, J. P. Weiss, and T. L. Gioannini. 2005. Molecular basis of reduced potency of underacylated endotoxins. J Immunol 175:4669-4676.

116. Saitoh, S., S. Akashi, T. Yamada, N. Tanimura, M. Kobayashi, K. Konno, F. Matsumoto, K. Fukase, S. Kusumoto, Y. Nagai, Y. Kusumoto, A. Kosugi, and K. Miyake. 2004. Lipid A antagonist, lipid IVa, is distinct from lipid A in interaction with Toll-like receptor 4 (TLR4)-MD-2 and ligand-induced TLR4 oligomerization. Int Immunol 16:961-969.

117. Akashi, S., Y. Nagai, H. Ogata, M. Oikawa, K. Fukase, S. Kusumoto, K. Kawasaki, M. Nishijima, S. Hayashi, M. Kimoto, and K. Miyake. 2001. Human MD-2 confers on mouse Toll-like receptor 4 species-specific lipopolysaccharide recognition. Int Immunol 13:1595-1599.

118. Shen, H., B. M. Tesar, W. E. Walker, and D. R. Goldstein. 2008. Dual signaling of MyD88 and TRIF is critical for maximal TLR4-induced dendritic cell maturation. J Immunol 181:1849-1858.

119. Windheim, M., M. Stafford, M. Peggie, and P. Cohen. 2008. Interleukin-1 (IL-1) induces the Lys63-linked polyubiquitination of IL-1 receptor-associated kinase 1 to facilitate NEMO binding and the activation of IkappaBalpha kinase. Mol Cell Biol 28:1783-1791. 
120. Chiang, E., O. Dang, K. Anderson, A. Matsuzawa, H. Ichijo, and M. David. 2006. Cutting edge: apoptosis-regulating signal kinase 1 is required for reactive oxygen species-mediated activation of IFN regulatory factor 3 by lipopolysaccharide. $J$ Immunol 176:5720-5724.

121. Navarro, L., and M. David. 1999. p38-dependent activation of interferon regulatory factor 3 by lipopolysaccharide. J Biol Chem 274:35535-35538.

122. Wadleigh, D. J., S. T. Reddy, E. Kopp, S. Ghosh, and H. R. Herschman. 2000. Transcriptional activation of the cyclooxygenase-2 gene in endotoxin-treated RAW 264.7 macrophages. J Biol Chem 275:6259-6266.

123. Lasa, M., K. R. Mahtani, A. Finch, G. Brewer, J. Saklatvala, and A. R. Clark. 2000. Regulation of cyclooxygenase 2 mRNA stability by the mitogen-activated protein kinase p38 signaling cascade. Mol Cell Biol 20:4265-4274.

124. Arndt, P. G., N. Suzuki, N. J. Avdi, K. C. Malcolm, and G. S. Worthen. 2004. Lipopolysaccharide-induced c-Jun NH2-terminal kinase activation in human neutrophils: role of phosphatidylinositol 3-Kinase and Syk-mediated pathways. $J$ Biol Chem 279:10883-10891.

125. Yamamoto, M., S. Sato, K. Mori, K. Hoshino, O. Takeuchi, K. Takeda, and S. Akira. 2002. Cutting edge: a novel Toll/IL-1 receptor domain-containing adapter that preferentially activates the IFN-beta promoter in the Toll-like receptor signaling. J Immunol 169:6668-6672.

126. Karin, M. 1995. The regulation of AP-1 activity by mitogen-activated protein kinases. J Biol Chem 270:16483-16486.

127. Wathelet, M. G., C. H. Lin, B. S. Parekh, L. V. Ronco, P. M. Howley, and T. Maniatis. 1998. Virus infection induces the assembly of coordinately activated transcription factors on the IFN-beta enhancer in vivo. Mol Cell 1:507-518.

128. Chu, W. M., D. Ostertag, Z. W. Li, L. Chang, Y. Chen, Y. Hu, B. Williams, J. Perrault, and M. Karin. 1999. JNK2 and IKKbeta are required for activating the innate response to viral infection. Immunity 11:721-731.

129. Ludwig, S., C. Ehrhardt, E. R. Neumeier, M. Kracht, U. R. Rapp, and S. Pleschka. 2001. Influenza virus-induced AP-1-dependent gene expression requires activation of the JNK signaling pathway. J Biol Chem 276:10990-10998. 
130. Thomas, K. E., C. L. Galligan, R. D. Newman, E. N. Fish, and S. N. Vogel. 2006. Contribution of interferon-beta to the murine macrophage response to the toll-like receptor 4 agonist, lipopolysaccharide. J Biol Chem 281:31119-31130.

131. Platanias, L. C. 2005. Mechanisms of type-I- and type-II-interferon-mediated signalling. Nat Rev Immunol 5:375-386.

132. de Weerd, N. A., J. P. Vivian, T. K. Nguyen, N. E. Mangan, J. A. Gould, S. J. Braniff, L. Zaker-Tabrizi, K. Y. Fung, S. C. Forster, T. Beddoe, H. H. Reid, J. Rossjohn, and P. J. Hertzog. 2013. Structural basis of a unique interferon-beta signaling axis mediated via the receptor IFNAR1. Nat Immunol 14:901-907.

133. Gallucci, S., M. Lolkema, and P. Matzinger. 1999. Natural adjuvants: endogenous activators of dendritic cells. Nat Med 5:1249-1255.

134. Santiago-Raber, M. L., R. Baccala, K. M. Haraldsson, D. Choubey, T. A. Stewart, D. H. Kono, and A. N. Theofilopoulos. 2003. Type-I interferon receptor deficiency reduces lupus-like disease in NZB mice. J Exp Med 197:777-788.

135. Meng, J., J. R. Drolet, B. G. Monks, and D. T. Golenbock. 2010. MD-2 residues tyrosine 42, arginine 69, aspartic acid 122, and leucine 125 provide species specificity for lipid IVA. J Biol Chem 285:27935-27943.

136. Fensterl, V., and G. C. Sen. 2011. The ISG56/IFIT1 gene family. J Interferon Cytokine Res 31:71-78.

137. Richez, C., K. Yasuda, A. A. Watkins, S. Akira, R. Lafyatis, J. M. van Seventer, and I. R. Rifkin. 2009. TLR4 ligands induce IFN-alpha production by mouse conventional dendritic cells and human monocytes after IFN-beta priming. $J$ Immunol 182:820-828.

138. Karaghiosoff, M., R. Steinborn, P. Kovarik, G. Kriegshauser, M. Baccarini, B. Donabauer, U. Reichart, T. Kolbe, C. Bogdan, T. Leanderson, D. Levy, T. Decker, and M. Muller. 2003. Central role for type I interferons and Tyk2 in lipopolysaccharide-induced endotoxin shock. Nat Immunol 4:471-477.

139. Rathinam, V. A., S. K. Vanaja, L. Waggoner, A. Sokolovska, C. Becker, L. M. Stuart, J. M. Leong, and K. A. Fitzgerald. 2012. TRIF licenses caspase-11dependent NLRP3 inflammasome activation by gram-negative bacteria. Cell 150:606-619. 
140. Orr, M. T., M. S. Duthie, H. P. Windish, E. A. Lucas, J. A. Guderian, T. E. Hudson, N. Shaverdian, J. O'Donnell, A. L. Desbien, S. G. Reed, and R. N. Coler. 2013. MyD88 and TRIF synergistic interaction is required for TH1-cell polarization with a synthetic TLR4 agonist adjuvant. Eur J Immunol 43:23982408 .

141. Bowen, W. S., S. K. Gandhapudi, J. P. Kolb, and T. C. Mitchell. 2013. Immunopharmacology of lipid A mimetics. Adv Pharmacol 66:81-128.

142. Lagerstrom, M. C., and H. B. Schioth. 2008. Structural diversity of G proteincoupled receptors and significance for drug discovery. Nat Rev Drug Discov 7:339-357.

143. Rajagopal, S., K. Rajagopal, and R. J. Lefkowitz. 2010. Teaching old receptors new tricks: biasing seven-transmembrane receptors. Nat Rev Drug Discov 9:373386.

144. Kahsai, A. W., K. Xiao, S. Rajagopal, S. Ahn, A. K. Shukla, J. Sun, T. G. Oas, and R. J. Lefkowitz. 2011. Multiple ligand-specific conformations of the beta2adrenergic receptor. Nat Chem Biol 7:692-700.

145. Wei, H., S. Ahn, S. K. Shenoy, S. S. Karnik, L. Hunyady, L. M. Luttrell, and R. J. Lefkowitz. 2003. Independent beta-arrestin 2 and $G$ protein-mediated pathways for angiotensin II activation of extracellular signal-regulated kinases 1 and 2. Proc Natl Acad Sci U S A 100:10782-10787.

146. Holloway, A. C., H. Qian, L. Pipolo, J. Ziogas, S. Miura, S. Karnik, B. R. Southwell, M. J. Lew, and W. G. Thomas. 2002. Side-chain substitutions within angiotensin II reveal different requirements for signaling, internalization, and phosphorylation of type 1A angiotensin receptors. Mol Pharmacol 61:768-777.

147. Raehal, K. M., J. K. Walker, and L. M. Bohn. 2005. Morphine side effects in beta-arrestin 2 knockout mice. J Pharmacol Exp Ther 314:1195-1201.

148. Soergel, D. G., R. A. Subach, B. Sadler, J. Connell, A. S. Marion, C. L. Cowan, J. D. Violin, and M. W. Lark. 2014. First clinical experience with TRV130: pharmacokinetics and pharmacodynamics in healthy volunteers. J Clin Pharmacol 54:351-357. 
149. DeWire, S. M., D. S. Yamashita, D. H. Rominger, G. Liu, C. L. Cowan, T. M. Graczyk, X. T. Chen, P. M. Pitis, D. Gotchev, C. Yuan, M. Koblish, M. W. Lark, and J. D. Violin. 2013. A G protein-biased ligand at the mu-opioid receptor is potently analgesic with reduced gastrointestinal and respiratory dysfunction compared with morphine. J Pharmacol Exp Ther 344:708-717.

150. Ohmori, Y., and T. A. Hamilton. 1993. Cooperative interaction between interferon (IFN) stimulus response element and kappa B sequence motifs controls IFN gamma- and lipopolysaccharide-stimulated transcription from the murine IP10 promoter. J Biol Chem 268:6677-6688.

151. Pasare, C., and R. Medzhitov. 2004. Toll-dependent control mechanisms of CD4 $\mathrm{T}$ cell activation. Immunity 21:733-741.

152. McAleer, J. P., D. J. Zammit, L. Lefrancois, R. J. Rossi, and A. T. Vella. 2007. The lipopolysaccharide adjuvant effect on T cells relies on nonoverlapping contributions from the MyD88 pathway and CD11c+ cells. J Immunol 179:65246535.

153. Mbow, M. L., E. De Gregorio, N. M. Valiante, and R. Rappuoli. 2010. New adjuvants for human vaccines. Curr Opin Immunol 22:411-416.

154. Napolitani, G., A. Rinaldi, F. Bertoni, F. Sallusto, and A. Lanzavecchia. 2005. Selected Toll-like receptor agonist combinations synergistically trigger a T helper type 1-polarizing program in dendritic cells. Nat Immunol 6:769-776.

155. Gilliet, M., W. Cao, and Y. J. Liu. 2008. Plasmacytoid dendritic cells: sensing nucleic acids in viral infection and autoimmune diseases. Nat Rev Immunol 8:594606.

156. Tovey, M. G., C. Lallemand, and G. Thyphronitis. 2008. Adjuvant activity of type I interferons. Biol Chem 389:541-545.

157. Orr, M. T., E. A. Beebe, T. E. Hudson, J. J. Moon, C. B. Fox, S. G. Reed, and R. N. Coler. 2014. A dual TLR agonist adjuvant enhances the immunogenicity and protective efficacy of the tuberculosis vaccine antigen ID93. PLoS One 9:e83884.

158. Coler, R. N., S. Bertholet, M. Moutaftsi, J. A. Guderian, H. P. Windish, S. L. Baldwin, E. M. Laughlin, M. S. Duthie, C. B. Fox, D. Carter, M. Friede, T. S. 
Vedvick, and S. G. Reed. 2011. Development and characterization of synthetic glucopyranosyl lipid adjuvant system as a vaccine adjuvant. PLoS One 6:e16333.

159. Leser, T. D., and L. Molbak. 2009. Better living through microbial action: the benefits of the mammalian gastrointestinal microbiota on the host. Environ Microbiol 11:2194-2206.

160. Kelly, C. P., C. Pothoulakis, and J. T. LaMont. 1994. Clostridium difficile colitis. N Engl J Med 330:257-262.

161. Grainger, J. R., M. H. Askenase, F. Guimont-Desrochers, D. M. da Fonseca, and Y. Belkaid. 2014. Contextual functions of antigen-presenting cells in the gastrointestinal tract. Immunol Rev 259:75-87.

162. Rescigno, M., M. Urbano, B. Valzasina, M. Francolini, G. Rotta, R. Bonasio, F. Granucci, J. P. Kraehenbuhl, and P. Ricciardi-Castagnoli. 2001. Dendritic cells express tight junction proteins and penetrate gut epithelial monolayers to sample bacteria. Nat Immunol 2:361-367.

163. Ellis, T. N., and M. J. Kuehn. 2010. Virulence and immunomodulatory roles of bacterial outer membrane vesicles. Microbiol Mol Biol Rev 74:81-94.

164. Al-Nedawi, K., M. F. Mian, N. Hossain, K. Karimi, Y. K. Mao, P. Forsythe, K. K. Min, A. M. Stanisz, W. A. Kunze, and J. Bienenstock. 2014. Gut commensal microvesicles reproduce parent bacterial signals to host immune and enteric nervous systems. FASEB $J$.

165. Denning, T. L., Y. C. Wang, S. R. Patel, I. R. Williams, and B. Pulendran. 2007. Lamina propria macrophages and dendritic cells differentially induce regulatory and interleukin 17-producing T cell responses. Nat Immunol 8:1086-1094.

166. Cao, A. T., S. Yao, B. Gong, C. O. Elson, and Y. Cong. 2012. Th17 cells upregulate polymeric Ig receptor and intestinal IgA and contribute to intestinal homeostasis. J Immunol 189:4666-4673.

167. Macpherson, A. J., and T. Uhr. 2004. Induction of protective IgA by intestinal dendritic cells carrying commensal bacteria. Science 303:1662-1665. 
168. O'Connor, W., Jr., M. Kamanaka, C. J. Booth, T. Town, S. Nakae, Y. Iwakura, J. K. Kolls, and R. A. Flavell. 2009. A protective function for interleukin 17A in T cell-mediated intestinal inflammation. Nat Immunol 10:603-609.

169. Coats, S. R., A. B. Berezow, T. T. To, S. Jain, B. W. Bainbridge, K. P. Banani, and R. P. Darveau. 2011. The lipid A phosphate position determines differential host Toll-like receptor 4 responses to phylogenetically related symbiotic and pathogenic bacteria. Infect Immun 79:203-210.

170. Hashimoto, M., Y. Asai, R. Tamai, T. Jinno, K. Umatani, and T. Ogawa. 2003. Chemical structure and immunobiological activity of lipid A from Prevotella intermedia ATCC 25611 lipopolysaccharide. FEBS Lett 543:98-102.

171. Darveau, R. P., and P. M. Chilton. 2013. Naturally occurring low biological reactivity lipopolysaccharides as vaccine adjuvants. Expert Rev Vaccines 12:707709.

172. Bates, J. M., J. Akerlund, E. Mittge, and K. Guillemin. 2007. Intestinal alkaline phosphatase detoxifies lipopolysaccharide and prevents inflammation in zebrafish in response to the gut microbiota. Cell Host Microbe 2:371-382.

173. De Luca, A., C. Montagnoli, T. Zelante, P. Bonifazi, S. Bozza, S. Moretti, C. D'Angelo, C. Vacca, L. Boon, F. Bistoni, P. Puccetti, F. Fallarino, and L. Romani. 2007. Functional yet balanced reactivity to Candida albicans requires TRIF, MyD88, and IDO-dependent inhibition of Rorc. J Immunol 179:5999-6008.

174. Kimura, A., and T. Kishimoto. 2010. IL-6: regulator of Treg/Th17 balance. Eur J Immunol 40:1830-1835. 


\section{CURRICULUM VITAE}

NAME:

CAMPUS ADDRESS:

HOME ADDRESS:

EMAIL:

EDUCATION:

$2009-2014$

$2008-2011$

$2004-2008$

AWARDS:

2013

2008

2008

$2004-2008$

PUBLICATIONS:
Joseph Peterson Kolb, Jr.

Donald Baxter Research Building, Rm. 411

University of Louisville

570 South Preston Street

Louisville, KY 40202, USA

6809 Spring Lawn Court

Louisville, KY 40291

jpkjr85@gmail.com

Ph.D. Candidate, Department of Microbiology and Immunology, University of Louisville, Louisville, KY

Master of Science, Department of Microbiology and Immunology, University of Louisville, Louisville, KY

Bachelor of Arts in Biology, Transylvania University, Lexington, $\mathrm{KY}$

American Association of Immunologists Immunology Trainee Abstract Award

Ruchman Biology Award, Transylvania University-Given to the most outstanding senior biology major

Senior Class Award, Transylvania University-Given to graduating seniors who maintained a cumulative GPA of 4.0

President’s Scholar, Transylvania University 


\section{$\underline{\text { Peer-reviewed Research Articles }}$}

J. P. Kolb, C. R. Casella, S. SenGupta, P. M. Chilton, T. C. Mitchell, Type I interferon signaling contributes to the bias that Toll-like receptor 4 exhibits for signaling mediated by the adaptor protein TRIF. Sci. Signal. 7, ra108 (2014).

Cekic, C., C. R. Casella, D. Sag, F. Antignano, J. Kolb, J. Suttles, M. R. Hughes, G. Krystal, T. C. Mitchell (2011). "MyD88-dependent SHIP1 regulates proinflammatory signaling pathways in dendritic cells after monophosphoryl lipid A stimulation of TLR4." J Immunol 186(7): 3858-3865.

\section{$\underline{\text { Reviews and Chapters }}$}

Bowen WS, Gandhapudi SK, Kolb JP, Mitchell, TC. Chapter 3: Immunopharmacology of lipid A mimetics. (2013) Adv. Pharmacol. 66:81-128.

\section{INVITED TALKS:}

5/4/2013. Joseph P. Kolb, Carolyn Casella, Shuvasree SenGupta, Thomas C. Mitchell. TLR4 as a TRIF-biased receptor. AAI Immunology 2013. Honolulu, HI.

\section{MEETING ABSTRACTS:}

9/18/2012. Joseph P. Kolb, Thomas C. Mitchell. TLR4/MD2 as a TRIF-biased receptor system. Research!Louisville. University of Louisville, KY.

11/2009. Joseph P. Kolb, Caglar Cekic, Thomas C. Mitchell. Differential TLR signaling by biological vs. synthetic monophosphorylated lipid A. Autumn Immunology Conference. Chicago, IL.

11/2009. Joseph P. Kolb, Caglar Cekic, and Thomas C. Mitchell. Differential TLR4 signaling by biological vs. synthetic monophosphoryl lipid A. Research!Louisville, University of Louisville, 2009.

\section{RESEARCH PRESENTATIONS:}

6/2014. Revisions to the Toll-like receptor 4 TRIF-bias hypothesis. Dr. Stefanie Vogel's research group. University of Maryland, Baltimore, MD.

5/2013. TLR4 as a TRIF-biased receptor. Dept. Seminar.

5/2012. TRIF bias by the TLR4 agonist, vaccine adjuvant monophosphoryl lipid A: An exploration of factors that may affect the TRIF signaling pathway. Dept. Seminar.

10/2010. Determining the role of CD14 in TLR4 signaling by monophosphoryl lipid A. Dept. Seminar. 